\title{
A comprehensive view of sex-specific issues related to cardiovascular disease
}




\title{
A comprehensive view of sex-specific issues related to cardiovascular disease
}

\author{
Louise Pilote, Kaberi Dasgupta, Veena Guru, Karin H. Humphries, Jennifer McGrath, \\ Colleen Norris, Doreen Rabi, Johanne Tremblay, Arsham Alamian, Tracie Barnett, Jafna Cox, \\ William Amin Ghali, Sherry Grace, Pavel Hamet, Teresa Ho, Susan Kirkland, Marie Lambert, \\ Danielle Libersan, Jennifer O'Loughlin, Gilles Paradis, Milan Petrovich, Vicky Tagalakis
}

\section{ABSTRACT}

Cardiovascular disease (CVD) is the leading cause of mortality in women. In fact, CVD is responsible for a third of all deaths of women worldwide and half of all deaths of women over 50 years of age in developing countries. The prevalence of CVD risk factor precursors is increasing in children. Retrospective analyses suggest that there are some clinically relevant differences between women and men in terms of prevalence, presentation, management and outcomes of the disease, but little is known about why CVD affects women and men differently. For instance, women with diabetes have a significantly higher CVD mortality rate than men with diabetes. Similarly, women with atrial fibrillation are at greater risk of stroke than men with atrial fibrillation. Historically, women have been underrepresented in clinical trials. The lack of good trial evidence concerning sex-specific outcomes has led to assumptions about CVD treatment in women, which in turn may have resulted in inadequate diagnoses and suboptimal management, greatly affecting outcomes. This knowledge gap may also explain why cardiovascular health in women is not improving as fast as that of men. Over the last decades, mortality rates in men have steadily declined, while those in women remained stable. It is also becoming increasingly evident that gender differences in cultural, behavioural, psychosocial and socioeconomic status are responsible, to various degrees, for the observed differences between women and men. However, the interaction between sex- and gender-related factors and CVD outcomes in women remains largely unknown.

CMAJ 2007;176(6):SI-44

\section{Burden of cardiovascular disease in women and men}

\author{
Doreen Rabi and Jafna Cox
}

Although cardiovascular disease (CVD) is common, significant sex-related differences in its epidemiology have only recently been appreciated. The objective of this section is to demonstrate that there are sex-specific differences in the prevalence, complications and burden of CVD in terms of mortality, hospital admissions and quality of life.

\section{Search strategy}

A MEDLINE search was conducted using the MeSH terms "cardiovascular disease" OR "atrial fibrillation" OR "congestive heart failure." A second search used the terms "prevalence" OR "incidence" OR "mortality" and the final search combined the results of the first 2 searches and added the in terms "gender" OR "sex." Articles identified in this manner were retrieved and their reference lists searched for additional relevant articles. The search was limited to English-language publications, but no other restrictions were applied. Other data sources included Web sites of the World Health Organization, the Canadian Institute for Health Information and the National Centre for Health Statistics. Thirty-three original studies were reviewed. Studies were included if they were cohort studies, case-control studies or nested cohort studies that examined the incidence, prevalence or mortality of CVD, congestive heart failure or atrial fibrillation. The studies had to include data on both men and women.

\section{Cardiovascular disease}

\section{Prevalence}

CVD is ubiquitous. Determining the extent of the burden this disease places on society is difficult as most databases and studies base the presence of CVD on presentation with an acute event, making the prevalence of asymptomatic disease difficult to establish. Public health surveys have been used to determine the prevalence of CVD in the ambulatory population. North American surveys indicate that CVD is diagnosed more frequently in men, with $5.4 \%$ of Canadian men (compared with $4.6 \%$ of women) ${ }^{1}$ and $8.4 \%$ of US men (compared with $5.6 \%$ of women $)^{2}$ reporting a prior diagnosis of CVD.

Trends in CVD vary considerably from region to region. ${ }^{3}$ In 
North America, Europe, Australasia and middle-income developing countries, men are reported to have a higher prevalence of CVD compared with women (Table r) ${ }^{4}$ However, the proportion of women presenting with clinically and angiographically significant disease has increased over the last 20 years. Overall, the incidence of CVD, and of coronary artery disease (CAD) in particular, has been declining in men but has remained stable in women. ${ }^{5}$

\section{Mortality}

CVD remains a leading cause of mortality throughout the world, affecting both women and men. ${ }^{6}$ Trends in CVD mortality, like trends in prevalence, display regional variations (Fig. I). ${ }^{7}$ Although the age-standardized mortality rates have been declining over the past 3 decades in Western Europe and North America, they have risen markedly in middle-income developing countries (Eastern Europe and China). Levi and colleagues $^{8}$ demonstrated that these trends are consistent for both men and women (Fig. 2).

Historically, men have had higher cardiovascular-related mortality rates than women. This finding is consistent across several countries. According to Manuel and colleagues, ${ }^{9}$ in 1999, Canadian men had an age-standardized CVD mortality rate of 288 per 100 ooo, while the rate for women was 175 per Ioo ooo. Sex-specific, age-standardized CVD mortality rates were very similar in the United States in 2003: 307 per Ioo 000 for men and 158 per 100 ooo for women. ${ }^{2}$ At the international level, CVD mortality rates are consistently higher in men (Table 2). ${ }^{6}$

Table 1: Prevalence of cardiovascular disease in men and women aged 35-64 years, 1980-1994

\begin{tabular}{|c|c|c|c|c|}
\hline \multirow{2}{*}{$\begin{array}{l}\text { Country } \\
\text { (region) }\end{array}$} & \multicolumn{2}{|c|}{$\begin{array}{c}\text { Annual coronary } \\
\text { event rate; } \\
\text { no. per } 100000\end{array}$} & \multicolumn{2}{|c|}{$\begin{array}{l}\text { Annual change } \\
\text { in event rate; } \%\end{array}$} \\
\hline & Men & Women & Men & Women \\
\hline $\begin{array}{l}\text { Canada } \\
\text { (Halifax) }\end{array}$ & 523 & 139 & -4.7 & +0.5 \\
\hline $\begin{array}{l}\text { United States } \\
\text { (Stanford) }\end{array}$ & 431 & 134 & -4.2 & -2.4 \\
\hline France (Lille) & 298 & 64 & -1.1 & -1.6 \\
\hline $\begin{array}{l}\text { Sweden } \\
\text { (Gothenburg) }\end{array}$ & 363 & 84 & -4.2 & -3.7 \\
\hline $\begin{array}{l}\text { United } \\
\text { Kingdom } \\
\text { (Glasgow) }\end{array}$ & 777 & 265 & -1.4 & +0.2 \\
\hline $\begin{array}{l}\text { Australia } \\
\text { (Newcastle) }\end{array}$ & 479 & 153 & -5.1 & -5.6 \\
\hline $\begin{array}{l}\text { China } \\
\text { (Beijing) }\end{array}$ & 81 & 35 & +2.3 & -0.5 \\
\hline $\begin{array}{l}\text { Poland } \\
\text { (Warsaw) }\end{array}$ & 586 & 153 & +0.8 & +1.0 \\
\hline $\begin{array}{l}\text { Russian } \\
\text { Federation } \\
\text { (Moscow) }\end{array}$ & 477 & 92 & -1.0 & -6.7 \\
\hline
\end{tabular}

Source of data: Tunstall-Pedoe et al. ${ }^{4}$

\section{Hospital admissions}

CVD is the leading cause of admission to hospital in North America for both men and women. In 2000, CVD accounted for $18 \%$ of all hospital admissions in Canada. Women experience longer stays in hospital related to CVD and suffer greater disability. The National Population Health Survey ${ }^{1}$ revealed that among respondents reporting a diagnosis of heart disease, women consistently reported higher levels of pain, discomfort, activity restriction and disability secondary to their heart disease than men.

\section{Coronary artery disease}

Men continue to have higher rates of mortality related to acute myocardial infarction (AMI) and CAD than women. In Canada in 1999, the age-standardized CAD mortality rate for men was I88 per 100 ooo compared with 97 per 100 ooo for women. ${ }^{9}$ A similar sex difference was noted in the United States in 2003 when the CAD mortality rate per 100000 was I87 for men and 77 for women. ${ }^{2}$ This difference appears to be consistent across international borders (Table 2). ${ }^{6}$ However, younger women with AMI have higher rates of mortality than men of the same age. ${ }^{10-12}$

\section{Heart failure}

\section{Prevalence}

Heart failure, a recognized complication of CAD and AMI, has become more prevalent over the past several years. Recent data from the Framingham study suggest that the lifetime risk of developing heart failure is about $20 \%$ for both men and women. ${ }^{13}$ Approximately $2 \%$ of people living in the Americas have a diagnosis of heart failure. The prevalence is similar in Europe, where it is estimated to be between $\mathrm{I} .8 \%$ (95\% confidence interval [CI] I.4-2.3) $)^{14}$ and $3.9 \%$ (95\% CI $3.0-4.7),{ }^{15}$ and it is as high as $6.3 \%(95 \%$ CI 5.0-7.7) in Australia. ${ }^{16}$ The risk of left-ventricular systolic dysfunction increases steadily with age in both men and women. After the age of 75 years, the prevalence of heart failure secondary to systolic dysfunction is estimated to be $8.4 \% .{ }^{17,18}$

In Canada, as elsewhere, most patients with heart failure are 65 years of age and older, with women comprising $51 \%$ of all new cases. ${ }^{19}$ As with ischemic heart disease, female patients with heart failure are older than males and more likely to be hypertensive and diabetic, but they tend to have better preserved systolic function, a lower prevalence of ischemic etiology and are less likely to have a history of prior AMI. ${ }^{20,21}$

\section{Mortality}

Once heart failure is present, the median survival time is $\mathrm{I} .7$ years for men and 3.2 years for women. ${ }^{13}$ Mortality following a diagnosis of heart failure remains significant. The 5 -year mortality rate is approximately $50 \%$ for both women and men. Although mortality associated with heart failure has declined significantly over the past 20 years in men $(28 \%-52 \%)$, 
the decrease has not been as significant in women $(6 \%-33 \%){ }^{22}$

\section{Hospital admissions}

Heart failure is a leading cause of hospital admission throughout the world, and women account for about $50 \%$ of these admissions. In North America, admissions to hospital with a primary diagnosis of heart failure have increased by $34 \%$ since 1990 , but this increase is more notable in women $(39 \%)$ than men $(29 \%)$. In fact, a review of the American National Hospital Discharge Survey ${ }^{23}$ noted that age-adjusted heart failure admission rates have been constant since I99I for men, but have continued to increase for women ( $19 \%$ ) (Fig. 3), suggesting that the increase in hospital admissions in recent years is largely the result of more women presenting with clinically significant disease. Once discharged from hospital, men and women appear to have similar rates of readmission (hazard ratio [HR] 0.89; 95\% CI 0.7I-I.II). ${ }^{21}$ Sex dif-

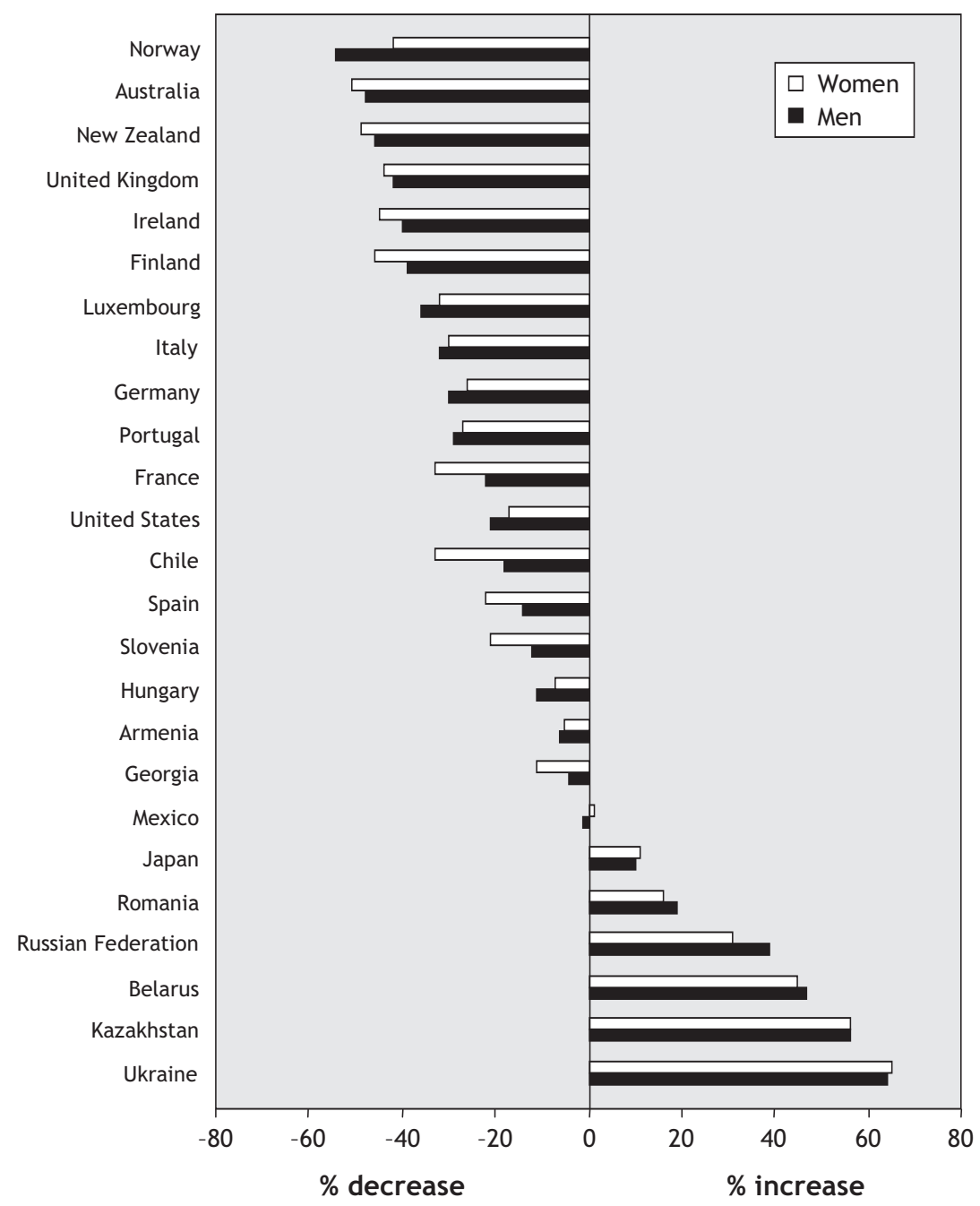

Fig. 1: Changes in rates of death from cardiovascular disease among men and women aged $35-74$ years between 1990 and 2000 in selected countries. Reproduced with permission from the World Health Organization. ${ }^{7}$ ferences in length of hospital stays have also been noted, with women having significantly longer hospital stays than men. ${ }^{24}$

\section{Atrial fibrillation}

\section{Prevalence}

Atrial fibrillation is the most common cardiac arrhythmia and is an established risk factor for stroke and premature death. North American and European studies indicate that about $0.95 \%-\mathrm{I} . \mathrm{I} \%$ of the population experiences atrial fibrillation. ${ }^{25-27}$ The Framingham study demonstrated that men were I. 5 times more likely to develop atrial fibrillation than women, ${ }^{28}$ but because the number of women older than 75 years is almost twice that of men, the absolute numbers of those with atrial fibrillation are roughly equal. ${ }^{26}$ Incidence increases with age; the prevalence of atrial fibrillation at age 55 is $0.1 \%$ and increases to $9.0 \%$ in those over 80 years of age. ${ }^{26,29}$ This age-related increase in prevalence is most striking in men (Table 3$).^{30}$

\section{Mortality}

Mortality rates are significantly higher in both women and men with atrial fibrillation. In longitudinal studies, mortality rates were approximately $25 \%$ higher than ageand sex-matched controls. ${ }^{31,32}$ In the United States, in-hospital mortality rate following admission for atrial fibrillation is estimated at $0.8 \%$. Men have a modestly higher (but statistically significant) risk of in-hospital mortality. Using administrative data (National Hospital Discharge Survey), Kairallah and colleagues ${ }^{33}$ demonstrated that male sex was an independent predictor of inhospital mortality (odds ratio [OR] I.Io; 95\% CI I.06-I.I4). However, analysis of administrative data from Scotland suggests that I-year mortality may be higher in women; Stewart and colleagues ${ }^{34}$ found the I-year case fatality rate in men to be $\mathrm{II} .9 \% \mathrm{~V}$. $\mathrm{I} 6.2 \%$ in women. The distribution of ages in this cohort is not known; the higher mortality rate seen in women may reflect a greater number of very elderly women diagnosed with atrial fibrillation. Wattigney and colleagues $^{35}$ have demonstrated in a US cohort that mortality remains higher among men after age standardization.

\section{Hospital admission and stroke}

Reflecting the sex differences in prevalence, admissions to hospital for atrial fibrillation are also more common in men at every age (Table 4). ${ }^{36}$ Among patients with atrial fibrillation, women seem to be at greater risk 


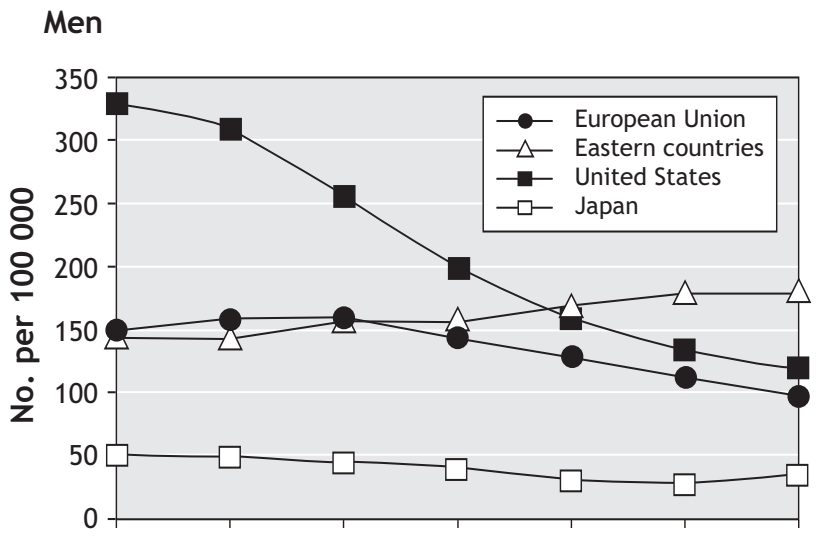

1965-69 1970-74 1975-79 $1980-84 \quad 1985-89 \quad 1990-94 \quad 1995-97$

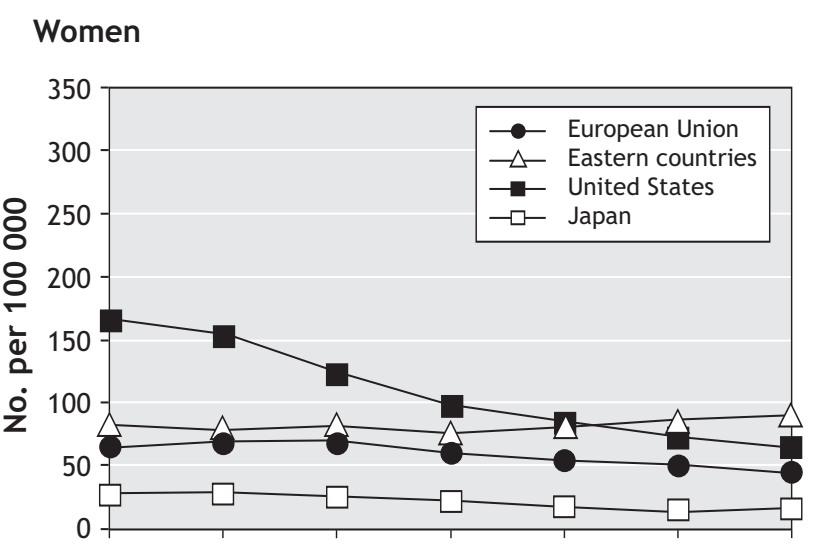

1965-69 1970-74 1975-79 $1980-84 \quad 1985-89 \quad 1990-94 \quad 1995-97$

Fig. 2: Trends in age-standardized (world population) cardiovascular disease mortality among men and women in the European Union, Eastern Europe (Bulgaria, Czech Republic, Hungary, Poland, Romania and Slovakia), the United States and Japan from 1965 to 1972 . Reproduced with permission from BMJ Publishing Group (Heart 2002;88:119-24). ${ }^{8}$

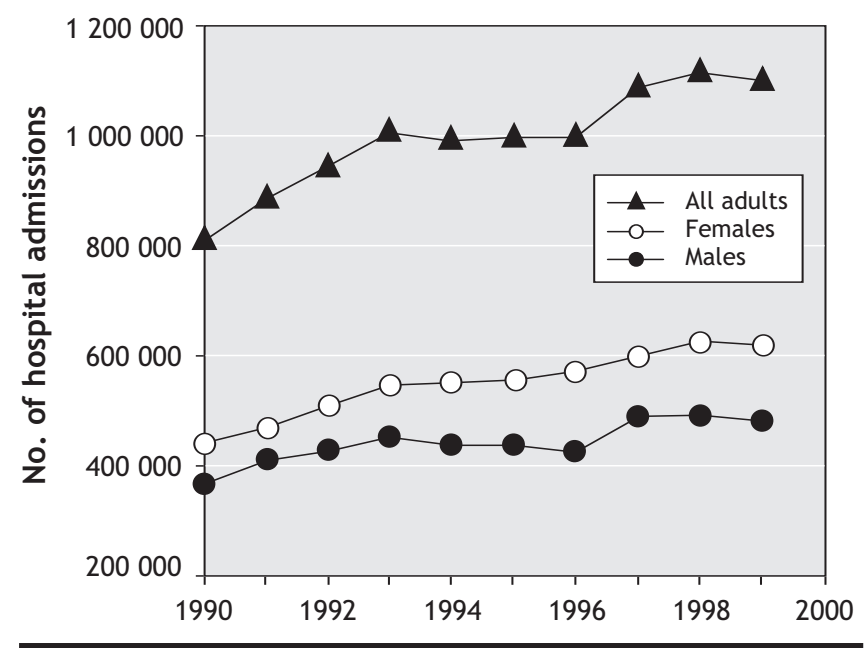

Fig. 3: American National Hospital Discharge Survey data on annual hospital admissions because of heart failure among adults 35 years and older, 1990-2000. Reproduced with permission from Elsevier (Am Heart J 2004;147:74-8). ${ }^{23}$ of stroke than men. In a cohort of US Medicaid patients, Wolf and colleagues ${ }^{31}$ found that, after controlling for other established risk factors, women with atrial fibrillation had a $22 \%-25 \%$ greater risk of stroke than women without atrial fibrillation (Table 5). In contrast, the increased risk of stroke in men with atrial fibrillation was completely attenuated by controlling for other stroke risk factors. ${ }^{31}$ Women have also been found to have higher readmission rates following stroke. $^{36}$

Table 2: Cardiovascular-related mortality rates per 100000 people for men and women aged $35-74$ years

\begin{tabular}{|c|c|c|c|c|c|c|c|c|}
\hline \multirow[b]{2}{*}{ Country (yr) } & \multicolumn{4}{|c|}{ Men } & \multicolumn{4}{|c|}{ Women } \\
\hline & CVD & CAD & CVA & Total & CVD & CAD & CVA & Total \\
\hline $\begin{array}{l}\text { Russian } \\
\text { Federation } \\
\text { (1998) }\end{array}$ & 1167 & 639 & 361 & 2502 & 540 & 230 & 229 & 1001 \\
\hline $\begin{array}{l}\text { China, rural } \\
\text { (1999) }\end{array}$ & 413 & 64 & 243 & 1260 & 286 & 110 & 84 & 748 \\
\hline $\begin{array}{l}\text { China, urban } \\
\text { (1999) }\end{array}$ & 389 & 106 & 217 & 1003 & 273 & 71 & 147 & 663 \\
\hline $\begin{array}{l}\text { United States } \\
(2003)\end{array}$ & 367 & 187 & 36 & 943 & 158 & 77 & 28 & 593 \\
\hline $\begin{array}{l}\text { England/ } \\
\text { Wales (2002) }\end{array}$ & 301 & 196 & 49 & 811 & 138 & 68 & 36 & 509 \\
\hline $\begin{array}{l}\text { Australia } \\
\text { (2001) }\end{array}$ & 206 & 138 & 31 & 679 & 92 & 47 & 22 & 396 \\
\hline $\begin{array}{l}\text { Canada } \\
\text { (2001) }\end{array}$ & 222 & 150 & 29 & 757 & 97 & 51 & 21 & 455 \\
\hline
\end{tabular}

Note: $\mathrm{CAD}=$ coronary artery disease, $\mathrm{CVA}=$ cerebrovascular accident, $\mathrm{CVD}=$ cardiovascular disease.

Source of data: World Health Organization. ${ }^{6}$

Table 3: Prevalence of atrial fibrillation in adults aged 65-84 years (\% of total population), 1968-1989

\begin{tabular}{lcccccc}
\hline & $1968-$ & $1971-$ & $1975-$ & $1979-$ & $1983-$ & $1987-$ \\
& 1970 & 1973 & 1977 & 1981 & 1985 & 1989 \\
\hline \multirow{2}{*}{ Men } & 3.2 & 5.3 & 6.5 & 7.8 & 7.5 & 9.1 \\
Women & 2.8 & 3.3 & 4.3 & 4.3 & 3.9 & 4.7 \\
\hline
\end{tabular}

Source of data: Wolf et al..$^{30}$

Table 4: Age- and sex-specific hospital admission rates for atrial fibrillation or flutter in Canada, 1997/98-1999/2000

\begin{tabular}{lcc}
\hline & \multicolumn{2}{c}{ Hospital admission rate; no. per 100000} \\
\cline { 2 - 3 } Age, yr & Men & Women \\
\hline $20-49$ & 40.1 & 17.1 \\
$50-64$ & 478 & 245 \\
$65-74$ & 2096.7 & 1297.6 \\
$75-84$ & 4891 & 3548.9 \\
$85+$ & 7645.9 & 5924.5 \\
\hline
\end{tabular}

Source of data: Humphries et al. ${ }^{36}$ 


\section{Health-related quality of life}

Although men are more likely to die from CAD, women are more likely to live with CAD-related disability. In North American cohort studies, women with a history of $\mathrm{CAD}$, heart

Table 5: Adjusted* mortality and stroke risk associated with atrial fibrillation following hospital admission by sex in adults aged $75-84$ years

\begin{tabular}{lcc}
\hline Outcome; group & Risk ratio & $\begin{array}{c}95 \% \text { confidence } \\
\text { interval }\end{array}$ \\
\hline Mortality & 1.07 & $0.96-1.19$ \\
\hline Men & 1.20 & $1.09-1.32$ \\
\hline Women & & \\
\hline Stroke & 1.05 & $0.94-1.16$ \\
Men & 1.25 & $1.14-1.37$ \\
\hline Women & 1.25 \\
\hline
\end{tabular}

*Adjusted for prior history of acute myocardial infarction, unstable angina, stable angina, congestive heart failure, hypertension, diabetes, valvular disease, stroke or chronic obstructive pulmonary disease. Patients were eliminated at death from stroke analysis. Source of data: Wolf et al. ${ }^{31}$ failure or atrial fibrillation consistently report lower healthrelated quality of life and greater disability related to their heart disease than men. Women are also less likely to return to work following admission to hospital for complications related to CVD. ${ }^{37}$

\section{Summary}

- CVD is prevalent among both women and men.

- Women have a lower CVD mortality rate than men.

- $\mathrm{CAD}$ and atrial fibrillation are more prevalent among men than among women.

- Women appear to have a relatively higher risk of atrial fibrillation-related stroke than men.

- Clinically significant heart failure is on the rise in women.

- Women are more likely to live with more CVD-related disabilities and have a lower health-related quality of life.

\section{Knowledge gap}

- Why are CVD incidence and mortality rates decreasing among men but stable among women?

\section{Cardiovascular risk factors in girls and boys}

Jennifer McGrath, Tracie Barnett, Marie Lambert, Jennifer O'Loughlin, Gilles Paradis, Arsham Alamian and Teresa Ho

Although most cardiovascular events occur in adulthood, the precursors of CVD manifest during childhood and adolescence. ${ }^{38,39} \mathrm{CVD}$ is partly attributable to modifiable lifestyle behaviours, and childhood is a critical developmental period when these habits are established. ${ }^{40}$ Further, risk factors such as smoking, sedentary behaviour and poor diet in children and adolescents persist through young adulthood and are important predictors of subsequent risk of CVD. ${ }^{41-44}$ Consequently, it is essential to promote cardiovascular health and direct primary prevention efforts toward children and adolescents to disrupt the progression of CVD risk factors and thereby offset both the risk of CVD in adulthood and the unprecedented potential burden on health care systems.

\section{Search strategy}

Studies included in this qualitative review of childhood cardiovascular risk factors were identified through the use of widely available computer databases (Ovid MEDLINE, Ovid EMBASE, PubMed, PsycInfo, the Cochrane Library). Boolean searches were carried out by combining the keyword ("boy" OR "girl" OR "child" OR "pediatric" OR "adolescent" OR "young adult") with each of the following keyword combinations using the AND operator: ("atherosclerosis" OR "cardiovascular" OR “coronary” OR "heart”), ("obesity” OR “overweight”), ("lipids" OR "lipoprotein"), ("hypertension" OR "blood pressure" OR "systolic" OR “diastolic"), ("cigarettes" OR "smoking" OR "tobacco"), ("diet" OR "nutrition”), ("exercise” OR "physical activity" OR "sedentary"), ("clustering" OR "behavior" OR "lifestyle"). Web sites of several well-known organizations, such as the World Health Organization, Centers for Disease Control and Prevention (CDC), Heart and Stroke Foundation of Canada and the American Heart Association, were reviewed for additional information and current recommendations. Finally, to obtain information from national and international statistical databases as well other "grey literature" and nonconventional documents, government Web sites (e.g., Statistics Canada, Health Canada, CDC) were examined. To reduce the copious amount of information this search strategy produced, the review emphasized children or adolescent populations; large studies with representative samples; longitudinal studies; and recent publications that reported sex- or gender-specific findings.

\section{Overweight and obesity}

Overweight and obesity are the most frequent nutritional disorders in industrialized countries in children as well as in adults; the prevalence of obesity has increased almost 3-fold over the past 2 decades. ${ }^{45,46}$ Although it is generally thought that girls are more likely to be overweight than boys, there are no differences in prevalence between girls and boys.

In a recent report based on heights and weights measured in the National Longitudinal Survey of Children and Youth ${ }^{47}$ and using Cole and colleagues ${ }^{48}$ age- and sex-specific body mass index (BMI) threshold values for overweight and obesity, 
Shields ${ }^{46}$ estimated that the prevalence of overweight and obesity of Canadian boys and girls aged $2-17$ years was $27 \%$ and $25 \%$, respectively; the corresponding figures for obesity only were $9 \%$ and $7 \%$, respectively. Although the overall prevalence of overweight and obesity was similar for boys and girls, trends varied for different age groups. The percentage of overweight and obese children 2-5 years old remained unchanged (21\%) between $1978-1979$ and 2004. However, the prevalence of overweight and obesity doubled among those 6-II years (from $\mathrm{I}_{3} \%$ to $26 \%$ ) and those $\mathrm{I} 2-17$ years (from $\mathrm{I}_{4} \%$ to $29 \%$ ), and the prevalence of obesity tripled among those $12-17$ years (from $3 \%$ to $9 \%$ ). Secular trends in body mass of Canadian children are shown in Fig. $4 .{ }^{49}$ Part of these sex-based differences may be attenuated by the fact that age- and sex-specific thresholds are used to define overweight and obesity.

In the United States, using height and weight measurements obtained in $1999-2000$ as part of the National Health and Nutrition Examination Survey (NHANES) and the 2000 CDC growth chart reference values, Ogden and colleagues ${ }^{45}$ reported that the prevalence of overweight and obesity was $20.5 \%, 26.2 \%$ and $26.5 \%$ among non-Hispanic white youth aged $2-5,6-$ II and I2-I9 years, respectively. The corresponding figures for obesity only were $\mathrm{I0.} \mathrm{I} \%, \mathrm{II} .8 \%$ and $\mathrm{I} 2.7 \%$. The prevalence of obesity was not significantly different for boys and girls.

Longitudinal studies have shown that measures of BMI taken during childhood and adolescence predict adult values. In the Bogalusa Heart Study, ${ }^{50}$ childhood and adult BMI were moderately correlated (Spearman's rank correlation coefficient 0.58 ), and this relation did not vary significantly with age, ethnic origin or sex. Similar results were observed in the Child and Adolescent Trial for Cardiovascular Health where the Kendall index of concordance for BMI was 0.86 over a follow-up period of 6 years and tracking was similar for both sexes. ${ }^{51}$

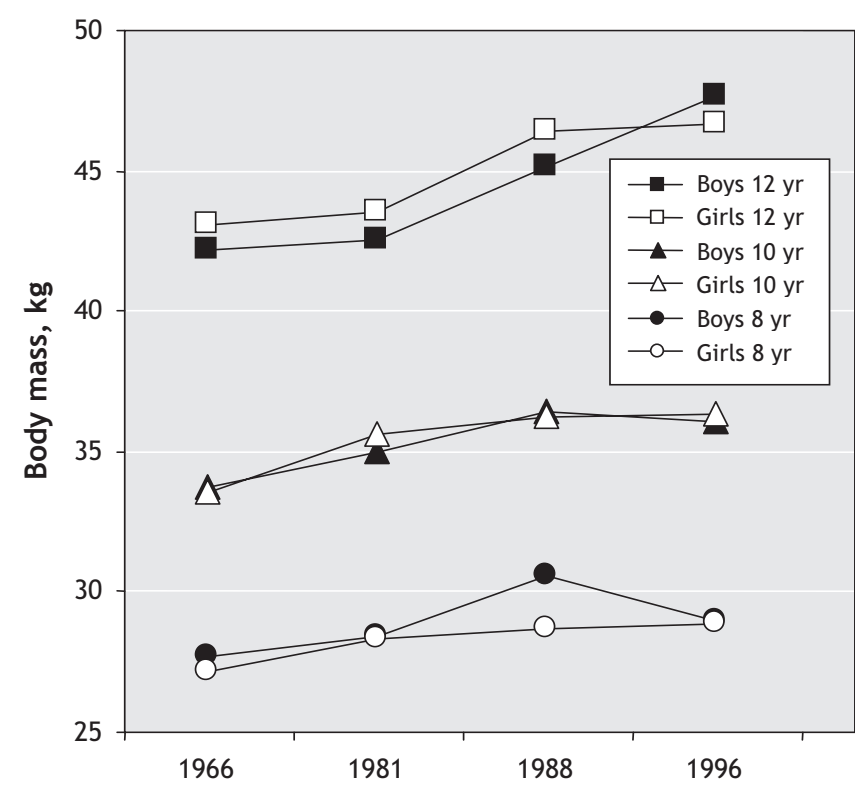

Fig. 4: Trends in body mass of Canadian boys and girls. Source: Adapted from Tremblay and Willms. ${ }^{49}$

\section{Summary}

- The prevalence of obesity has increased almost 3 -fold over the past 2 decades.

- There are no significant differences between girls and boys in the prevalence of overweight and obesity.

- A large proportion of obese adolescents will become obese adults.

\section{Knowledge gap}

- Additional research is needed on factors that contribute to the onset of overweight or obesity in childhood and adolescence and factors that contribute to its persistence into adulthood.

- The basic biologic characteristics of appetite, weight control, genetic susceptibility and environmental triggers remain elusive.

- We do not know specific prevention or treatment strategies that have sustained benefits in a broad spectrum of individuals.

\section{Lipids and insulin resistance}

Overweight and obesity are associated with significant health problems in the pediatric population and are important early risk factors for much of the adult morbidity and mortality associated with type 2 diabetes mellitus and CVD.

A large number of studies have consistently shown associations among childhood obesity, dyslipidemia, hyperinsulinemia and high blood pressure..$^{52-54}$ The clustering of these CVD risk factors defines the metabolic syndrome called insulin resistance syndrome (IRS). The likelihood of IRS is the same for girls and boys. In the I999 Quebec Child and Adolescent Health and Social Survey (QCAHS), a representative cross-sectional survey of Quebec youth, the overall prevalence of IRS was $\mathrm{II} .5 \%$ in youth aged $9, \mathrm{I} 3$ and $\mathrm{I} 6$ years. ${ }^{55}$ This is the only report on the prevalence of IRS in a provincially representative sample of youth in Canada. Findings from the third NHANES survey show a prevalence of IRS of $9.2 \%(95 \%$ CI 7.8-10.6) in US youth aged I2-I9 years. ${ }^{56}$ Prevalence was comparable for girls ( $8.9 \%$; $95 \%$ CI 7.I-I0.7) and boys ( $9.5 \%$; $95 \%$ CI 7.5-II.5) and for older (8.3\%; 95\% CI 6.5-IO.I) and younger (I0.3\%; 95\% CI 8.3-I2.3) adolescents. The ethnic distribution was similar to that in adults: Mexican Americans (I2.9\%; 95\% CI I0.4-I5.4) and non-Hispanic white people (I0.9\%; 95\% CI 8.4-I3.4) had a greater prevalence of IRS compared with non-Hispanic black people (2.5\%; 95\% CI I.3-3.7). Nearly a third (3I.2\%; $95 \%$ CI $28.3-34$. I) of overweight or obese adolescents had IRS.

Given the link between excess weight and dyslipidemia, the increase in overweight and obesity among youth in North America is expected to affect trends in lipid and glucose levels adversely. However, comparing data from 2 NHANES surveys of US youth aged 4-17 years in 1988-1994 and 1999-2000, Ford and colleagues ${ }^{57}$ found that the mean concentrations of total cholesterol, high-density lipoprotein (HDL) cholesterol and low-density lipoprotein (LDL) cholesterol were almost 
the same in the 2 groups. However, in 1999-2000, mean triglyceride concentration was almost 10\% lower than in I988-1994 and mean glucose concentration decreased by $3 \%$. These inconsistent trends in CVD risk factors, especially in HDL cholesterol and triglyceride levels, are difficult to explain. Changes in mean levels may not be sensitive enough to detect variations occurring at the extremities of the distributions; it would have been interesting to compare selected percentiles in the 2 surveys.

Although longitudinal data for plasma lipid levels in Canadian youth are not available, mean concentrations of plasma lipids in the 1999 QCAHS and in the 1999-2000 NHANES were similar. ${ }^{55,57}$ Body composition and fat distribution are different between boys and girls and across ages, and these differences may influence the relation between fatness and lipids.

\section{Summary}

- There are no significant differences between girls and boys in prevalence of IRS.

- There are no significant differences in the trends in lipid and glucose profiles of girls and boys over the last decade.

\section{Knowledge gap}

- Little is known about the natural history of the metabolic consequences of excess adiposity in childhood and adolescence.

- Surveillance of trends in obesity and the potential effects on CVD risk factors is needed.

- Better understanding of the relative importance of genetic, biologic, environmental and psychosocial determinants of metabolic abnormalities associated with excess fat is required.

\section{Blood pressure}

Knowledge of blood pressure distributions in youth is important: both systolic and diastolic pressure persist from childhood to adulthood ${ }^{42,58,59}$ and the current youth obesity epidemic has important effects on blood pressure distribution in this segment of the population. ${ }^{60}$

There are few data on blood pressure distribution and the prevalence of elevated blood pressure in Canadian children. The 1999 QCAHS reported important increases in mean systolic blood pressure and in height-specific systolic blood pressure percentile values compared with reference values from the National High Blood Pressure Education Program Working Group on Hypertension Control in Children and Adolescents ${ }^{61}$ for both boys and girls in all age groups. ${ }^{52}$ The proportion of children aged 9, I3, and 16 years with highnormal or elevated systolic pressure was $12 \%, 22 \%$ and $30 \%$, respectively, for boys and $14 \%, 19 \%$ and $17 \%$ for girls. Elevated systolic pressure occurred in almost twice as many I6year-old boys as girls. The mean systolic pressure of $\mathrm{I}_{3}$ - and I6-year-old boys was $2 \mathrm{~mm} \mathrm{Hg}(p=0.004)$ and Io $\mathrm{mm} \mathrm{Hg}$ $(p<0.000 \mathrm{I})$ higher, respectively, than that of girls. Less than $\mathrm{I} \%$ of youth had elevated or borderline diastolic blood pres- sure, and this did not differ between sexes. These findings were recently confirmed in a longitudinal study of Canadian adolescents. The likelihood of high systolic blood pressure values among boys compared with girls was $\mathrm{I} .29$ ( $95 \% \mathrm{CI}$ $0.77-2.16$ ) in grade $7, \mathrm{I} .98$ ( $95 \%$ CI I.35-2.93) in grade 9 , and 2.74 (95\% CI I.52-4.94) in grade II. ${ }^{6}$

A similar trend in high blood pressure has been observed in US children (Fig. 5). ${ }^{63}$ In age-matched boys and girls, ${ }^{64}$ cross-sectional analyses of the baseline data from the $\mathrm{Na}$ tional Heart, Lung, and Blood Institute Growth and Health Study showed significantly higher systolic (I05 v. Ioo $\mathrm{mm} \mathrm{Hg}$ ) and diastolic (7I v. $65 \mathrm{~mm} \mathrm{Hg}$ ) blood pressure levels among overweight white girls aged 9 years than among those who were not overweight. ${ }^{65}$

Limited data are available from representative samples of children from other parts of the world. Comparisons are further complicated by variations in sampling design and blood

\section{Systolic}

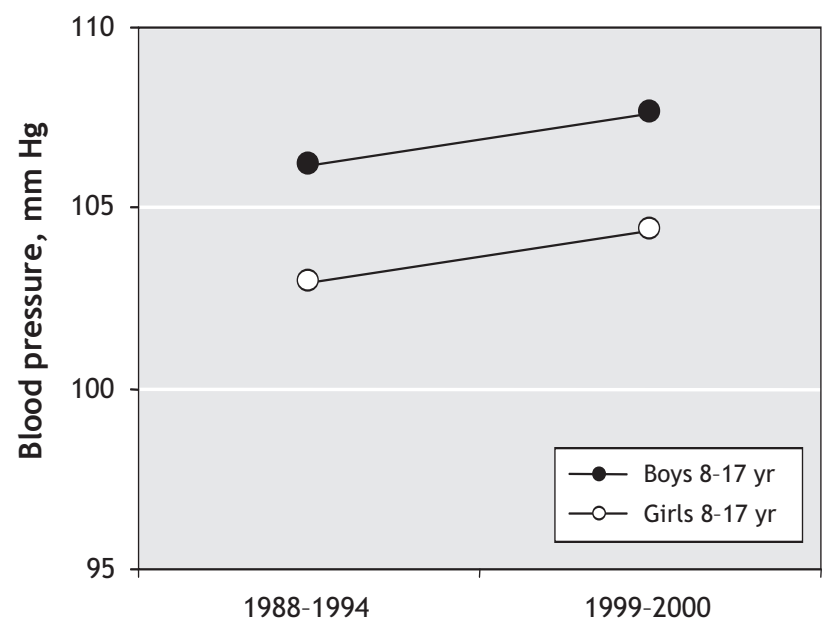

\section{Diastolic}

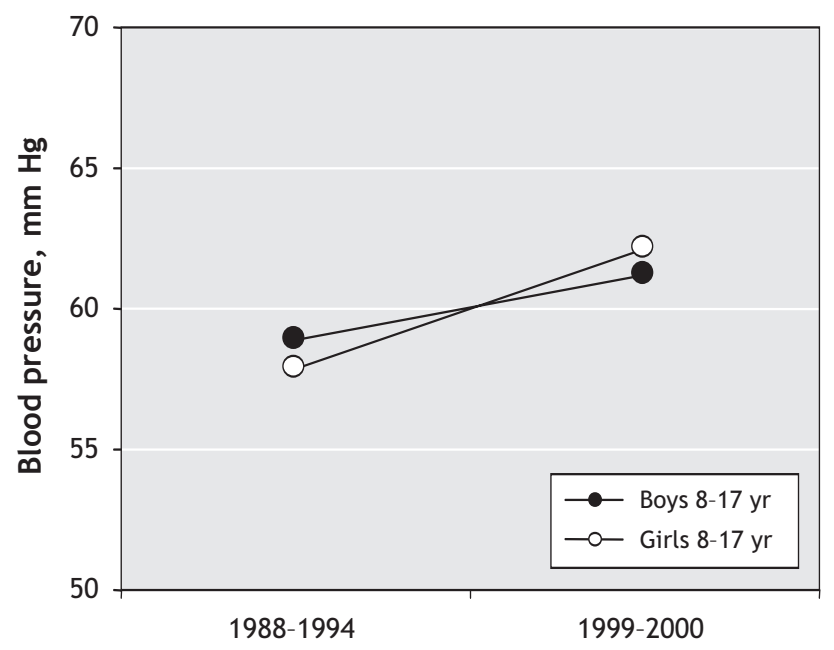

Fig. 5: Trends in systolic and diastolic blood pressure among children and adolescents in the United States. Source: Adapted from Muntner et al. ${ }^{63}$ 
pressure measurement. For example, a recent survey of 809 boys and 842 girls aged 7-I4 years from Belgrade, Serbia and Montenegro revealed average blood pressures of II $3 / 70 \mathrm{~mm} \mathrm{Hg}$ in boys and $115 / 7 \mathrm{I} \mathrm{mm} \mathrm{Hg}$ in girls. High systolic pressure was present in $5 \%$ of boys and girls, and high diastolic pressure was found in $6 \%$ of boys and $5 \%$ of girls. ${ }^{66}$ Conversely, a study of over 1200 children aged 6-II years in Milan reported a significantly higher prevalence of elevated blood pressure in girls $(5 \%)$ than in boys $(3 \%) .^{58}$ Sex differences in blood pressure may be due to differences in BMI between boys and girls at any given age, differences in activity levels and differences in pubertal stage at any given age.

\section{Summary}

- Elevated blood pressure persists from childhood to adulthood.

- Elevated blood pressure is prevalent in both girls and boys.

- Boys have higher systolic blood pressure than girls.

\section{Knowledge gap}

- Criterion-related reference values are necessary to clarify the significance of blood pressure levels in youth.

- More information is needed on blood pressure distribution and the prevalence of elevated blood pressure in groups of Canadian girls and boys.

- Sex differences in blood pressure require explanation at biologic, environmental and behavioural levels.

\section{Smoking}

Although data from the Global Youth Tobacco Survey ${ }^{67}$ and the National Tobacco Information Online System ${ }^{68}$ suggest that, in many developing countries, proportionately more boys than girls smoke, there have been few notable differences in the prevalence of smoking by boys and girls in developed countries over the last decade. ${ }^{69}$ Recent data for Canadian youth ${ }^{70,71}$ concur (Fig. 6). ${ }^{72}$ In Canada, $25 \%$ of girls $15-17$ years old smoke compared with $19 \%$ of same-age boys, but by age 19 the prevalence is equal $(31 \%) .{ }^{73} \mathrm{How}$ ever, there appear to be sex differences in the number of cigarettes smoked per day, at least among young daily smokers. In 2002, Canadian boys in grades $5-9$ smoked 8.8 cigarettes a day on average, compared with 7.3 cigarettes among girls. ${ }^{70}$ There are currently no nationally representative data comparing the incidence of smoking initiation by sex, although I prospective Canadian study suggests that boys are more likely than girls to escalate cigarette consumption rapidly after initiation. ${ }^{74}$ Although smoking cessation in youth is understudied, several surveys suggest that there are few differences in cessation attempts and successful cessation by sex. ${ }^{70}$

Although prevalence does not differ markedly by sex, girls and boys may smoke for different reasons. Among adolescent girls, body image, eating disorders and targeted advertising by tobacco companies likely relate to initiation of and sustained smoking, whereas aggression and conduct disorders appear to be fairly consistent predictors of smoking among boys. ${ }^{75}$ However, the current literature on sex differences in the determinants of smoking is generally inconclusive because many studies are cross-sectional, the definitions of smoking and of the potential determinants of smoking are widely divergent across studies and most studies investigated only small subsets of potential determinants.

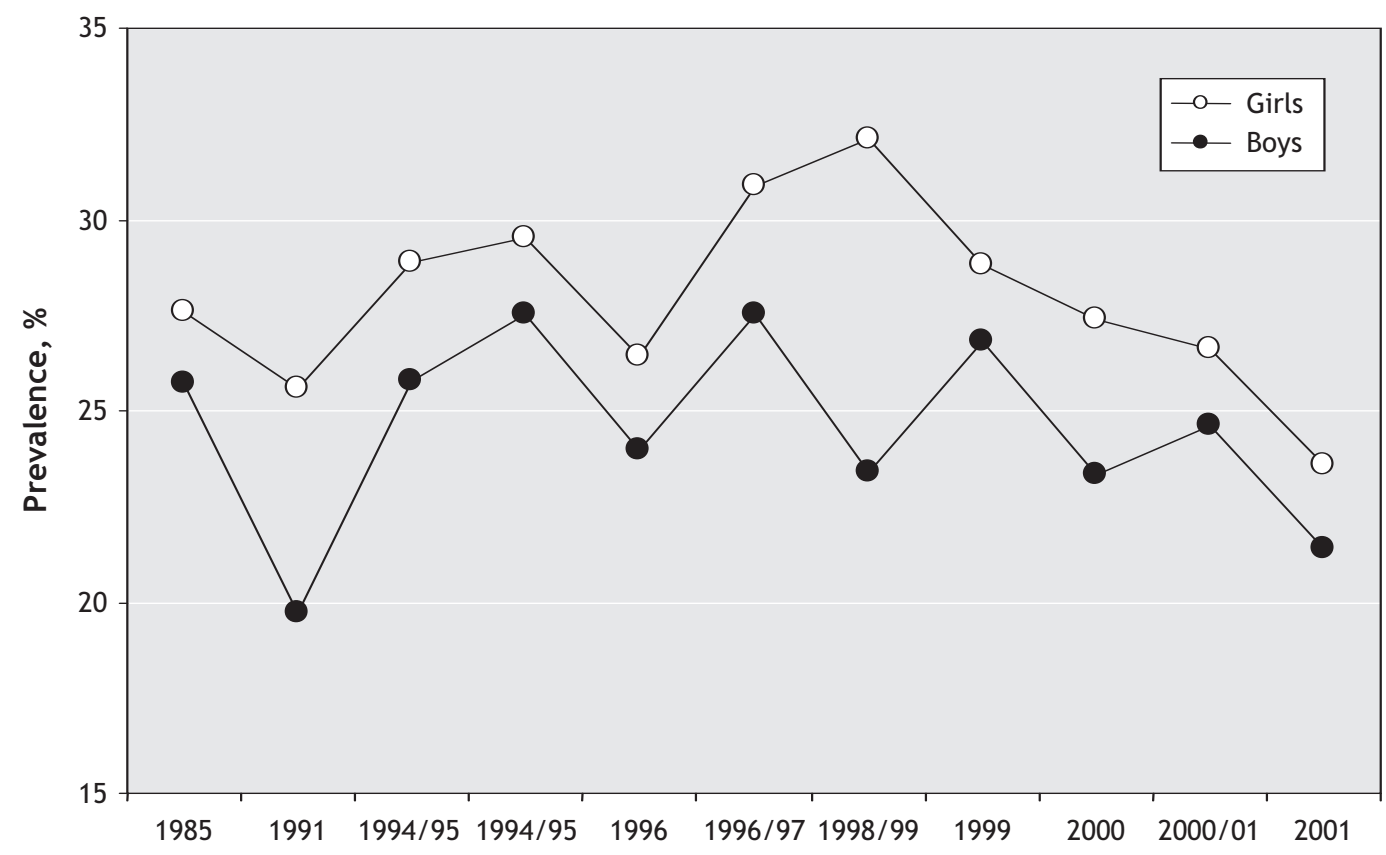

Fig. 6: Trends in current-smoker prevalence among Canadian adolescents, $15-19$ years of age. Source: Adapted from Gilmore. ${ }^{72}$ 


\section{Summary}

- The prevalence of smoking is similar in girls and boys.

- Boys who smoke daily smoke more cigarettes a day than girls who smoke daily.

- Determinants of smoking differ with sex.

\section{Knowledge gap}

- The sex-specific incidence and prevalence of smoking should be monitored throughout the life course.

- Longitudinal life-course studies based on socioecologic models of health behaviour are needed to determine whether girls smoke for different reasons than boys.

- Researchers should examine the relative importance of individual (genetic, sociodemographic, psychosocial, behavioural) and environmental (social influences, policy, advertising) factors that influence smoking.

\section{Diet}

Dietary habits are important lifestyle behaviours that develop in early childhood. Although food consumption patterns have changed over the last several decades, no differences in these patterns have been noted between US boys and girls (except for the expected sex differences in mean energy intake [Fig. 7])..$^{76,77}$ Carbohydrate consumption by children and adolescents has increased by $\mathrm{I} 50-200 \mathrm{kcal} / \mathrm{day}(\mathrm{I} \mathrm{kcal}=4.184 \mathrm{~kJ})$, while fat intake has decreased by $100 \mathrm{kcal} /$ day or less. ${ }^{78,79}$ Significant increases

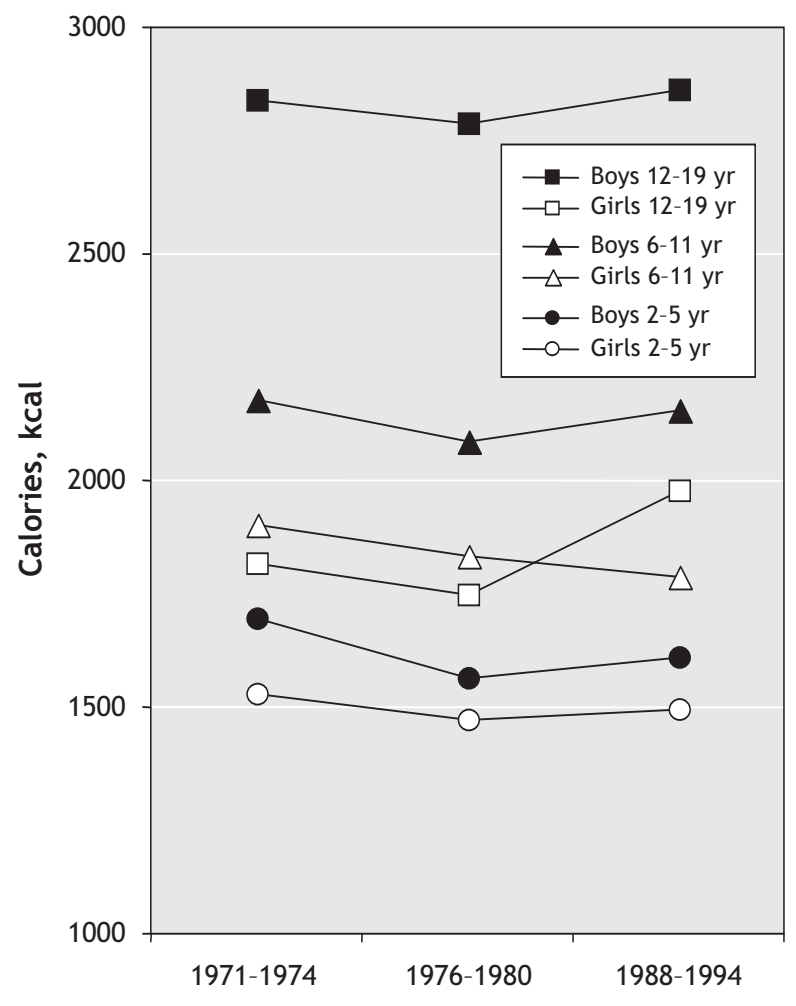

Fig. 7: Trends in mean daily caloric intake among children and adolescents. Source: Adapted from Troiano et al. ${ }^{77}$ in consumption of carbohydrates such as pizza and salty snacks have also been reported. The percentage of foods eaten at home has decreased, as more food is eaten in restaurants and fastfood chains..$^{80}$ The prevalence of snacking has increased among youth of all ages - both portion sizes and frequency - accounting for the increase in average daily intake attributable to snacks. ${ }^{81}$

There are fewer data available for Canadian children and adolescents, but the results of the few studies that have been conducted largely parallel US findings. A survey of 5 th-grade children in Nova Scotia found that almost half do not meet the recommendations for consumption of milk products (42.3\%) or fruits and vegetables $(49.9 \%) .{ }^{82}$ Carbohydrate intake contributed $56.7 \%$ of total energy intake, of which $\mathrm{II}^{\mathrm{O}} \%$ (32 g/day) was sucrose. Of the children, $13.9 \%$ exceeded the recommended range for fat intake ( $25 \%-35 \%$ of total calories). In I study that examined "diet quality" as an index of dietary variety, adequacy, moderation and balance, boys were found to have poorer diet quality than girls. ${ }^{82}$ In the Canadian Community Health Survey, ${ }^{71} 57.8 \%$ of boys aged I2-I9 years and $54.5 \%$ of similarly aged girls consumed less than 5 servings of fruit and vegetables a day. Eating at a fast-food restaurant more than 3 times a week was associated with a $56 \%$ increase in risk of lower diet quality. The Food Habits of Canadians study also provided data on food consumption patterns of adolescents based on 24-h dietary recall. ${ }^{83}$ These Canadian teenagers frequently consumed cakes, cookies, sweetened beverages, salty snacks and other nutrient-poor foods.

Several researchers have consistently found an increase in the consumption of sweetened beverages ${ }^{84}$ that is similar for boys and girls. Health Canada data from 1990 to 1998 indicate similar rates of consumption of soft drinks, colas and other drinks containing sugar for children aged II, I3 and I5 years. Adolescents aged $\mathrm{II}-\mathrm{I} 6$ years participated in the 200I-2002 Canadian component of the World Health Organization Health Behaviour in School-Aged Children Survey, which associated increased soft drink consumption with greater odds of overweight and obesity. ${ }^{85}$ Sweetened beverages contribute $20 \%-24 \%$ of energy to the diet of children and adolescents, ${ }^{77}$ and the percentage of total energy intake from soft drinks is greater among boys than girls. ${ }^{86}$ Milk consumption has decreased, although the decrease has been greater among boys.

\section{Summary}

- Total energy intake has remained largely constant over the past 4 decades with boys having an expected higher daily caloric intake than girls.

- Dietary patterns, including consumption of sweetened beverages and percentage of foods eaten outside the home, are similar for boys and girls.

- Boys and girls are eating more energy-dense, nutrientpoor foods in larger portions, a pattern that is consistent with the obesity epidemic.

\section{Knowledge gap}

- Researchers should evaluate socioecologic influences 
(e.g., parental dietary habits, psychosocial and behavioural factors, social influences, media and advertising) on dietary behaviour.

- Researchers should improve assessment procedures to determine more accurately children's dietary intake (advancing 24-h dietary recall, food frequency questionnaires and prospective food records or diaries).

- The sex-specific prevalence and trends in dietary and total energy intake should be monitored throughout the life course.

\section{Physical activity and sedentary behaviour}

Data from recent national surveys suggest a favourable trend in physical activity among Canadian adolescents. ${ }^{87}$ Between I994 and 2003, the proportion of I2-I9-year-olds classified as active (i.e., average energy expenditure $\geq 3.0 \mathrm{kcal} / \mathrm{kg}$ body weight a day) increased from $44.6 \%$ to $54.6 \%$ for boys and from $27.3 \%$ to $39.5 \%$ for girls. Despite this encouraging trend, the physical activity gap between boys and girls remains wide (Fig. 8). ${ }^{87}$ Girls report less physical activity than boys, both before and during adolescence. ${ }^{88-92}$ Sex differences are particularly apparent for vigorous physical activity, with girls less likely than boys to engage in such activity during their free time or in the context of organized physical activity, during school and outside school. ${ }^{93-95}$

Although girls and boys are equally likely to be enrolled in organized physical activity and lessons outside school, girls are less likely to belong to sports clubs or participate in unorganized physical activity or in school sports outside physical education classes. ${ }^{96}$ Not surprisingly, boys and girls differ substantially in their physical activity preferences ${ }^{97,98}$ and in their patterns of involvement in physical activity. ${ }^{99,100}$ Boys

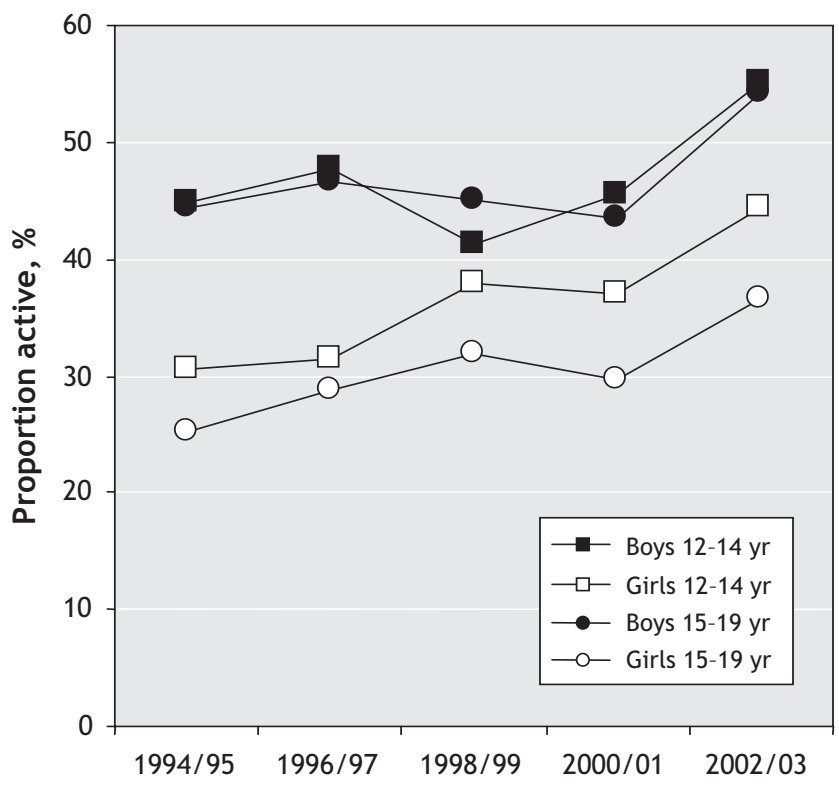

Fig. 8: Trends in leisure-time physical activity among Canadian adolescents. Proportion active are those with an average daily energy expenditure of at least $3.0 \mathrm{kcal} / \mathrm{kg}$. Source: Adapted from Statistics Canada. ${ }^{87}$ and girls also differ in their attitudes and beliefs regarding physical activity, ${ }^{101,102}$ as well as their motivation for ${ }^{97,103}$ and barriers to ${ }^{104,105}$ engaging in physical activity.

Individual and environmental factors do not influence boys and girls equally. ${ }^{106,107}$ There is evidence that genetic effects are associated with sports participation and with leisure time physical activity to a greater extent in boys than in girls. ${ }^{108}$ Boys' and girls' physical activity levels are similarly affected by peer and family social support, ${ }^{109,110}$ but appear to be influenced by different neighbourhood factors. For example, perceived neighbourhood opportunities for physical activity are associated with girls' but not boys' activity levels, ${ }^{111}$ and physical features of the school environment appear to influence physical activity to a greater extent in boys. ${ }^{112,113}$ Finally, significant effects by sex are frequently observed in interventions promoting physically active lifestyles among youth. ${ }^{104,114}$

Data on sedentary pursuits are limited. A recent review concluded that total media use among youth in industrialized countries has remained stable in the past decades at approximately $5 \mathrm{~h} /$ day. ${ }^{104,115}$ The most recent data show that the proportion of adolescents aged I2-I7 years who spend $30 \mathrm{~h}$ or more a week in sedentary activities (i.e., watching television, playing video games, spending time on the computer) is $30.0 \%$ in boys and $18.2 \%$ in girls. ${ }^{116}$ Most of the discrepancy between older boys and girls concerning time spent in sedentary pursuits relates to greater computer use and video game play in boys, not to television viewing. ${ }^{115,116}$

Sex and gender differences in physical activity and sedentary behaviour may be largely due to interactions between individual characteristics (e.g., physical maturation, personal motivation) and responses to environmental cues that enhance or inhibit involvement in these pursuits.

\section{Summary}

- Despite recent increases in physical activity in all youth, sex-related disparities in involvement in physical activity have not diminished.

- Boys are consistently more active than girls at all ages, and age-related decreases in physical activity occur earlier in girls than in boys.

- Most girls are not active enough to meet guidelines for optimal growth and development.

\section{Knowledge gap}

- Refine methods of physical activity assessment to capture the different dimensions and contexts of both sexes, including low- and moderate-intensity activities of daily living and active transportation, as well as the more traditional structured, free play and vigorous physical activities.

- Investigate the possible role of genetic inheritance in adaptation to sedentary or active lifestyles.

- Investigate how individual, familial, school and neighbourhood characteristics interact with sex and gender to determine involvement in physical activity.

- An increased understanding of the clustering of active and sedentary behaviours over the life course is required to 
help devise more effective sex-specific prevention and promotion programs.

\section{Clustering of behavioural risk factors}

According to the Canadian Cardiovascular Society's 1998 consensus on the prevention of CVD, the major CVD behavioural risk factors in youth include smoking, physical inactivity and obesity. ${ }^{117}$ These modifiable risk factors persist from childhood into adulthood ${ }^{4-44}$ and tend to cluster among youth. ${ }^{118-121}$ In the longitudinal Cardiovascular Risk in Young Finns Study, Raitakari and colleagues ${ }^{118}$ found that I5- and I8-year-old boys and girls who smoked were more likely to be regular users of alcohol and physically inactive compared with non-smokers. Obesity was more prevalent among physically inactive compared with active males (I $4 \%$ v. $8 \%, p<0.05)$, female drinkers compared with nondrinkers $(20 \%$ v. $9 \%, p<0.00 \mathrm{I})$ and smokers compared with non-smokers (males $15 \%$ v. $9 \%, p<0.05$; females $16 \% \mathrm{v}$. $9 \%, p<0.0 I$ ). In males, those with 4 selected CVD behavioural risk factors, including smoking, physical inactivity, obesity and intake of dietary fat, had a 5.5 times greater risk of having an atherogenic lipid profile and high diastolic blood pressure compared with those with o or I behavioural risk factor. ${ }^{118}$ In another prospective study investigating the association between family socioeconomic status and an adverse cardiovascular risk profile among I4- and I7-year-old boys and girls in Sweden, Bergstrom and colleagues ${ }^{119}$ reported clustering of high BMI, low physical fitness and daily smoking among girls living in families of low socioeconomic status compared with girls of the same age in families of medium or high socioeconomic status.

In the United States, Pate and colleagues ${ }^{120}$ investigated the association between physical activity and other healthrelated behaviours, including smoking and dietary habits, in a representative sample of adolescents aged $\mathrm{I} 2-\mathrm{I} 8$ years. Boys and girls who smoked I or more cigarettes over the past 30 days and who did not eat fruits or vegetables on the previous day were I. 5 and 2 times more likely to be less active than those who did not report these behaviours, respectively. In a more recent study, Pronk and colleagues ${ }^{121}$ reported that only $3 \mathrm{I} \%$ of US adolescents aged $\mathrm{I} 3-\mathrm{I} 7$ years met recommended guidelines for multiple healthy lifestyle factors including physical activity, non-smoking, high-quality diet and healthy weight. This implies that more than two-thirds of US adolescents have I or more CVD behavioural risk factors, an estimate that is quite alarming given the potential synergistic effects associated with the presence of multiple behavioural risk factors on the risk of chronic diseases in adult life. ${ }^{122}$ Pronk and colleagues ${ }^{121}$ also found that depression is associated with clustering of health-related behaviours in adolescents. Specifically, non-depressed adolescents were 2.15 times more likely to engage in 4 healthy lifestyle factors. The clustering of health-related behaviours in US adolescents was similar for boys and girls.

Data on the prevalence and potential determinants of multiple CVD behavioural risk factors in Canada are scarce. The studies reviewed in this section suggest that CVD behavioural risk factors cluster in children and adolescents. Certain sociodemographic characteristics, including age and sex, ${ }^{109,110}$ and psychosocial variables, such as depression and family socioeconomic status, ${ }^{112}$ seem to be associated with the clustering of CVD behavioural risk factors in youth, but evidence in this area remains limited and inconsistent.

\section{Critical analysis of studies}

All the studies reviewed were observational, cross-sectional cohort or longitudinal studies. Wherever possible, results of studies specifically focusing on girls or on boys or providing sex comparisons have been included. The areas not sufficiently addressed by existing studies have been highlighted as knowledge gaps.

\section{Why are there sex differences?}

When sex differences in risk factors are apparent, they appear to be attributable to a combination of biologic (sex) and behavioural (gender) factors. Compared with age-matched boys, girls have lower systolic blood pressure. However, this sex difference is attenuated with age and may be partly attributable to sex hormones or their receptors. In terms of health behaviours, the prevalence of smoking does not differ markedly by sex, although boys smoke more cigarettes a day than girls, and they are more likely than girls to escalate cigarette consumption rapidly after initiation. Boys and girls appear to smoke for different reasons. Body image, eating disorders and targeted advertising by tobacco companies likely relate to initiation and sustained smoking among adolescent girls, while aggression and conduct disorders are predictors of smoking among boys. Sex differences in physical activity are also apparent; girls are less likely to engage in physical activity than boys, both before and during adolescence. This may be partly due to sex and gender factors.

\section{Summary}

- The major CVD behavioural risk factors, including smoking, physical inactivity and obesity, cluster among young boys and girls.

- Having multiple CVD behavioural risk factors increases the risk of atherogenic profile and high blood pressure among boys.

- Age, gender, depression and family socioeconomic status are associated with clustering of CVD behavioural risk factors in youth.

\section{Knowledge gap}

- Studies identifying the prevalence and determinants of multiple CVD behavioural risk factors in youth are warranted.

- A better understanding of the frequency and clustering patterns of CVD behavioural risk factors in young girls and boys is needed to facilitate health professionals' efforts to reduce the incidence of CVD. 


\title{
Cardiovascular risk factors in women and men
}

\author{
Kaberi Dasgupta, Susan Kirkland, Doreen Rabi and Vicky Tagalakis
}

The Framingham Heart Study established the independent impact of cigarette smoking, elevated blood pressure, elevated total cholesterol and LDL cholesterol, low HDL cholesterol, diabetes, male sex and advancing age on the development of CVD. ${ }^{123}$ Based on Framingham cohort data, equations for the calculation of risk of CVD have been developed and treatment targets for blood pressure and lipid levels are now dictated by global recommendations. ${ }^{124,125}$

Excess weight and physical inactivity have an adverse impact on blood glucose levels, blood pressure and lipid profiles. ${ }^{126}$ Individuals in the Framingham cohort who lost at least $2.25 \mathrm{~kg}$ over $\mathrm{I} 6$ years had a $40 \%-50 \%$ reduction in their total cardiovascular risk factor score. ${ }^{127}$ Independent of its impact on weight, regular exercise has favourable effects on glucose control, blood pressure, serum lipids and fitness levels. ${ }^{126,128-133}$ Higher fitness levels have been demonstrated to be independently associated with a reduction in CVD events and mortality. ${ }^{134,135}$

A number of additional markers of risk for CVD have been identified, including biomarkers, such as C-reactive protein and plasminogen activator inhibitor type-I, and demographic factors, such as low socioeconomic status. It remains to be determined whether such markers are independent risk factors, predisposing or intermediary factors associated with established risk factors, or noncausally associated with CVD.

Although Framingham data indicate that men are generally at increased risk for CVD than women, the distribution and impact of other CVD risk factors and markers may also differ between men and women, with implications for prevention, detection and management of CVD in both sexes. In this section, we review the existing literature regarding sex differences in the prevalence and impact of overweight and obesity, physical activity, hypertension, diabetes, smoking, dyslipidemia, selected cardiovascular risk markers and socioeconomic factors.

\section{Search strategy}

Boolean searches of MEDLINE from I966 to August 2005 were performed by combining the MeSH term "cardiovascu- lar disease" with each of the following MeSH terms: "obesity," "physical activity," "hypertension," "diabetes," "socioeconomic status," "smoking," "C-reactive protein," "homocysteine," "apolipoprotein E," "dyslipidemia," "fibrinogen," "plasminogen activator inhibitor type-I" and "lipoprotein (a)." Each of these searches was combined using the term "AND" with a search that used the terms "gender" and "sex" and the term "OR." Searches were restricted to Englishlanguage publications, but no other restrictions applied. In addition, the references of the resulting publications were hand searched for further articles.

\section{Overweight and obesity}

Obesity-related complications include

- Vascular risk factors - Hypertension, dyslipidemia and type 2 diabetes

- Vascular disease - Ischemic heart disease, hypertensive heart disease, stroke, renal failure, peripheral vascular disease and retinopathy

- Other conditions - Osteoarthritis, malignancy (breast cancer), depression and polycystic ovary syndrome

\section{Sex differences in prevalence of overweight conditions}

In the United States, data from NHANES indicate that the overall prevalence of overweight (BMI $\geq 25 \mathrm{~kg} / \mathrm{m}^{2}$ ) was $55.9 \%$ in $1988,{ }^{136}$ rising to $64.6 \%$ by $1999 .{ }^{137}$ Data from the Canadian Community Health Survey indicate that the prevalence of overweight remained stable at $48 \%$ between I $994 / 95$ and $2000 / 0 \mathrm{I}$ in the population aged $20-64$ years, although $2 \%$ of individuals shifted from the overweight (BMI $\left.25-30 \mathrm{~kg} / \mathrm{m}^{2}\right)$ to the obese $\left(\mathrm{BMI} \geq 30 \mathrm{~kg} / \mathrm{m}^{2}\right)$ category. ${ }^{138}$

Sex differences in overweight and obesity are influenced by geography and ethnic background (Table 6). For example, among white and Mexican Americans, the prevalence of overweight is higher among men than among women. However, among black Americans, the prevalence of overweight is higher among women than men. The prevalence of obesity is

Table 6: Increase in the prevalence of overweight and obesity in the United States among men and women aged 20-74 years by ethnic background

\begin{tabular}{|c|c|c|c|c|c|c|c|c|}
\hline Ethnic group & \multicolumn{4}{|c|}{ Prevalence of overweight $\left(\mathrm{BMI}>25 \mathrm{~kg} / \mathrm{m}^{2}\right), \%$} & \multicolumn{4}{|c|}{ Prevalence of obesity $\left(\mathrm{BMI} \geq 30 \mathrm{~kg} / \mathrm{m}^{2}\right), \%$} \\
\hline Black (non-Hispanic) & 58.2 & 60.1 & 68.5 & 78.0 & 21.3 & 28.8 & 39.1 & 50.8 \\
\hline Mexican American & 69.4 & 74.4 & 69.6 & 71.8 & 24.4 & 29.4 & 36.1 & 40.1 \\
\hline
\end{tabular}

Source: NHANES. ${ }^{139}$ 
higher among US women than men, with the highest prevalence among black American women. ${ }^{139}$

In Canada, for both men and women, the prevalence of overweight is lower among black Canadians (50\%) than white Canadians $(60 \%) .{ }^{140}$ Consistent with this, among men, the prevalence of obesity is lower among black Canadians (Io\%) than white Canadians (15\%), although among Canadian women, the prevalence of obesity is higher among black people (20\%) than white people (15\%). The ethnic group with the highest rates of overweight and obesity is the Aboriginal population $(60 \%$ overweight in women and $65 \%$ in men; $25 \%-30 \%$ obesity in men and women). Between 1994/95 and 2000/OI, the prevalence of obesity increased in all age and sex groups in Canada, with the exception of women 20-34 years of age. These trends are consistent with those documented in other countries. ${ }^{141-144}$

Overweight and obesity are also prevalent in many developing countries. Nishida and Mucavel ${ }^{145}$ found that the prevalence of obesity was higher in women than in men in the following countries: Brazil, II.7\% v. 4.8\%; Egypt, $33.0 \%$ v. I2.6\%; South Africa, 30.1\% v. 9.4\%; Seychelles, $28.2 \%$ v. $8.5 \%$. The prevalence of overweight was similar for the 2 sexes, but countries reporting higher levels of overweight among women were located in Africa, Latin America, Asia and Oceania, whereas male overweight was more prevalent than women's in countries of Europe and North America.

\section{Recommendations for the prevention and treatment of obesity}

- Reduced consumption of energy-dense foods

- Regular physical activity

- Weight loss for those with BMI $\geq 25 \mathrm{~kg} / \mathrm{m}^{2}$ (diet and exercise counselling, behavioural counselling)

- Those with BMI $\geq 35 \mathrm{~kg} / \mathrm{m}^{2}$ or with $\mathrm{BMI} \geq 30 \mathrm{~kg} / \mathrm{m}^{2}$ and obesity-related complications may consider bariatric surgery

\section{Periods of risk}

Women appear to be particularly susceptible to significant weight increase during adolescence, ${ }^{146}$ pregnancy ${ }^{136}$ and menopause. ${ }^{147}$ The weight increase that occurs during menopause has been shown to be associated with a significant increase in blood pressure. ${ }^{148}$ The period after marriage appears to be a period of risk for weight gain among men. ${ }^{149}$

\section{Knowledge gap}

- Does the utility of weight loss for the prevention of CVD differ between women and men?

- Why do obese people appear to have lower rates of fatal recurrent cardiovascular events?

- What weight-loss strategies are particularly effective among men?

- What weight-loss strategies are particularly effective among women?
- Why are black women in both the United States and Canada at high risk of obesity?

\section{Physical activity}

\section{Sex differences in activity levels}

Many studies suggest that women are more likely to be sedentary than men. A questionnaire administered by Pitsavos and colleagues $^{150}$ in the Attica region of Greece revealed that, overall, $53 \%$ of men and $48 \%$ of women were physically active, and men tended to be more physically active than women across all age groups. In an interview-based survey conducted in Portugal, $79 \%$ (95\% CI $75.7-8$ r.6) of men and $86 \%$ ( $95 \%$ CI 84.0-88.0) of women were found to be sedentary. ${ }^{151} \mathrm{In}$ Finland, the proportion of people classified as sedentary or only moderately active during their leisure time was $75 \%$ among males and $82 \%$ among females. ${ }^{152}$ Men in Japan have also been found to be more active than women. ${ }^{153}$

There is some evidence that, although both men and women are both less likely to be active when weather conditions are unfavourable, women are less likely to increase activity levels when weather conditions become more favourable. In community-dwelling adults in Massachusetts, mean physical activity during the summer increased by 5 I minutes/day (95\% CI 20-82) in men, but only by I6 minutes/day (95\% CI -I2-45) in women. ${ }^{154}$

\section{Potential mechanisms}

Low levels of physical activity render weight maintenance difficult, contribute to the development of insulin resistance, with associated increases in blood pressure, blood glucose level, dyslipidemia and thrombogenic factors. In addition, there is increasing evidence that low levels of activity and fitness are directly related to increased CVD risk. In a prospective cohort study that examined the impact of physical activity on mortality, Blair and colleagues ${ }^{155}$ found that women in the lowest tertile of physical activity had a greater than 5 -fold increased risk of mortality compared with women in the highest physical activity tertile. Men in the lowest physical activity tertile were at a 3 -fold higher increase in risk of mortality compared with men in the highest fitness tertile.

\section{Barriers to physical activity in women}

Findings from Canada's National Population Health Survey demonstrate that the presence of children in the household is a significant deterrent to becoming active for women, but not for men. ${ }^{156}$ The most commonly reported barrier to women's participation in physical activity is lack of time due to family responsibilities. ${ }^{157,158}$ Middle-aged and older women appear to have positive attitudes toward exercise, but are unable or unwilling to take action. ${ }^{159}$

\section{Physical activity recommendations}

- To remain healthy and maintain body weight - moderate 
exercise (e.g., walking) 30 minutes daily or vigorous exercise (e.g., jogging) 20 minutes daily.

- To lose weight - vigorous exercise 30 minutes daily.

\section{Knowledge gap}

- What are the barriers to physical activity in women?

- Are the barriers largely related to child care or competing work-home responsibilities or both?

- How can activity levels among women be increased?

\section{Hypertension}

Excess body weight and physical inactivity may promote the development of a number of CVD risk factors, including high blood pressure (see Table 7 for the general classification of blood pressure levels).

\section{Hypertension-related comorbidities}

- ischemic heart disease

- hypertensive cardiomyopathy

- stroke

- renal failure

\section{Sex differences in blood pressure}

In the third NHANES (I988-I994) evaluation, among US adults under 45 years of age, men had higher systolic blood pressure levels than women. ${ }^{160}$ By $60-69$ years of age, nonHispanic white women had blood pressure levels similar to those of men and by 70-79 years of age, had higher levels than men. ${ }^{161}$ By $60-69$ years of age, non-Hispanic black and Hispanic women had higher blood pressure levels than men of similar ethnic background. ${ }^{161}$ Overall, among those 45 years of age and older, systolic blood pressure levels were higher among women. ${ }^{160}$ In a cohort study conducted in Denmark, 24-h mean blood pressure levels were 6-ro mm Hg higher among men than women until 70-79 years of age, but similar thereafter. ${ }^{162}$ Women from developing countries have higher mean systolic blood pressure than their male counter-

Table 7: General classification of blood pressure

\begin{tabular}{ll}
\hline Classification & \multicolumn{1}{c}{ Blood pressure } \\
\hline Normal & $\begin{array}{l}\text { Systolic } 120-129 \mathrm{~mm} \mathrm{Hg} \\
\text { Diastolic } 80-84 \mathrm{~mm} \mathrm{Hg}\end{array}$ \\
\hline High normal* & $\begin{array}{l}\text { Systolic } 130-139 \mathrm{~mm} \mathrm{Hg} \\
\text { Diastolic } 85-89 \mathrm{~mm} \mathrm{Hg}\end{array}$ \\
\hline Grade 1 & $\begin{array}{l}\text { Systolic } 140-159 \mathrm{~mm} \mathrm{Hg} \\
\text { Diastolic } 90-99 \mathrm{~mm} \mathrm{Hg}\end{array}$ \\
\hline Grade 2 & $\begin{array}{l}\text { Systolic } 160-179 \mathrm{~mm} \mathrm{Hg} \\
\text { Diastolic } 100-109 \mathrm{~mm} \mathrm{Hg}\end{array}$ \\
\hline Grade 3 & $\begin{array}{l}\text { Systolic } \geq 180 \mathrm{~mm} \mathrm{Hg} \\
\text { Diastolic } \geq 110 \mathrm{~mm} \mathrm{Hg}\end{array}$ \\
\hline
\end{tabular}

*Considered high in the context of diabetes or renal disease. parts. ${ }^{163}$ It is also noteworthy that women from these countries have higher blood pressure than women from developed countries. Women from the African region have the highest mean systolic blood pressure.

Among young and middle-aged adults, population surveys report hypertension to be more frequent among men compared with women, with sex differences of $4 \%$ in the United States, $8 \%$ in Canada and $\mathrm{II} \%$ in Western Europe. ${ }^{164}$ After 60 years of age, however, the prevalence of hypertension appears to be higher among women than among men.

\section{Potential mechanisms}

Androgen is thought to play a role in the sex differences in blood pressure. One possible mechanism may be the blunting of the pressure-natriuresis relation. ${ }^{165}$ Female sex hormones and their receptors may also be implicated in blood pressure differences between men and women. A genetic association study by the Victorian Family Heart Study investigators found that men inheriting the "a" allele on the estrogen receptor a gene had significantly higher systolic blood pressure levels $(5 \mathrm{~mm} \mathrm{Hg})$ than men with other genotypes. ${ }^{166}$ No significant associations between estrogen receptor genes and blood pressure were detected among women.

\section{Knowledge gap}

- How can the postmenopausal increase in hypertension be prevented?

- Should the threshold for hypertension diagnosis in women be lower to prevent the postmenopausal increase in hypertension?

- Can earlier detection of hypertension in boys and young men reduce the sex-gender differential in incidence of CVD between men and premenopausal women?

\section{Diabetes}

Diabetes is highly prevalent; over I5I million people live with this condition worldwide (Table 8). Diabetes is an established

Table 8: Crude prevalence of diabetes among adults aged 20

79 years in various countries

\begin{tabular}{lcc}
\hline Country (year) & Men, \% & Women, \% \\
\hline Canada (1999) & 5.0 & 4.6 \\
\hline United States (2002) & 6.9 & 6.1 \\
\hline Mexico (2003) & 2.7 & 4.7 \\
United Kingdom (1998) & 2.2 & 2.0 \\
Spain (2003) & 4.0 & 5.9 \\
Sweden (2003) & 3.3 & 3.9 \\
Australia (2003) & 3.4 & 2.7 \\
China (Hong Kong) (2003) & 4.3 & 4.6 \\
Japan (2003) & 3.6 & 3.3 \\
\hline
\end{tabular}

Source of data: Haffner et al. ${ }^{167}$ 
risk factor for the development of CVD. ${ }^{167}$ People with diabetes have a 2- to 4 -fold greater risk of developing CVD compared with those without diabetes. ${ }^{168} \mathrm{CVD}$ is the leading cause of morbidity and mortality for those living with diabetes.

Although the prevalence of diabetes is lower in developing countries, these countries have experienced the greatest increase in diabetes. The prevalence is highest in the Eastern Mediterranean and Middle East (7.0\%), South and Central America (5.6\%), Southeast Asia (5.6\%), Western Pacific (3.1\%) and Africa (2.4\%). The prevalence of diabetes is higher among women than among men in Latin America $(57.5 \% \mathrm{v}$. $42.5 \%)$ and in the Western Pacific (53.7\% v. $46.3 \%) .{ }^{169}$

\section{Diabetes-related vasculopathy}

\section{Microvasculature \\ - retinopathy \\ - nephropathy}

\section{Macrovasculature}

- peripheral vascular disease

- cerebrovascular disease

- ischemic heart disease

Because CVD is more prevalent among men, it follows that most studies that have examined the significance of diabetes as a risk or prognostic factor have predominantly male participants. However, $\mathrm{Hu}$ and colleagues ${ }^{170}$ examined the prognostic significance of diabetes in their analysis of the Nurse's Health Study Cohort and found that women with diabetes had surprisingly high cardiovascular-related mortality. This study demonstrated that the adjusted relative risk (RR) for cardiovascular-related death among women who had established CVD, after controlling for other vascular risk factors, such as smoking status, family history of ischemic heart disease and BMI, was 13.6 (95\% CI 8.45-21.8). However, it should be noted that there was no control for differences in hypertension, hypercholesterolemia or socioeconomic status, risk factors that are well known to be more prevalent among both women and men with diabetes.

\section{Diabetes as a prognostic factor among patients with CAD}

Although diabetes is an established risk factor for the development of CVD, the significance of diabetes as a prognostic factor following an ischemic event remains less clear. Numerous studies have demonstrated that patients with diabetes appear to have poorer clinical outcomes following myocardial infarction (MI), stroke and percutaneous and surgical revascularization compared with non-diabetic patients. However, in a prospective cohort study of II 468 patients presenting for coronary catheterization ( $17 \%$ of whom had diabetes), Ghali and colleagues ${ }^{171}$ demonstrated that, after controlling for all clinically relevant variables, the survival of patients with diabetes was the same as for those without diabetes at I year (OR I.I; 95\% CI o.8-I.3) and 3 years (HR I.2; 95\% CI I.O-I.4).

Graham and colleagues ${ }^{172}$ completed a large prospective cohort study examining sex differences in the prognostic significance of diabetes following coronary catheterization. After adjusting for several clinical variables, they demonstrated a trend toward increased mortality in women with diabetes, although this was not statistically significant. Several systematic reviews and meta-analyses have been carried out to determine the association between sex and CVD mortality. ${ }^{173-175}$ Lee and colleagues ${ }^{173}$ found that women with diabetes had a relative risk of coronary death from diabetes of 2.58 (95\% CI 2.05-3.26) compared with non-diabetic women, which was significantly higher than for men with diabetes (RR I.85; 95\% CI I.47-2.33). This review was limited in that the included studies had variably controlled for other coronary risk factors. When Kanaya and colleagues ${ }^{174}$ reviewed studies that adjusted for age, hypertension, hyperlipidemia and smoking status, they found that there was no longer a significant difference in cardiovascular-related mortality between men and women with diabetes. Reviewing data from North America, Europe and the Asian Pacific Cohort Studies Collaboration, Huxley and colleagues ${ }^{175}$ found, like Lee and colleagues, that women with diabetes had a 3.5-fold (95\% CI 2.7-4.5) increase in CVD mortality compared with non-diabetic women and that this was significantly higher than for their male counterparts (RR 2.I; 95\% CI o.8I-2.34). Sensitivity analyses

Table 9: Risk of cardiovascular-related mortality among men and women with diabetes compared with men and women without diabetes

\begin{tabular}{lllll}
\hline Study (year) & \multicolumn{1}{c}{ Population } & Outcome (OR or RR) & Men & Women \\
\hline Rancho Bernardo (1991)* & White American & IHD death (OR) & 1.9 (1.3-2.8)† & $3.3(2.0-5.6)$ \\
\hline NHANES1 (1988)* & White American & CVD death (OR) & $2.6(2.0-3.4)$ & $2.2(1.6-3.1)$ \\
\hline Kannel and Wilson (1995) & White American & CVD death (OR) & $1.5(0.68-1.55)$ & $3.7(1.05-10.8)$ \\
Collins (1996) & Melanesian & IHD death (OR) & $1.6(0.4-6.0)$ & $5.4(1.2-24.3)$ \\
Vilbergsson (1998) & White Icelandic & CVD death (RR) & $2.0(1.5-2.6)$ & $2.4(1.6-3.6)$ \\
\hline San Antonio Heart Study (1998) & Multi-ethnic American & CVD death (OR) & $3.2(1.4-7.1)$ & $8.5(2.8-25)$ \\
\hline
\end{tabular}

Note: $C V D=$ cardiovascular disease, $I H D=$ ischemic heart disease, $\mathrm{OR}=$ odds ratio, $\mathrm{RR}=$ relative risk.

${ }^{*}$ Multivariate estimate controlling for age, hypertension, hyperlipidemia and smoking status.

†5\% confidence interval.

Soutce of data: Kanaya et al. ${ }^{174}$ 
that corrected for coronary risk factors revealed that this sex difference was attenuated, but remained statistically significant (Table 9).

A recent cohort study demonstrated that a history of diabetes in women was associated with a $37 \%$ increase in CVDrelated mortality compared with a history of AMI. However, the presence of a previous AMI in men increased the risk of CVD-related mortality by $43 \%$ compared with a history of diabetes. ${ }^{176}$

\section{Potential mechanisms}

Several mechanisms may explain the apparent sex difference in CVD mortality among patients with diabetes. There is evidence that different pathophysiologic processes - in terms of endothelial function, dyslipidemia and thrombosis - may result in different cardiovascular outcomes among men and women with diabetes.

Diabetes has been shown to abrogate the vascular protection afforded to premenopausal women. Steinberg and colleagues ${ }^{177}$ elegantly demonstrated that premenopausal women have an enhanced vasodilatory response to endogenously produced nitric oxide compared with men. This study also illustrated that the development of diabetes is associated with abnormal endothelial-dependent vasodilation in both sexes. This loss of vasodilation is most striking in women. Sowers ${ }^{178}$ has further demonstrated that hyperglycemia significantly

\begin{tabular}{|c|c|c|c|c|c|}
\hline Variable & 1991 & 1995 & 1999 & 2003 & $\%$ change $†$ \\
\hline \multicolumn{6}{|l|}{ Age group, yr } \\
\hline $20-44$ & 17.6 & 19.1 & 18.6 & 20.3 & $15.3 \neq$ \\
\hline $45-64$ & 33.5 & 35.3 & 36.8 & 41.3 & $23.3 \neq$ \\
\hline$\geq 65$ & 33.4 & 38.4 & 42.3 & 47.5 & $42.2 \ddagger$ \\
\hline \multicolumn{6}{|l|}{ Sex§ } \\
\hline Women & 25.4 & 27.3 & 27.6 & 29.4 & $15.7 \neq$ \\
\hline Men & 24.9 & 27.1 & 28.3 & 33.0 & $32.5 \neq$ \\
\hline \multicolumn{6}{|l|}{ Ethnic group§ } \\
\hline $\begin{array}{l}\text { White, non- } \\
\text { Hispanic }\end{array}$ & 25.4 & 27.6 & 28.2 & 31.5 & 24.0‡ \\
\hline $\begin{array}{l}\text { Black, non- } \\
\text { Hispanic }\end{array}$ & 24.0 & 25.7 & 26.8 & 28.9 & $20.4 \ddagger$ \\
\hline Hispanic & 23.4 & 26.3 & 27.0 & 29.9 & $27.8 \mp$ \\
\hline $\begin{array}{l}\text { Asian/Pacific } \\
\text { Islander }\end{array}$ & 28.4 & 28.8 & 32.2 & 29.2 & 2.8 \\
\hline $\begin{array}{l}\text { Native } \\
\text { American }\end{array}$ & 26.3 & 21.5 & 31.6 & 31.2 & 18.6 \\
\hline Total§ & 25.3 & 27.3 & 28.0 & 31.1 & $22.9 \neq$ \\
\hline \multicolumn{6}{|c|}{$\begin{array}{l}\text { †Difference in prevalence of high cholesterol level between } 1991 \text { and } 2003 \text { as } \\
\text { percentage of } 1991 \text { prevalence. }\end{array}$} \\
\hline $\begin{array}{l}\ddagger t \text {-test is significant } \\
\text { §Age-standardized } t \\
\text { Source: Centers for }\end{array}$ & $\begin{array}{l}p<0.05 \\
\text { e } 2000 \mathrm{l} \\
\text { ase Cont }\end{array}$ & $\begin{array}{l}\text { ed Sta } \\
\text { and P }\end{array}$ & 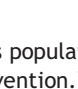 & & \\
\hline
\end{tabular}

decreases estrogen-mediated nitric oxide production. It seems that a unique interaction between diabetes and sex makes women more vulnerable to endothelial dysfunction.

The noted sex differences in CVD outcomes may be influenced by factors beyond biology. A study by Wexler and colleagues ${ }^{179}$ suggests that sex differences in CVD mortality may be due to disparities in medical management. This prospective cohort study demonstrated that women with diabetes were less likely to be treated until they reached established therapeutic targets than men with diabetes, even if the women had established CVD. Whether these disparities are related to physician factors (underappreciation of cardiovascular risk in women, hesitation to use vasoprotective medications in reproductive women) or patient factors (adherence to or tolerance of prescribed medications) remains unclear.

\section{Dyslipidemia}

Abnormal levels of lipoprotein cholesterols are significant predictors of atherosclerosis in all populations, with a fifth of global stroke events and about $56 \%$ of global heart disease attributable to high cholesterol levels. In particular, elevated levels of total cholesterol, LDL cholesterol and triglycerides and low levels of HDL cholesterol have been associated with CAD, stroke and peripheral vascular disease and are often associated with such significant comorbidities as diabetes, hypertension and obesity. In both US and Canadian populations, abnormal cholesterol levels are highly prevalent across different age and ethnic groups (Table Io and Table II) ${ }^{180}$ and there appear to be sex differences in the prevalence of elevated cholesterol $^{181,182}$ (see Table I2 for classification of lipoprotein levels).

\section{Low-density lipoprotein}

LDL cholesterol is believed to be the principal lipoprotein in the development of atherosclerosis and remains the primary

Table 11: Distribution (\%) of blood cholesterol in Canadians aged 55-74 years, 1986-1992

\begin{tabular}{cccccc}
\hline & \multicolumn{3}{c}{$\begin{array}{c}\text { Total cholesterol, mmol/L; } \\
\text { population estimate, } \%\end{array}$} & \\
\cline { 2 - 4 } $\begin{array}{c}\text { Group; } \\
\text { age, yr }\end{array}$ & $<5.20$ & $\begin{array}{c}5.20- \\
6.19\end{array}$ & $\begin{array}{c}6.20- \\
6.49\end{array}$ & $\geq 6.85$ & $\begin{array}{c}\text { No. of } \\
\text { participants }\end{array}$ \\
\hline Men & & & & & \\
\hline $55-64$ & 41 & 41 & 11 & 7 & 843 \\
\hline $65-74$ & 38 & 38 & 16 & 7 & 1713 \\
\hline Total & 40 & 40 & 13 & 7 & 2556 \\
\hline Women & & & & & \\
\hline $55-64$ & 22 & 41 & 18 & 18 & 833 \\
\hline $65-74$ & 22 & 38 & 18 & 22 & 1586 \\
\hline Total & 23 & 40 & 18 & 20 & 2419 \\
\hline $\begin{array}{c}\text { Overall } \\
\text { total }\end{array}$ & 30 & 40 & 16 & 14 & 4975 \\
\hline
\end{tabular}

Reprinted with permission from the Canadian Medical Association (CMAJ 1999;161[8 Suppl]:S3-9). ${ }^{182}$ 
target of therapy for the prevention of CVD. Elevated LDL cholesterol levels are more predictive of coronary risk in men than in women, particularly premenopausal women. ${ }^{183}$ This might be due in part to lower levels of LDL cholesterol in premenopausal women than in middle-aged men ( $35^{-6} 65$ years). However, after age 50 years, LDL cholesterol levels plateau in men and increase in women between ages 40 and 60 years at an average rate of $0.05 \mathrm{mmol} / \mathrm{L}$ a year. ${ }^{184}$ This increase in LDL cholesterol at menopause is thought to be partly the result of advancing age and declining levels of estrogen, which result in downregulation of LDL receptors in the liver leading to decreased clearance of LDL cholesterol from the serum.

\section{High-density lipoprotein}

HDL cholesterol is an important independent predictor of CVD in both men and women, ${ }^{185,186}$ but may have greater predictive potential in women than men. ${ }^{185,187}$ In the Framingham Heart Study, a $0.025-\mathrm{mmol} / \mathrm{L}$ increase in HDL cholesterol level was associated with a $3 \%$ decrease in the incidence of CAD in women compared with a $2 \%$ decrease in men. ${ }^{185} \mathrm{In}$ the Lipid Research Clinics Prevalence Mortality Follow-up Study, a $0.025-\mathrm{mmol} / \mathrm{L}$ increase in HDL cholesterol was associated with a $4.7 \%$ reduction in CVD mortality among women ( $p=0.002$ ) compared with a $3.7 \%$ reduction among men $(p<0.001) .{ }^{188}$ On average, HDL cholesterol levels are $0.25 \mathrm{mmol} / \mathrm{L}$ higher in premenopausal women than in men, which may account for the lower incidence of CVD before age 50 in women compared with men. With menopause, HDL cholesterol levels have been shown to decrease, although the administration of exogenous estrogen can increase levels. ${ }^{189}$ However, the protective effect of exogenous estrogens remains controversial. Although oral estrogens can increase HDL cholesterol and decrease LDL cholesterol, they also increase the potential for coagulation and possibly for inflammation.

\section{Triglycerides}

There is some evidence to suggest that high levels of triglycerides are a significant independent risk factor for CVD in both sexes, but more so in women than men. ${ }^{185,190}$ In a metaanalysis of $\mathrm{I} 7$ prospective population-based studies, elevated triglyceride levels adjusted for HDL cholesterol levels were associated with a $37 \%\left(95 \% \mathrm{CI}_{13}-66\right)$ increase in risk of CVDrelated events in women compared with a I4\% (95\% CI 5-28) increase in men. ${ }^{191}$ The mechanism for increased risk of CVD associated with hypertriglyceridemia is unclear, but elevated triglycerides are often accompanied by other metabolic disturbances that may predispose to CVD, including reduced HDL cholesterol, increased levels of very low-density lipoprotein cholesterol and insulin resistance, which makes it difficult to assess the independent risk associated with triglycerides. Moreover, some analyses suggest that elevated triglycerides interact with some of these other risk factors to modulate the risk of CVD and that the interaction may differ between men and women. For example, a study of I74 patients with type 2 diabetes mellitus who were not receiving lipid-lowering therapy concluded that the severity of CAD (as examined by angiography) was related to the number of triglyceride-rich lipoproteins and that the relation was stronger for women than men, independent of HDL and LDL cholesterol. ${ }^{192}$

\section{Knowledge gap}

- Triglyceride and HDL cholesterol levels must be measured and addressed, especially in women with other metabolic disturbances.

- Changes in triglycerides, HDL cholesterol and other lipid metabolites may be indicators of unrecognized metabolic disturbances, especially in women.

- Pharmacologic interventions to elevate HDL cholesterol in women have not been undertaken.

\section{Smoking}

Smoking has been identified as the primary preventable cause of morbidity and mortality in Canada, contributing to $27 \%$ of all deaths among men and $17 \%$ of all deaths among women, the majority being due to CVD. ${ }^{193}$ Trends in smokingattributable mortality reflect the smoking behaviour of the population 2-3 decades earlier. Whereas smoking rates for men peaked in the mid I96os, the rates for women did not begin to decline until the late I970s. As a result, deaths due to CVD among women have yet to decrease. ${ }^{193,194}$

Ongoing national and provincial surveillance initiatives monitor smoking trends and the effect on health. Smoking prevalence has steadily declined over the last few decades,

Table 12: Classification of levels of low-density lipoprotein (LDL) cholesterol, high-density lipoprotein (HDL) cholesterol and triglycerides

Cholesterol or triglyceride
level Classification

\begin{tabular}{|c|c|}
\hline \multicolumn{2}{|c|}{ LDL cholesterol, mmol/L } \\
\hline$<2.59$ & Optimal \\
\hline $2.59-3.36$ & Near-above optimal \\
\hline $3.37-4.14$ & Borderline high \\
\hline $4.15-4.90$ & High \\
\hline$>4.90$ & Very high \\
\hline \multicolumn{2}{|c|}{ HDL cholesterol, mmol/L } \\
\hline$<1.04$ & Low for men \\
\hline$<1.30$ & Low for women \\
\hline$>1.55$ & $\begin{array}{l}\text { High (protective against } \\
\text { heart disease) }\end{array}$ \\
\hline \multicolumn{2}{|c|}{ Triglyceride, mmol/L } \\
\hline$<1.70$ & Desirable \\
\hline $1.70-2.25$ & Borderline high \\
\hline $2.26-5.64$ & High \\
\hline$\geq 5.65$ & Very high \\
\hline
\end{tabular}

Source of data: National Cholesterol Education Program. ${ }^{180}$ 
with a stronger decrease in men than women (Fig. 9). ${ }^{195}$ According to the 2004 Canadian Tobacco Use Monitoring Survey (CTUMS), ${ }^{196}$ approximately $22 \%$ of men and $17 \%$ of women aged 15 years and older are current smokers. Although women experiment with smoking at a younger age than men, smoking rates are higher for men than women in all age groups. Prevalence peaks at ages 20-29 years in both sexes - at $37.3 \%$ in men and $30.9 \%$ in women. For both sexes, the prevalence begins to decline at age 30-49 years and smoking prevalence among those aged 55 years and older is half that of 20-29 year olds. ${ }^{195,197,198}$ The overall smoking rate of $20 \%$ is among the lowest in the OECD countries and is favourably consistent with trends in other developed countries. However, we may have reached a point at which the prevalence rates reflect hard-to-reach populations, and further decreases may be difficult to achieve. In a survey similar to CTUMS conducted in the Northwest Territories, the prevalence of smoking was $44 \%$ and $38 \%$ among men and women, respectively, yet Aboriginal residents had a prevalence of over twice that of non-Aboriginal residents, $60 \%$ V. $25 \% .{ }^{199}$

In developing countries, the prevalence of smoking is substantially higher among men (50\%) than among women ( $9 \%$ ). However, female smoking is increasing rapidly due, at least in part, to targeted promotional strategies of the tobacco industry. Worldwide, the lowest smoking prevalence for both men and women is in African countries, while the highest prevalence for men is in Eastern Europe (where rates exceed 6o\%) and for women in Central Europe and parts of South America. ${ }^{200}$ The greatest increases in smoking prevalence over the next decade are expected to occur in Africa and the Middle East.

The determinants of smoking primarily reflect social and economic disadvantage. A higher prevalence of smoking has been found among women and men who live in low-income households, have low-status jobs or are unemployed, are single

parents or divorced, and have low levels of education. ${ }^{194,201}$ This is consistent with the epidemic description of smoking as it spreads through a population, reverting from a positive association to a negative association with socioeconomic status, first among men and then among women in later stages of the epidemic, as seen in developed countries. ${ }^{202}$ Qualitative research has shown that men and women may smoke for different reasons. For example, women use smoking as a coping mechanism to deal with gendered stresses such as child care. ${ }^{203}$ They may also encounter greater difficulties in quitting. ${ }^{199}$

Epidemiologic studies have consistently documented the risk of CVD associated with smoking in both sexes. It is generally thought that the CVD risk is similar, except among women smokers taking oral contraceptives, where the risk of stroke is much greater. However in ARIC, a large prospective population study of 15792 men and women aged 45-64 years at entry, investigators found that the hazard ratio for coronary heart disease was greater for women than men (2.95 V. I. 55 for current smoking). ${ }^{204}$

\section{Potential mechanisms}

The precise mechanisms connecting increase in CVD risk with smoking are not completely clear. Possible deleterious impacts of smoking include endothelial dysfunction, lipid abnormalities, increased concentration of fibrinogen and platelet aggregation. ${ }^{205,206} \mathrm{Few}$ studies have investigated the possible mechanisms underlying sex differences in CVD associated with smoking. Interactions between smoking and hormonal factors may be involved in development of CVD. It is possible that smoking may increase the risk of CVD in women smokers via an anti-estrogenic effect. ${ }^{205}$

\section{Cardiovascular risk markers}

\section{C-reactive protein}

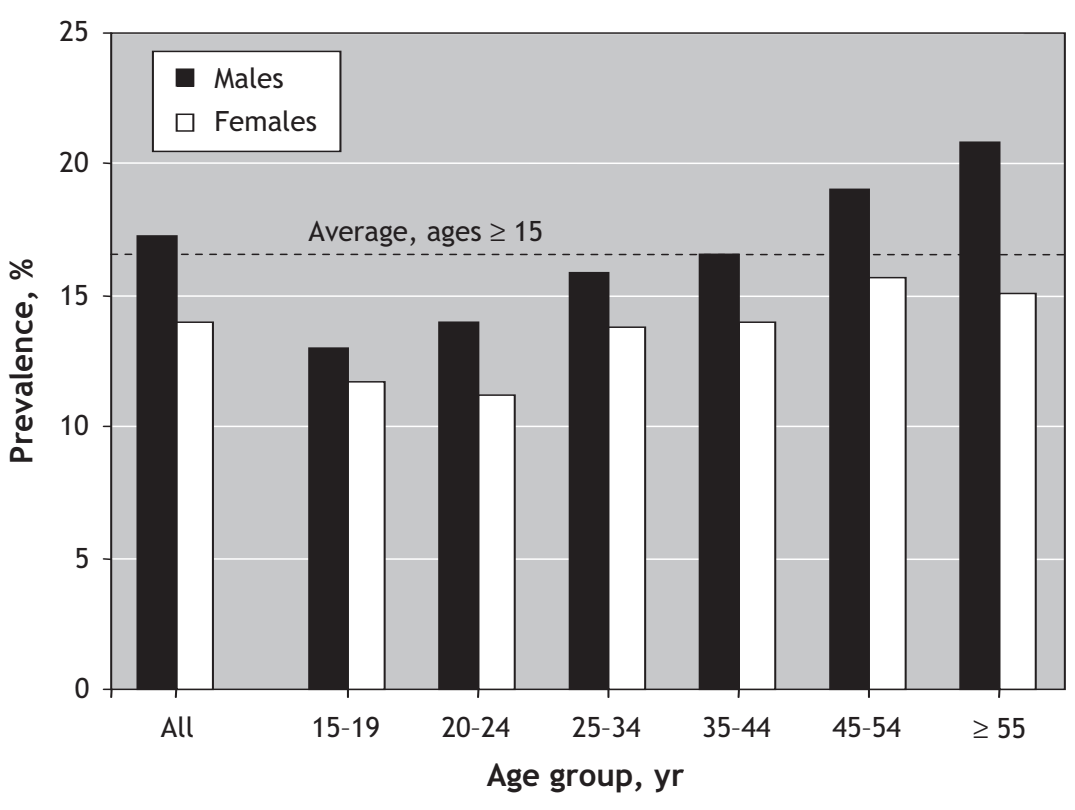

Fig. 9: Prevalence of current smoking by age and sex, 2003. Source: Adapted from Canadian Tobacco Use Monitoring Survey. ${ }^{195}$
Inflammatory mechanisms have been shown to play an important role in the pathogenesis of CVD, and increasing attention has been paid to the measurement of inflammatory biomarkers, particularly C-reactive protein (CRP). ${ }^{207-209}$ Indeed, of 12 plasma markers evaluated simultaneously, Ridker and colleagues $^{207}$ found CRP to be the most significant predictor of CVD risk in healthy postmenopausal women. Adjusted for other plasma markers and conventional risk factors, a I-quartile increase in CRP concentration increased the risk of a CVD event by $50 \%$ (OR I.5; 95\% CI I.I-2.I). These findings were supported in a meta-analysis of 22 prospective studies conducted in general (apparently healthy) populations. ${ }^{208}$ Those in the top third of the study group, with respect to CRP level, had a $58 \%$ increase (OR I. $58 ; 95 \%$ CI I.48-I.68) in risk of CAD compared with the bottom third, after adjusting for the major 
conventional CVD risk factors. Although most studies were predominantly in men, the summary odds ratio reported separately for women in 3 studies did not differ markedly from the summary odds ratio based on I2 studies that reported their findings for men only. Studies in groups with established heart disease have also demonstrated that high CRP levels are associated with increased AMI or mortality. ${ }^{210}$

A number of other studies have reported higher adjusted baseline CRP values for women than men. ${ }^{209,211}$ Bertran and colleagues $^{211}$ found that, on average, CRP concentrations were $29 \%$ higher in women than men. An age-sex interaction has also been demonstrated, whereby CRP was predictive of death or AMI, or both, in women and men under 55 years of age, but only for men over the age of 55 years. ${ }^{209}$

\section{Homocysteine}

Elevated levels of homocysteine have also been implicated in CVD. Blood levels of homocysteine have been found to be higher in men than in women. ${ }^{212,213}$ For example, homocysteine levels in the control group were $9.7 \pm 4.9 \mu \mathrm{mol} / \mathrm{L}$ for men and 7.6 $\pm 4 . \mathrm{I} \mu \mathrm{mol} / \mathrm{L}$ for women $(p<0.00 \mathrm{I})$ in a casecontrol study of French-Canadians. ${ }^{213}$ Men and women with CAD had significantly higher homocysteine levels (II.7 $\pm 5.8 \mu \mathrm{mol} / \mathrm{L}$ and $\mathrm{I} 2.0 \pm 6.3 \mu \mathrm{mol} / \mathrm{L}$, respectively), but no sex difference in CAD was observed.

A systematic review ${ }^{214}$ of the association between plasma homocysteine level and CVD suggested that moderately increased homocysteine levels are prevalent in the general population and are independently associated with an increased risk of CVD. In a more recent meta-analysis, ${ }^{215}$ elevated homocysteine level was found to be a modest independent predictor of ischemic heart disease in healthy populations; a decline of $3 \mu \mathrm{mol} / \mathrm{L}$ in homocysteine level was associated with an $\mathrm{II} \%$ decrease in risk of ischemic heart disease (OR 0.89 ; $95 \%$ CI $0.83-0.96$ ).

\section{Apolipoprotein E}

Apolipoprotein E (APOE) is a component of lipoproteins, with considerable variation as a result of cysteine-arginine exchanges in 3 alleles known as $\varepsilon_{2}, \varepsilon_{3}$ and $\varepsilon_{4}$. Numerous population studies have implicated APOE as a major modulator of total cholesterol and LDL cholesterol. ${ }^{216-218}$ The presence of the $\varepsilon_{4}$ allele has been associated with elevations in LDL cholesterol, whereas the $\varepsilon 2$ allele has been associated with decreased levels of LDL cholesterol. ${ }^{216-218}$ Data from the Framingham Offspring Study have also indicated that the association of APOE phenotype with LDL cholesterol level is significantly greater in postmenopausal women than in premenopausal women or in men. ${ }^{218}$

Some studies have indicated that the APOE polymorphism may be a sex-specific predictor of CVD. ${ }^{219,220}$ Most recent data from the Framingham Heart Study suggest an increased risk in men with the $\varepsilon 2$ and $\varepsilon_{4}$ alleles compared with those with the $\varepsilon_{3}: \varepsilon_{3}$ genotype. After adjustment for all risk factors including age and lipids, the increase in risk of CVD with an $\varepsilon_{4}$ allele was $5 \mathrm{I} \%$ for men (OR I.5I; 95\% CI I.05-2.I8) and $48 \%$ for women (OR I.48; 95\% CI 0.93-2.34). The association between the $\varepsilon 2$ allele and CVD remained significant in men after adjusting for all risk factors, including lipids (OR I.94; 95\% CI I.23-3.04). However, no association between the $\varepsilon 2$ allele and increased CVD risk was found in women. ${ }^{219}$ Neither the mechanism underlying the excess in $\varepsilon_{4}$ allele in CVD patients nor the effect of interaction between sex and APOE polymorphisms on CVD is completely clear.

\section{Fibrinogen}

Increased plasma fibrinogen levels have been independently associated with an increased risk of AMI and stroke in prospective studies of healthy people and patients with preexisting CVD. ${ }^{221-223}$ Both men and women in the highest third for plasma fibrinogen have a 2 - to 3 -fold higher risk than those in the lowest third. ${ }^{224}$ In a meta-analysis of 3 I prospective studies that included I54 2II participants from Western Europe, North America and Japan, the age- and sex-adjusted hazard ratio per $\mathrm{I}-\mathrm{g} / \mathrm{L}$ increase in usual fibrinogen level was 2.42 (95\% CI 2.24-2.60) for coronary heart disease and 2.06 (95\% CI I.83-2.33) for stroke. ${ }^{225}$ Although the risk of CVD is similar for men and women with elevated fibrinogen levels, there are some small sex differences with regard to modulators of fibrinogen levels; women tend to have higher levels of fibrinogen than men when stratified for age and ethnicity. ${ }^{226,227}$ Plasma fibrinogen increases with menopause, pregnancy and the use of oral contraceptives; treatment with hormone replacement therapy may decrease fibrinogen levels, and the effect of smoking, which is regarded as the strongest determinant of high fibrinogen levels, ${ }^{226}$ is not as consistent in women as it is in men. ${ }^{228,229}$ Possible reasons include differences in nutritional habits and more powerful determinants of fibrinogen in women, such as hormonal status, that could mask the smoking effect. Although the clinical significance of these sex differences remains to be elucidated, they may be useful in the development of sex-specific interventions to lower fibrinogen levels.

\section{Plasminogen activator inhibitor type-1}

Increased levels of plasminogen activator inhibitor type-I (PAI-I) have been associated with CAD. ${ }^{223,230-232}$ In a recent prospective nested case-control study of 2246 Swedish patients with a first AMI matched for age and sex, elevated levels of PAI-I were significantly associated with a 2 -fold increased risk of AMI in both men and women. ${ }^{233} \mathrm{~A}$ few studies have shown that premenopausal women have lower plasma PAI-I levels than postmenopausal women. ${ }^{234}$ In addition, postmenopausal women receiving hormone replacement therapy have lower plasma PAI-I levels than those not receiving such therapy. ${ }^{235,236}$

The presence of polymorphisms in the PAI-I gene has been found to correlate with increased plasma levels of PAI-I and may help explain differences among men and women and even among pre- and postmenopausal women. For example, a large cohort study of men and women with recent AMI revealed that the risk of AMI, after adjusting for common 
CVD risk factors, was significantly associated with $4 \mathrm{G} / 5 \mathrm{G}$ polymorphism in women compared with men. ${ }^{237}$ More recently, a few case-control studies have shown a higher prevalence of this mutation in postmenopausal women with $\mathrm{CAD}$ compared with premenopausal women with and without $\mathrm{CAD}$, and the addition of hormone replacement therapy decreases PAI-I levels in women with CAD, which correlates with the presence of the $4 \mathrm{G}$ allele. ${ }^{238}$

\section{Lipoprotein (a)}

Lipoprotein (a) (Lp(a)) has been postulated to be highly atherothrombotic. A recent meta-analysis of $\mathrm{I} 8$ prospective population-based studies, which included over 3500 women, largely from Nordic countries, Germany, the United Kingdom and the United States, showed a combined risk ratio for CVD of I.7 (95\% CI I.4-I.8) for those in the top third of baseline $\mathrm{Lp}$ (a) concentrations compared with those in the bottom third. ${ }^{239}$ Adjustment for conventional risk factors including LDL cholesterol did not significantly change the association. Moreover, data from the Quebec Cardiovascular Study ${ }^{240}$ and the Italian Longitudinal Study on Aging ${ }^{241}$ suggest that, among men, elevated Lp(a) levels interact positively with high LDL cholesterol levels, hypertension, hyperhomocysteinemia and elevated fibrinogen concentrations. In a recent cohort study $^{242}$ using data from the Nurses' Health Study Initiative which showed that women in the highest quintile of $\operatorname{Lp}(\mathrm{a})$ were twice as likely to develop CVD compared with women in the lowest quintile, independent of other conventional risk factors - no significant interactions with LDL cholesterol, HDL cholesterol or fibrinogen were found. This may be partly explained by the fact that levels of $\operatorname{Lp}(\mathrm{a})$ tend to increase with age, more so in women than men, ${ }^{243}$ which parallels the agerelated increase in LDL cholesterol and fibrinogen levels seen in women.

\section{Socioeconomic status}

There is a clear socioeconomic gradient in risk of CVD, with those in the lowest socioeconomic strata having the highest risk of cardiovascular events. ${ }^{24,245}$ Although this gradient exists for both men and women, there is increasing evidence to suggest that there may be an interaction between sex and socioeconomic status in the development of both cardiovascular risk factors and CVD.

Socioeconomic status is a complex construct that is influenced by financial, employment and education experiences. The protective effect of high social standing was convincingly and elegantly demonstrated in the Whitehall study. Marmot and colleagues ${ }^{246}$ clearly showed that, in a cohort of British Civil servants, those in the lowest social strata were 2.6 times more likely to die from CVD than those in the wealthiest class. This negative relation between CVD and socioeconomic status has been demonstrated consistently in numerous studies throughout the developed world. Recent studies indicate that there may be a gender-socioeconomic status interaction in terms of CVD mortality. Gerward and colleagues $^{247}$ examined the effect of neighbourhood socio- economic factors on mortality in the first 28 days after an AMI in a Swedish cohort. They demonstrated that low socioeconomic status and early CVD mortality were most closely associated in men over 75 years of age ( $p$ value for trend 0.007$)$. This analysis was limited in that it used ecologic measures of both socioeconomic status and cardiac risk. However, examining the influence of social class on CVD mortality in another large Swedish cohort, Baigi and colleagues $^{248}$ demonstrated that although labourers have much higher CVD mortality than their white-collar counterparts, female labourers have a CVD mortality risk that is double that of male labourers. Results from the NHANES cohort ${ }^{249}$ were similar: low-income women had a $6 \mathrm{r} \%$ increase in risk of CVD mortality compared with high-income women. Low income also increased risk of CVD mortality in men, but the elevation $(29 \%)$ was less striking. This analysis adjusted for several other risk factors that may vary with income, including smoking status, blood pressure, cholesterol level and diabetes status.

\section{Health care access}

People with low income do not appear to obtain health care as effectively as the wealthy. ${ }^{250,251}$ Barriers to health care appear to be larger for poor women than men in both single and multipayer systems. In universal systems in Canada, women are more likely to visit their primary care physician, but are less likely to be referred to specialty care and are more likely to be admitted to hospital. ${ }^{251,252}$ In private systems, such as those in the United States, women are less likely to be able to afford essential medications. This inability to obtain evidence-based therapy is associated with a $50 \%$ increase in the incidence of angina, non-fatal AMI and non-fatal stroke among US women. ${ }^{252}$

\section{CVD risk factors and health behaviours}

Diabetes, obesity, sedentary lifestyle, smoking and hypertension are more prevalent in populations at low socioeconomic levels. ${ }^{253}$ Lower social class has consistently been found to be associated with lower levels of HDL cholesterol and APO-AI in both men and women. ${ }^{254}$ No consistent relation between socioeconomic status and LDL cholesterol has been found. The interaction between socioeconomic status and gender appears to have an impact on specific cardiovascular risk factors. Although low socioeconomic status women are at much greater risk of diabetes mellitus and obesity than men, ${ }^{255,256}$ the negative relation between smoking behaviour and wealth is more evident in men.

\section{Psychosocial factors}

There is increasing awareness of the influence of psychologic and social factors on the development of heart disease. ${ }^{257}$ In North America, people who experience depressive symptoms are more likely to be women and are more likely to have low income. ${ }^{258}$ US women who are involuntarily unemployed have been found to have higher blood pressure and higher rates of 
anginal pain compared with employed women and homemakers. The effect is most striking in African-American women. An unemployed African-American woman is 2.6 times more likely to have CVD compared with an unemployed non-Hispanic white woman. ${ }^{259}$ Van Lenthe and colleagues ${ }^{260}$ showed the independent and significant relation between social and financial deprivation and heart disease in the GLOBE study. Even after controlling for the behavioural risk factors smoking, alcohol use, physical inactivity and obesity, material factors such as unemployment, poor housing and crowding were associated with a $25 \%-80 \%$ increase in the incidence of AMI in this Dutch cohort. Wang and colleagues ${ }^{261}$ suggest that different components of the socioeconomic status construct affect men and women differently. They examined the association of self-reported health with various aspects of socioeconomic status (income, education, social support and connectedness) in a large Japanese cohort $(n=9650)$. They found that high income was associated with better selfreported health in both men and women. Among those in lower social classes, poor self-reported health was more closely associated with low income in men, but in women, poor self-reported health was more closely associated with social isolation and lack of social support.

\section{Critical analysis of studies}

The studies reviewed above include observational cohort studies and cross-sectional assessments. Results of studies specifically focusing on women, on men, or providing sex comparisons were included. Areas not sufficiently addressed by existing studies are highlighted as knowledge gaps.

\section{Why are there sex differences?}

Review of the existing literature suggests that sex differences in cardiovascular risk factors are attributable to a combination of biologic and behavioural factors that may be further modified by age, geography and ethnic background. Compared with their male counterparts, adolescent girls and premenopausal women tend to have more favourable risk profiles, not only in terms of blood pressure and serum lipids, but also in terms of emerging cardiovascular risk factors. However, this "sex protection" is much attenuated with age among postmenopausal women. There is a possibility that the evolution of sex differences in risk profiles is at least partly attributable to sex hormones or their receptors. In terms of health behaviour, women tend to be less physically active and are more likely to be obese than men, but smoking rates are higher among adult men than women. Possible rea- sons for these behavioural differences include child care and household duties limiting physical activity in women, postpartum retention of weight and lower likelihood of smoking because of concerns about its impact during pregnancy. Although lower levels of activity and higher rates of obesity may be offset by better overall cardiovascular risk profiles before menopause, they may contribute to a marked deterioration in risk profile following menopause.

\section{Summary}

- Men are more likely to be overweight than women.

- The prevalence of obesity is higher among women, particularly among black women.

- Women tend to be less physically active than men.

- Prior to menopause, women have better cardiovascular risk profiles than men, with lower levels of blood pressure, LDL cholesterol and plasminogen activator inhibitor typeI and higher levels of HDL cholesterol.

- Following menopause, cardiovascular risk profiles of women and men become more similar.

- Diabetes appears to abrogate the vascular protection afforded to premenopausal women.

- Rates of absolute CVD are higher among men with diabetes than among women with diabetes. However, diabetes accounts for a larger proportion of the CVD that occurs among women than men.

- Smoking rates are higher for men than women.

- The association of APOE phenotype with LDL cholesterol level is significantly greater in postmenopausal women than in premenopausal women or in men.

- Low socioeconomic status has an adverse impact on access to health care and cardiovascular risk profiles.

- Low socioeconomic status is associated with high prevalence of obesity and diabetes in women, but not consistently so among men.

- Women are less likely to be referred for specialty care than men.

\section{Knowledge gap}

- What strategies can be employed to optimize detection and treatment of hypertension and dyslipidemia among men and women?

- What are the barriers to improving physical activity levels among women?

- Can the relative risk of CVD among women with diabetes be reduced through optimal diabetes management?

- How can we improve access to health care among women of low socioeconomic status? 


\title{
Differences in cardiovascular presentation in women and men
}

\author{
Colleen Norris, Kaberi Dasgupta and Susan Kirkland
}

Increasing evidence suggests that there are sex or gender differences in the presentation and prodromal symptoms of acute coronary syndrome (ACS). ${ }^{262-264}$ However, the model used to identify the symptoms of ACS continues to be consistently based on data sets in which men are the normative standard. ${ }^{265}$ Furthermore, this phenomenon, described as the "Yentl syndrome," has been evidenced by lower use of diagnostic and therapeutic procedures for women and, perhaps more important, a decreased ability to identify female patients at risk for acute coronary events. ${ }^{265}$ Consequently, if women do in fact experience symptoms that deviate from what is understood as "normal," the presenting symptoms may not be recognized as prodromal to ACS, resulting in delayed treatment. As well, if women seek attention for the "abnormal" symptoms, they may be misinterpreted by medical personnel, delaying or giving rise to misdiagnosis and lack of treatment typically provided to men.

\section{Search strategy}

A comprehensive review of the literature from I999 to 2005 was undertaken using the following combination of $\mathrm{MeSH}$ headings: "myocardial ischemia," "myocardial infarction," "unstable angina," "stable angina" and "presenting symptoms," "prodromal symptoms" and "gender" and "women."

\section{Sex differences in symptoms of ACS}

Sex differences in anatomic, physiologic, biologic and psychologic characteristics may explain sex differences in symptoms of ACS. ${ }^{264,266}$ Women have smaller coronary artery lumens and less collateral circulation than men, which may lead to an increase in ischemia, particularly during exertion or stress. From a physiologic perspective, the syndrome X, possibly the result of dysfunctional coronary microvasculature or smooth muscle vasomotor tone, may contribute to the difference in symptoms experienced by women and men. Sex hormones may partly account for symptom differences. For example, diminishing estrogen levels in premenopausal and menopausal women may affect lipid metabolism and the activation of the coagulation cascade and vasoactive mediators. Finally, psychosocial differences between women and men may also explain differences in the experience of symptoms. Depression is 3 times more common in women than men. ${ }^{267}$ The similarities among symptoms for anxiety, depression and ACS may complicate the diagnostic process.

\section{Sex differences in the diagnosis of ACS}

The prevalence of ACS diagnosed in emergency departments is lower for women than men, ${ }^{268}$ with rates dependent on clinical presentation at admission. The percentage of women diagnosed with ACS can range from $33 \%$ to $45 \%$. Most stud- ies addressing sex differences in ACS have focused specifically on AMI. ${ }^{268-270}$ Framingham data indicate that $69 \%$ of women initially present with unstable angina compared with $30 \%$ of men. ${ }^{271}$ As women are less likely to present with AMI, fewer women than men have been studied with respect to ACS presentation. There is a need for studies addressing symptomatology among women with unstable angina, a more common ACS presentation in women.

\section{Sex differences in prodromal symptoms of ACS}

Atypical prodromal symptoms in women include fatigue; difficulty breathing, shortness of breath and dyspnea; neck and jaw pain; palpitations; cough; nausea and vomiting; and indigestion. Few studies have addressed prodromal symptoms from a sex perspective. Recently, Bahr and colleagues ${ }^{272}$ reviewed the "state of the science" about the phenomenon termed "prodromal." Their search included literature from I937 to 2000 although "an effort was made to identify the more rigorous studies (in English) from the last ro years that included randomized prospective trials." The results highlighted the fact that, although prodromal symptoms appear to play an important role in the evolution of ACS, there is no standard definition of symptoms, nor any consistent pattern in their reporting. More important, of the 28 studies that focused on patients who were diagnosed with AMI, the proportion of women in the study sample, when reported, varied from $\mathrm{II} \%$ to $28 \%$, making it impossible to determine whether women and men experienced or described different symptoms. With the exception of the work of McSweeney and colleagues ${ }^{263}$ whose sample included only women, the studies reported on by Bahr and colleagues did not address differences between women and men in either the presence or proportion of prodromal or acute symptoms reported.

In contrast, in their seminal work on women's prodromal and acute symptoms of AMI, McSweeney and colleagues ${ }^{263}$ identified a number of important issues that may explain the lack of consistent findings regarding the differences between women and men. The foremost issue was the fact that the tools used to describe the symptoms of ACS are typically closed-ended or structured questions based on retrospective chart reviews from studies conducted primarily on men. Therefore, women are restricted to choices that inaccurately describe their symptoms. In addition, there may be a semantic difference in the definitions of the symptoms themselves. Questions concerning pain "in the back" may be interpreted as lower back pain and may not elicit descriptions of discomfort in the upper back, posterior to the shoulder. The time frame, specifically whether symptoms were prodromal or acute, has not been well described among women. Finally, studies that included only questions on symptoms that occurred during hospital stays and gathered this information 
retrospectively from hospital records (including the majority of the 28 studies identified by Bahr and colleagues) would have excluded sex differences in symptoms that may have become apparent had patients been queried prospectively.

Having identified these issues, McSweeney and colleagues went on to develop and test the McSweeney Acute and Prodromal Myocardial Infarction Symptom Survey (MAPMISS). In a multicentre study, ${ }^{273} 95 \%$ of women reported prodromal symptoms before AMI, but only $29.7 \%$ reported chest discomfort, a hallmark symptom in men.

\section{Evidence for sex differences in symptoms presentation}

Among the 37 studies identified in our search, 8 addressed the diagnosis of ACS; ${ }^{274-281} 4$ reported on treatment or outcomes; $;^{282-285} 2$ addressed the predictive relation between prodromal symptoms and infarct size; ${ }^{286,287} 4$ discussed the clinical presentation for other coronary conditions including stent restenosis, ${ }^{288}$ hemostasis and vascular reactivity, ${ }^{289}$ calcification $^{290}$ and nonobstructive coronary disease in women; ${ }^{291}$ and I investigated the presence of "distressed personality." ${ }^{292}$ Of the remaining I8 studies, 3 were restricted to women, ${ }^{273,293,294}$ and 7 observed that women with ACS experience more "atypical" symptoms than men. ${ }^{262-264,266,273,293,295}$ Ryan and colleagues $^{296}$ found that patients, namely older adults and women, presenting with atypical symptoms including chest pain in areas other than substernum or left side or no chest pain, often had delayed diagnosis, less-aggressive treatment and higher rates of in-hospital mortality. Similarly, Boccardi and Verde's review ${ }^{265}$ of gender differences in clinical presentation to the emergency department for chest pain found that women with ACS were older and had a higher prevalence of diabetes and hypertension, longer delays from symptom onset to presentation and higher in-hospital mortality compared with men.

Herein lies the source of the paucity of data concerning sex differences in prodromal and presenting symptoms of ACS.
The fact that $69 \%$ of women initially presenting with angina compared with $30 \%$ of men, ${ }^{264}$ combined with data that suggest that women with ACS experience more "atypical" symptoms, ${ }^{262-264,266,273,293,295}$ means that fewer women with ACS are studied, and there is a lack of understanding as to whether the sex-gender differences in prodromal and presenting symptoms of ACS are significant enough to require change in clinical practice.

As shown in reviews, ${ }^{264,297}$ the data are inconsistent with regard to sex differences in the prodromal and presenting symptoms of ACS. Methodologic issues around the collection of the data, particularly the reliability of retrospective designs that rely on medical records, the understanding of "typical" and "atypical" symptoms of ACS and the presenting diagnostic or inclusion criteria may have significantly altered the results. A greater understanding of the clinical relevance of sex differences in ACS will only be achieved by evaluating both male and female patients with both unstable angina and AMI.

\section{Summary}

- Women are more likely than men to present with unstable angina.

- Women experience more atypical symptoms than men.

- Delayed diagnosis and treatment are more likely to occur in women than in men.

- Depression is more likely to occur in women than in men.

\section{Knowledge gap}

- A better understanding of typical and atypical symptoms of ACS in women is needed.

- Public health educational programs are needed to raise awareness of factors involved in treating women.

- Research is needed to determine whether gender and sex differences in the symptoms of ACS are significant enough to require a change in clinical practice.

\section{Genetic and sex determinants of hypertension and CVD}

\section{Johanne Tremblay, Milan Petrovich and Pavel Hamet}

Sex differences have been virtually ignored in genetic studies of hypertension and other CVD, and few studies have focused exclusively on females or have examined the 2 sexes separately. The sexual dichotomy observed in the prevalence of hypertension may be related to genetic factors, including the $\mathrm{X}$ and $Y$ chromosomes and the genes that control sex steroids. This section highlights recent studies using genomic approaches to help elucidate the causes of sexual dimorphism in patients and animal models of CVD.

\section{Search strategy}

Literature searches were conducted using PubMed with the following keywords: "genomics," "genetics," "sex" and "cardiovascular disease," and "sex" and "genetics." We also mention our recent studies in rats, in which we were first to search the whole genome for sex differences in the determinants of stress response.

\section{Y chromosome}

The $\mathrm{Y}$ chromosome is passed intact from father to son. Originally it was thought that most of the genes on the Y chromosome contribute to male differentiation, but it now appears that they may also be responsible for differences in blood pressure and stress responses between males and females. 
Several groups have investigated the pathophysiologic mechanisms of the Y chromosome effect. Ely and colleagues ${ }^{298}$ demonstrated its possible involvement in blood pressure regulation through activation of the sympathetic nervous system. Higher sympathetic nervous system indices, such as plasma norepinephrine and adrenal chromogranin A levels, were observed in male rats, which could result in differences in renal and cardiac norepinephrine turnover. Our studies on stress response have revealed the essential role of the kidney in the $\mathrm{Y}$ chromosome effect, as the $\mathrm{Y}$ chromosome influences modulation of the response to dietary salt via altered sodium and potassium excretion. ${ }^{299}$

In humans, Uehara and colleagues ${ }^{300}$ suggested that a hypertensive father, but not a hypertensive mother, determines blood pressure in male offspring, providing indirect evidence of the importance of the $\mathrm{Y}$ chromosome. The impact of the $\mathrm{Y}$ chromosome was assessed directly in 2 populations of Caucasian origin ${ }^{301,302}$ by looking at the association between microsatellite markers located in the centromeric region of the $\mathrm{Y}$ chromosome and blood pressure. Some specific markers were significantly associated with diastolic blood pressure and with serum cholesterol levels in Polish males ${ }^{303}$ and in a Japanese population that was genotyped for an Alu insertion polymorphism. ${ }^{304}$ Men with the Alu insertion polymorphism had significantly higher HDL levels than those without the variant. Familial data and association studies confirmed that the $\mathrm{Y}$ chromosome harbours genes affecting cardiovascular phenotypes. However, such an association was not found in all populations, ${ }^{305}$ and it is most probable that the genes located within the nonrecombinant $Y$ locus that are closely related to hypertension and other CVD factors may interact with other genes and environmental factors. In addition, the magnitude of the effect differs with ethnic origin.

Only $5 \%$ of the Y chromosome participates in meiotic recombination by pairing with the $\mathrm{X}$ chromosome; the remaining $95 \%$ is not recombined and is male specific. These genes are broadly expressed in various tissues and may thus determine other phenotypic differences between males and females. They also interact with the environment, including risk factors for CVD (such as smoking, higher serum cholesterol, low HDL cholesterol and obesity). The Y chromosome is also suspected of interacting with androgens and their receptors $^{303,306,307}$ and hormones of the renin-angiotensinaldosterone system ${ }^{303}$ in blood pressure regulation.

Although evidence supports the contribution of the $\mathrm{Y}$ chromosome to the regulation of blood pressure and other cardiovascular phenotypes in males, no genes on the $\mathrm{Y}$ chromosome have been found to contribute directly to hypertension, although confirmation is still required for some candidate genes. ${ }^{308}$ Genetic heterogeneity (i.e., relevance limited to some families but not to others) at other blood pressure loci tends to obscure the isolated $\mathrm{Y}$ chromosome effect.

\section{X chromosome}

Whereas the Y chromosome is male specific, the X chromosome is shared by both sexes. Although women have $2 \mathrm{X}$ chromosomes, $\mathrm{I}$ is inactive. The $\mathrm{X}$ chromosome is associated with quantitative trait loci (QTLs) that might play an important role in hypertension and other diseases, such as CVD, cardiovascular malformation, dilated cardiomyopathy, renal diseases and Turner syndrome. QTLs for blood pressure have been mapped on rat chromosomes Io and $\mathrm{X}^{309}$ and QTLs for hypertensive renal disease, but not for hypertension per se have been mapped on the X chromosome. ${ }^{310,311}$ Interestingly, the angiotensin type-2 receptor subtype (AT2-R) is located on the $\mathrm{X}$ chromosome. ${ }^{312}$

\section{X-linked disorders}

Turner syndrome: Turner syndrome is a result of complete or partial loss of $\mathrm{I}$ of the $2 \mathrm{X}$ chromosomes in females and is associated with short stature, gonadal dysgenesis, somatic stigmata, cardiovascular and renal anomalies and a large spectrum of other disorders. The increased mortality associated with Turner syndrome is primarily a result of cardiovascular complications. Congenital cardiac anomalies (coarctation of the aorta, bicuspid aortic valve, anomalous venous drainage) are present in $23 \%-40 \%$ of patients. There is an increased risk of aortic dilatation ( $42 \%$ ) and dissection, and of ischemic heart disease, and the risk of hypertension is increased 3fold. In addition, insulin resistance may be present in up to $50 \%$ of women with Turner syndrome, and an atherogenic lipid profile favours the development of CAD. ${ }^{313}$ It has also been shown that systolic, but not diastolic, blood pressure is higher in women with Turner syndrome. ${ }^{314}$

Dilated cardiomyopathy: Genetic transmission of disease has been identified in a significant proportion of patients with dilated cardiomyopathy. Autosomal dominant transmission is the most frequent mechanism, and several candidate disease loci have been identified by genetic linkage analysis. Three disease genes are currently known: the cardiac actin gene, the desmin gene and the lamin $\mathrm{A} / \mathrm{C}$ gene. The last-named has recently been found to be responsible for both the autosomal dominant form of dilated cardiomyopathy with subclinical skeletal muscle disease ( $8 \%$ of cases) and the familial form with conduction defects ( $3 \%$ of cases) or the autosomal variant of Emery-Dreifuss muscular dystrophy. The autosomal recessive form of dilated cardiomyopathy accounts for $\mathrm{I} 6 \%$ of cases and is characterized by a worse prognosis. An X-linked form of dilated cardiomyopathy manifests in the adult population and is due to mutations in the dystrophin gene. Clinical and experimental evidence suggests that in a large number of cases, dilated cardiomyopathies are diseases of the cytoskeleton. ${ }^{315}$

\section{Genes of interest on $\mathrm{X}$ chromosomes}

The renin-angiotensin system plays a pivotal role in blood pressure regulation by influencing salt-water homeostasis and vascular tone. Angiotensin II exerts its effect via 2 receptor types, ATI-R and AT2-R. Both receptor genes are considered good candidates for producing hypertension and CVD. ${ }^{316}$ A polymorphism in this receptor has been associated with hypertension in women but not in men. ${ }^{317}$ Moreover, 
this female-specific association was more pronounced in premenopausal than in postmenopausal women.

Angiotensin-converting enzyme type 2 (ACE2) is another genetic anomaly that may affect hypertension. ACE2, which was discovered recently, is $42 \%$ identical to ACE. ${ }^{318}$ It has been suggested that ACE2 might negatively regulate the activated renin-angiotensin system by diverting the generation of the vasoconstrictor angiotensin II toward the inactive angiotensin $\mathrm{I}-9$ and vasodilatory angiotensin $\mathrm{I}-7$ peptides. Competition between ACE2 and ACE for the same substrate could thus serve as a counterbalancing function. ${ }^{319,320}$ The ACE2 gene maps to a QTL for blood pressure on the X chromosome in hypertensive rats. ACE2 mRNA and protein levels are greatly reduced in the kidney and inversely correlated with elevation in blood pressure, and salt loading was also shown to reduce $\mathrm{ACE} 2$ further and raise blood pressure.

Although Benjafield and colleagues ${ }^{321}$ did not find any significant association between ACE2 polymorphism and essential hypertension, we found a significant association with early onset hypertension in French-Canadian families. ${ }^{322}$ The impact of the ACE 2 variant on hypertension was much stronger in hemizygous males than in heterozygous or homozygous females. We also showed that this variant is associated with obesity. In fact, obesity and smoking appear to be important modifiers of the ACE2 association with predisposition to early onset hypertension.

\section{Autosomal chromosomes and sex differences}

Genetic sex differences in the development of hypertension and CVD are not confined to the sex chromosomes. For instance, in the rat, blood pressure is controlled by QTLs affecting different regulatory systems. In a genome scan to search for genetic determinants of blood pressure, we identified specific loci located on different chromosomes for males and females. ${ }^{323,324}$ Other QTL mapping studies in rats also showed quite different results in males and females. ${ }^{325}$ Blood pressure QTLs in the female population differed considerably from those previously identified in males, and the same appears to be true in humans. We recently reanalyzed our total genome scans of a cohort of French-Canadian families ${ }^{326}$ and found sex-specific QTLs for many metabolic phenotypes related to hypertension. Recently, Weiss and colleagues ${ }^{327}$ expanded this notion into the sex-specific architecture of quantitative traits for various diseases, including CVD and hypertension.

Although sexual specificity of QTL effects can be explained by action of the sex chromosome, hormonal interaction at the transcriptional and post-transcriptional levels represents an alternative possibility that needs to be addressed.

\section{Mitochondrial DNA}

Mitochondria have their own genome. No recombination or exchange takes place between mitochondrial DNA (mtDNA), which is transmitted from the mother. This allows tracing of a direct genetic line; if a mutation arises in a woman's mtDNA, every one of her descendants will have that mutation. Mutations of mtDNA can lead to a number of illnesses.
Several studies have shown excess maternal transmission of essential hypertension, suggesting possible mitochondrial involvement. ${ }^{328}$ To assess the contribution of mtDNA to human essential hypertension, Schwartz and colleagues ${ }^{328}$ carried out systematic, extended screening of hypertensive individuals to identify potentially pathogenic mtDNA mutations. Watson and colleagues ${ }^{329}$ described a possible mechanism involving energy-driven sodium transport in the renal tubules, which is largely responsible for sodium homeostasis. The energy is provided by numerous mitochondria located in the renal tubular walls. Mutations could lead to aberrant energy production, which, in turn, would lead to sodium retention and ultimately contribute to or cause hypertension. Watson and colleagues' results appear to support the hypothesis that mutations in mtDNA causing renal tubule dysfunction may be partly responsible for the susceptibility to hypertension of African-Americans who have progressed to end-stage renal disease. Moreover, Fukuda and colleagues $^{330}$ suggest that $\mathrm{mtDNA}$ mutations in Japanese diabetic patients are related to the development of diabetes and that these mutations are associated not only with a decrease in insulin secretion but also with advanced diabetic microvascular complications.

\section{Future research}

A better understanding of the pathogenetic mechanisms of sexual dimorphism in the development of CVD is clearly needed. The rapid access to vertiginously increasing novel genomic information; the development of powerful tools for fine mapping, including single nucleotide polymorphism microarrays, offering dense coverage of the whole genome; and development of novel genetically designed animal models will help unlock the secrets of sexual dimorphism of CVD, but only if studies are performed in a targeted way in both sexes in humans and animal models. The combination of linkage disequilibrium and functional studies in human and genetically designed rat strains will help identify the genomic determinants implicated in CVD and hypertension. Gender and genoethnic stratification may help decrease the genetic heterogeneity of the studied populations. A major enigma that remains to be unravelled concerns the differences in the contribution of distinct loci in each sex to the same phenotype. Is it all in genes or should we look more carefully at the $99 \%$ non-coding material of our genome to find new clues to sex-gender differences in CVD? With the magnificent tools now available, sex-specific therapeutic approaches and, eventually, preventive measures are now foreseeable.

\section{Why are there sex differences?}

Sex is a biologic status, determined by sex chromosomes and their interactions with autosomes, $\mathrm{X}$ chromosome inactivation, sex hormones and related determinants. It was only recently realized that genes show variation in expression and action in men and women. Sex-specific transcriptional regulation could be due to different growth hormone and sex hormone profiles in the 2 sexes, which can affect the expression 
of numerous genes, and these genes in turn affect the transcriptome of many tissues.

Gender is in part determined by the above, but also involves social, cultural and educational shaping resulting from societal influences and geoethnic modulation. In this context, the observable traits in humans are a result of both sex and gender influences, even in the presence of a strong genetic component, as the eventual phenotype expression may be modulated differentially in men and women by society. However, many questions remain regarding molecular contributions to sexual dimorphism.

\section{Summary}

- The Y chromosome contributes to differences in blood pressure and stress responses between males and females.

- The X chromosome may play an important role in hypertension, cardiovascular malformation, dilated cardiomyopathy, renal disease and Turner syndrome.
- Sex-specific genetic architecture of human traits contributing to CVD is a result of interplay between sex and autosomal chromosomes.

- A polymorphism in the angiotensin II receptor has been associated with hypertension in women but not in men.

- The impact of the ACE2 variant on hypertension is much stronger in males than females, yet the role played by this newly discovered gene in the therapeutic response to antihypertensive agents remains to be determined.

\section{Knowledge gap}

- Research addressing sex differences in genetic susceptibility to the development of CVD or CVD outcomes is needed.

- Studies should be performed in a targeted way in both sexes.

- Hormonal interaction at the transcriptional and post-transcriptional levels must be addressed to assess the impact of autosomes on the sexual dimorphism of CVD determinants.

\title{
Delivery of cardiac care in women and men
}

\author{
Veena Guru, Jafna Cox, William Amin Ghali, Sherry Grace and Karin H. Humphries
}

\section{Search strategy}

A literature search using MEDLINE was conducted using the keywords "gender," "women" or "female" in combination with "acute myocardial infarction" and "treatment," "secondary prevention," "cardiac catheterization," "coronary artery bypass surgery" and "percutaneous coronary intervention." Data from the Canadian Cardiovascular Research Outcomes Team (CCORT) atlas were obtained to elucidate sex-related trends in the delivery of cardiac care in Canada and were aggregated to provide an overview of observed sex differences.

\section{Acute myocardial infarction}

Many studies have documented sex differences in the treatment of AMI. Some have found that women present to hospital later after symptom onset, wait longer for initiation of treatment, are less likely to receive treatment and are less likely to be admitted to monitored intensive care settings. ${ }^{331,332}$ Others suggest that women tend to present when they are older and are more likely to have comorbidities that may make them ineligible for certain therapies. ${ }^{282,333,334}$ Women are also less likely to receive any type of reperfusion therapy (thrombolysis, angioplasty), ${ }^{335,336}$ and elderly women in particular have lower rates of thrombolysis compared with men. ${ }^{335}$ These observations have been documented in other regions of the world ${ }^{337-344}$ as well as in Canada and the United States (Table I3). However, there are also data suggesting no sex bias in treatment allocation $^{345}$ and overall rates of reperfusion once they are adjusted for various clinical factors. ${ }^{343,344}$ Women have also been observed to consume more hospital resources than men. ${ }^{346}$

Canadian survey data suggest that the delay in seeking treatment may relate to a lack of public awareness of the urgency associated with experiencing "heart attack-like" symptoms. ${ }^{347}$ This delay has been observed in both men and women, with as many as 50\% waiting more than $2 \mathrm{~h}$ and $25 \%$ waiting more than 5 h. ${ }^{348}$ The sociodemographic factors that describe those most likely to present late to hospital include female gender, older age, ethnic minority, low income, lower education level and living alone. ${ }^{349}$ Women are more likely to be concerned about "not troubling others," whereas men are more likely to have delayed treatment due to no prior knowledge of the option of thrombolysis. ${ }^{350}$ It has also been suggested that women may be less likely to realize they are having a heart attack for 2 reasons: primarily because their symptoms are more likely to differ from those classically reported and studied in men and secondarily because of sex differences in pain thresholds (i.e., women have been shown to have a higher pain threshold). ${ }^{351}$ This theory may be supported by the Framingham study observation that the rate of silent or unrecognized AMI is higher in women than men. ${ }^{352}$

\section{Secondary prevention after acute myocardial infarction}

There are no visible sex differences in secondary prevention practice patterns in Canada, at least in terms of medication prescription, such as the use of beta-blockers, statins and ACE inhibitors following admission to hospital for $\mathrm{AMI}^{353}$ (Table I4). This is similar to findings observed in other regions of the world. ${ }^{354-356}$ In Sweden, no sex-specific differences in access to medical therapy were observed, and no dif- 
ferences in LDL cholesterol levels by sex were documented at I year following the implementation of a national quality improvement program targeting secondary prevention following AMI. ${ }^{357}$ However, this same study demonstrated higher systolic blood pressure values for women suggesting ineffective dosing of antihypertensive drugs relative to men. ${ }^{357}$

In Canada, older patients are less likely to receive medications for secondary prevention, and this becomes a sex issue as approximately $45 \%$ of patients with AMI aged 65 years or older are women. ${ }^{353}$ This is a significant issue for both sexes and, in fact, some have argued that age is a stronger gradient influencing the bias in secondary prevention than sex.

Sex differences are evident in the lower participation of women in cardiac rehabilitation programs. It is unclear

Table 13: Overall arrival times and rates of treatment of STelevation myocardial infarction by sex in Canada and other regions of the world*

\begin{tabular}{|c|c|c|c|}
\hline \multirow[b]{2}{*}{ Country } & \multirow[b]{2}{*}{ Measure of difference } & \multicolumn{2}{|c|}{$\%$ of patients $\dagger$} \\
\hline & & Men & Women \\
\hline \multirow[t]{4}{*}{$\begin{array}{l}\text { Canada }{ }^{335} \\
(1999-2002)\end{array}$} & $\begin{array}{l}\text { Symptom onset at } \\
\text { arrival }\end{array}$ & & \\
\hline & $0-6 \mathrm{~h}$ & 77 & 72 \\
\hline & $6-12 \mathrm{~h}$ & 9 & 10 \\
\hline & $>12 \mathrm{~h}$ & 14 & 19 \\
\hline \multirow[t]{3}{*}{$\begin{array}{l}\text { USA }^{338} \\
(1993-1994)\end{array}$} & $\begin{array}{l}\text { Symptom onset at } \\
\text { arrival }\end{array}$ & & \\
\hline & $<6 \mathrm{~h}$ & 90 & 65 \\
\hline & $6-24 \mathrm{~h}$ & 10 & 35 \\
\hline $\begin{array}{l}\text { Germany }{ }^{340} \\
(1999-2002)\end{array}$ & $\begin{array}{l}\text { Median time to } \\
\text { treatment }\end{array}$ & $2 \mathrm{~h}$ & $2.6 \mathrm{~h}$ \\
\hline $\begin{array}{l}\text { Spain } 342 \\
(1990-1995)\end{array}$ & $\begin{array}{l}\text { Median time to } \\
\text { treatment }\end{array}$ & $6 \mathrm{~h}$ & $8 \mathrm{~h}$ \\
\hline $\begin{array}{l}\text { Canada } 335 \\
(1999-2002)\end{array}$ & $\begin{array}{l}\text { Any reperfusion } \\
\text { therapy }\end{array}$ & 69 & 58 \\
\hline $\begin{array}{l}\text { Germany }{ }^{340} \\
(1999-2002)\end{array}$ & $\begin{array}{l}\text { Any reperfusion } \\
\text { therapy }\end{array}$ & 69 & 50 \\
\hline $\begin{array}{l}\text { Germany }^{339} \\
(1994-1997)\end{array}$ & $\begin{array}{l}\text { Reperfusion within } \\
48 \mathrm{~h} \text { of arrival }\end{array}$ & 63 & 49 \\
\hline $\begin{array}{l}\text { Spain }^{342} \\
(1990-1995)\end{array}$ & $\begin{array}{l}\text { Any reperfusion } \\
\text { therapy }\end{array}$ & 61 & 45 \\
\hline $\begin{array}{l}\text { Italy }{ }^{343} \\
(2000-2001)\end{array}$ & $\begin{array}{l}\text { Any reperfusion } \\
\text { therapy }\end{array}$ & 58 & 49 \\
\hline \multirow[t]{5}{*}{$\begin{array}{l}\text { Canada }^{335} \\
(1999-2002)\end{array}$} & $\begin{array}{l}\text { Median door-to- } \\
\text { needle time }\end{array}$ & & \\
\hline & $<30 \min$ & 43 & 33 \\
\hline & $30-40 \mathrm{~min}$ & 15 & 16 \\
\hline & $40-60 \mathrm{~min}$ & 18 & 21 \\
\hline & $>60 \mathrm{~min}$ & 22 & 27 \\
\hline $\begin{array}{l}\text { France }^{341} \\
(1993-1995)\end{array}$ & $\begin{array}{l}\text { Median time to } \\
\text { medical treatment }\end{array}$ & $135 \mathrm{~min}$ & $180 \mathrm{~min}$ \\
\hline $\begin{array}{l}\text { Canada } 335 \\
(1999-2002)\end{array}$ & $\begin{array}{l}\text { Median door-to- } \\
\text { balloon time }\end{array}$ & $90 \mathrm{~min}$ & $92 \mathrm{~min}$ \\
\hline
\end{tabular}

*Studies in other regions of the world are not national. tUnless stated otherwise. whether this is due to patient-specific issues, such as greater susceptibility of women to depressive symptoms following AMI, which could limit participation in such programs, or to physician factors. ${ }^{358}$ Physician referral biases have been documented; for example, in one French study, female gender was independently associated with a $56 \%$ lower rate of referral to a cardiac rehabilitation program at discharge. ${ }^{355}$ A recent Canadian study found that after an ischemic coronary event, more women than men reported receiving much less information than they wanted from health professionals in understanding their treatment decisions. ${ }^{359}$ Whatever the barriers, cardiac rehabilitation is an important part of AMI care that has several physical and psychologic benefits for the elderly and women and, as such, should be more readily available to them..$^{300}$

\section{Cardiac catheterization}

There is a body of literature suggesting that women are less likely to undergo cardiac catheterization after an AMI. ${ }^{361,362}$ Some have speculated that this may be due to the fact that exercise stress tests are less likely to be positive in women with disease and that the predictive value of these tests is correspondingly lower than in men. When such test characteristics are taken into account, the sex differences disappear. ${ }^{363,364}$ Nonetheless, sex-based patterns have been noted in the referral of patients for diagnostic testing. ${ }^{365,366}$ Men are more likely to undergo exercise testing and angiography, whereas women are more likely to receive echocardiography. ${ }^{365}$ Even after risk adjustment for clinical characteristics, women are still less likely to undergo noninvasive studies and coronary angiography than men (OR for the underuse of angiography within I2 h of an AMI, I.28; 95\% CI I.I5-I.4I), with the sex

Table 14: Post-discharge use of beta-blockers, ACE inhibitors and statins for acute myocardial infarction in patients aged 65 years and older in Canada (1997-2000) and Sweden (1998)

\begin{tabular}{|c|c|c|c|c|c|c|}
\hline \multirow{2}{*}{$\begin{array}{l}\text { Group; } \\
\text { variable }\end{array}$} & \multicolumn{6}{|c|}{ Rate of use, \%* } \\
\hline & \multicolumn{3}{|c|}{ Men } & \multicolumn{3}{|c|}{ Women } \\
\hline \multicolumn{7}{|c|}{ Canada $^{353}$ ( 90 days post discharge) } \\
\hline Age, yr & $65-74$ & $75-84$ & $\geq 85$ & $65-74$ & $75-84$ & $\geq 85$ \\
\hline $\begin{array}{l}\text { Beta- } \\
\text { blocker }\end{array}$ & 70 & 60 & 48 & 67 & 62 & 51 \\
\hline $\begin{array}{l}\text { ACE } \\
\text { inhibitor }\end{array}$ & 54 & 59 & 57 & 56 & 59 & 57 \\
\hline Statin & 45 & 29 & 10 & 47 & 27 & 8 \\
\hline \multicolumn{7}{|c|}{ Sweden 357 (1 year post discharge) } \\
\hline Age, yr & $<70$ & & $\geq 70$ & $<70$ & & $\geq 70$ \\
\hline $\begin{array}{l}\text { Beta- } \\
\text { blocker }\end{array}$ & 87 & & 83 & 86 & & 86 \\
\hline $\begin{array}{l}\text { ACE } \\
\text { inhibitor† }\end{array}$ & 43 & & 44 & 41 & & 48 \\
\hline Statin $\neq$ & 91 & & 85 & 90 & & 86 \\
\hline
\end{tabular}

Note: $\mathrm{ACE}=$ angiotensin-converting enzyme.

*Unless stated otherwise.

†Includes angiotensin II blocker.

flncludes other lipid-lowering agent. 
gap widest in the most elderly cohort of patients. ${ }^{342,366}$ Other research has shown that with changes in techniques over the last few decades, these differences are no longer evident. ${ }^{367}$

Women admitted to hospital with an AMI are known to have lower rates of severe coronary disease, and this may influence physician referral practices. ${ }^{368}$ Yet, a recent Dutch study uncovered no sex differences in the extent of coronary disease or in referral patterns for cardiac catheterization. ${ }^{369}$ Women undergoing stress myocardial perfusion imaging have lower pretest probabilities of coronary disease and, when this is taken into account, there is little evidence for a sex bias in subsequent referral for angiography. ${ }^{370,371}$ It is important to emphasize, however, that the prognostic implications of a positive result at stress imaging are the same in both men and women. ${ }^{372,373}$ Finally, as with secondary prevention practices, some argue that age is the major driver for differences in referral for cardiac catheterization after an AMI, not sex. ${ }^{374}$

\section{Cardiac procedures after acute myocardial infarction}

Women in Canada are less likely to undergo percutaneous coronary intervention (PCI) or coronary artery bypass grafting (CABG) after AMI and are more likely to be treated with medical therapy than men (Table I5). This may relate to the fact that women tend to be older than men when presenting with AMI, and referral for revascularization in Canada becomes less likely with advancing age. ${ }^{375}$ Some reports from the United States have similarly demonstrated lower rates of revascularization for women following AMI. ${ }^{364}$ Others have found no sex differences in referrals for PCI and CABG, at least not if the cohort examined is limited to those who have already received angiography following AMI. ${ }^{269}$

In Canada, wait times for revascularization procedures have not been found to differ between sexes. ${ }^{375}$ However, there is a large age gradient in wait time; elderly women wait much longer than younger women for either PCI or CABG. ${ }^{375}$

Table 15: Aggregated sex-specific revascularization* rates (\%) 1 year after acute myocardial infarction in Canada by province (1997/98 to $1999 / 2000)$

\begin{tabular}{lcc}
\hline Province & Men & Women \\
\hline Prince Edward Island & 6.2 & 5.3 \\
Nova Scotia & 30 & 21 \\
\hline New Brunswick & 28 & 20 \\
\hline Quebec & 35 & 24 \\
\hline Ontario & 27 & 17 \\
\hline Manitoba & 25 & 18 \\
\hline Saskatchewan† & 33 & 33 \\
\hline Alberta & 39 & 30 \\
\hline British Columbia & 37 & 23 \\
\hline
\end{tabular}

*Percutaneous coronary intervention and coronary artery bypass graft. †Only province in which rates are not lower for women than men. Source of data: Pilote et al. ${ }^{375}$

\section{Cardiac procedure rates in all patients with CAD}

Studies have repeatedly reported that PCI and CABG rates are higher in men than in women (Table I6) in Canada, the United States ${ }^{376,377}$ and other regions of the world, including the United Kingdom. ${ }^{378}$ Reasons commonly given for the lower CABG rates in women include more comorbidity, which augments their operative risk, and smaller coronary arteries, which present greater technical challenges and increase the potential for incomplete revascularization. ${ }^{379,380}$

A conflicting view has been put forward by investigators who have shown that PCI rates in women are similar to those for men after adjustment for age. ${ }^{368,381} \mathrm{~A}$ report from Alberta $^{382}$ found that apparent sex differences in the rates of revascularization were eliminated once demographic and clinical characteristics were taken into account. Thus, in their view, the observed variation in access reflected appropriate decision-making rather than sex bias. Similarly, other studies have shown that although women were more likely to have PCI compared with CABG, when both procedures were con-

Table 16: Sex- and age-specific rates of percutaneous coronary intervention $(\mathrm{PCI})$ and coronary artery bypass graft $(\mathrm{CABG})$ in Canada (1997-2001) and the United States (2001)

\begin{tabular}{|c|c|c|c|}
\hline \multirow[b]{2}{*}{ Age, yr } & \multirow[b]{2}{*}{ Procedure } & \multicolumn{2}{|c|}{ No. per 100000 population } \\
\hline & & Men & Women \\
\hline \multicolumn{4}{|c|}{ Canada ${ }^{376}$} \\
\hline \multirow[t]{2}{*}{$20-34$} & $\mathrm{PCl}$ & 3.4 & 0.9 \\
\hline & CABG & 0.9 & 0.3 \\
\hline \multirow[t]{2}{*}{$35-49$} & $\mathrm{PCl}$ & 98.1 & 21.9 \\
\hline & CABG & 40.4 & 7.9 \\
\hline \multirow[t]{2}{*}{$50-64$} & $\mathrm{PCl}$ & 396.5 & 117.4 \\
\hline & CABG & 300.2 & 64.4 \\
\hline \multirow[t]{2}{*}{$65-74$} & $\mathrm{PCl}$ & 541.8 & 244.3 \\
\hline & CABG & 613.0 & 197.7 \\
\hline \multirow[t]{2}{*}{$\geq 75$} & $\mathrm{PCl}$ & 368.8 & 185.3 \\
\hline & CABG & 400.6 & 129.5 \\
\hline \multicolumn{4}{|c|}{$\begin{array}{l}\text { United } \\
\text { States }^{377}\end{array}$} \\
\hline \multirow[t]{2}{*}{$<45$} & $\mathrm{PCl}$ & 20 & 6 \\
\hline & CABG & 6 & 2 \\
\hline \multirow[t]{2}{*}{$45-54$} & $\mathrm{PCl}$ & 325 & 93 \\
\hline & CABG & 136 & 34 \\
\hline \multirow[t]{2}{*}{$55-64$} & $\mathrm{PCl}$ & 740 & 253 \\
\hline & CABG & 430 & 103 \\
\hline \multirow[t]{2}{*}{$65-74$} & $\mathrm{PCl}$ & 1022 & 464 \\
\hline & CABG & 752 & 233 \\
\hline \multirow[t]{2}{*}{$75-84$} & $\mathrm{PCl}$ & 1004 & 557 \\
\hline & CABG & 751 & 248 \\
\hline \multirow[t]{2}{*}{$\geq 85$} & $\mathrm{PCl}$ & 492 & 318 \\
\hline & CABG & 257 & 60 \\
\hline
\end{tabular}


sidered there was no sex difference in overall mechanical revascularization rates. ${ }^{383}$

\section{Critical analysis of studies}

The studies reviewed included a combination of retrospective and prospective observational cohort data. There was a paucity of randomized controlled trial evidence regarding sex-related cardiac care delivery.

\section{Why are there sex differences?}

The lack of trial evidence for cardiac therapies in women could explain why there appear to be sex differences in their care. Many have attempted to solve this issue through female subgroup analyses of trial data; however, these analyses are often underpowered and subject to bias. As a result, it is no surprise that, internationally, there are numerous reports describing the underutilization of evidence-based cardiac therapies in women. Ongoing surveillance into cardiac care delivery in Canada and elsewhere is needed, as well as, possibly, the development of evidence-based, tailored sex-specific care. We need to develop a better understanding of effective methods of diagnosis of heart disease in women, including sex differences at disease presentation; development of effective treatment, including decision-making specific to women; the dissemination of evidence-based practices specifically targeting those areas neglected for women; and general public awareness of differences in cardiac symptom presentation in women. We hope to pursue these goals in Canada to equalize cardiac care delivery for women.

\section{Summary}

- Women present later after onset of symptoms, wait longer for treatment initiation and are less likely to be admitted to monitored intensive care settings than men.

- There are no sex differences in prescription rates for secondary prevention practice.

- Women have lower rates of participation than men in cardiac rehabilitation programs.

- Women are less likely than men to receive PCI or CABG after AMI, and they have lower rates of revascularization.

\section{Knowledge gap}

- Determine whether age, comorbidities and clinical presentation are important determinants of access to care.

- Determine whether other factors, such as ethnic origin and socioeconomic status, are important determinants of access to care.

- Implement evidence-based, sex-specific care.

\section{Outcomes of CVD in women and men - clinical trials}

\section{Karin H. Humphries, William Amin Ghali, Jafna Cox, Veena Guru and Colleen Norris}

\section{Search strategy}

Manuscripts were identified by searching MEDLINE between I982 and June 2005 using the keywords "gender," "sex," "women," "female" and "acute coronary syndrome," "acute myocardial infarction," "congestive heart failure," "atrial fibrillation," "percutaneous coronary intervention" and "coronary artery bypass graft." The reference lists from relevant articles were also searched to identify additional studies. Wherever possible, randomized clinical trials, systematic reviews and meta-analyses were identified.

\section{Acute coronary syndromes}

Women admitted to hospital for ACS are older than men and have a higher prevalence of diabetes, heart failure and stroke. On admission, women are more likely to have tachycardia, atrioventricular block, pulmonary rales and a high Killip class. ${ }^{384}$ Women are also more likely to present with non-ST elevation ACS compared with men. ${ }^{385,386}$ During hospitalization, women are more likely to experience complications such as shock, heart failure, recurrent chest pain, cardiac rupture and stroke. ${ }^{384,387}$

Several studies have demonstrated sex differences in early mortality (4-6 weeks) after AMI. ${ }^{385,388-394}$ Crude short-term mortality has been shown to be consistently higher in women, with some studies estimating that it is $0.5^{-2}$ times higher than in men. Much of this increase, but not all, is attributable to older age and greater burden of comorbid disease. ${ }^{394,395}$

CCORT recently completed an evaluation of in-hospital mortality following AMI using administrative data from across Canada. Table I7 provides the sex-specific in-hospital mortality rates from 1997/98 through $1999 / 2000 .{ }^{396}$ Consistent with other work, crude mortality was higher in women than men across all age groups.

In contrast, long-term mortality appears to favour women, when adjustments are made for age and differences in base-

Table 17: Overall sex-specific acute myocardial infarction (AMI) in-hospital mortality rate in Canadian patients aged 20 years and over, 1997-2000

$\mathrm{AMI}$ mortality rate, $\%$ of $\mathrm{AMI}$ patients

\begin{tabular}{lcc}
\cline { 2 - 3 } Year & Men & Women \\
\hline $1997 / 98$ & 10.0 & 16.9 \\
$1998 / 99$ & 10.1 & 16.7 \\
$1999 / 2000$ & 9.7 & 16.5 \\
Total & 9.9 & 16.7 \\
\hline
\end{tabular}

Source of data: Tu et al. ${ }^{396}$ 
line conditions..$^{10,392,394}$ Vaccarino and colleagues ${ }^{10-12}$ also noted an age-sex interaction in which younger women, but not older women, had higher rates of both long- and shortterm mortality compared with men of the same age. These results suggest that younger women with ACS are a particularly high-risk group. At older age, there were no differences in long-term mortality and, in the very oldest group, women had better outcomes than men.

\section{Summary}

- Women are more likely than men to present with non-ST elevation ACS.

- Short-term mortality from ACS is higher among women than among men, in part because of their older age at presentation and greater burden of comorbid disease.

- Women have lower long-term mortality from ACS.

- Women < 50 years old with AMI are at particularly high risk of death.

\section{Percutaneous coronary intervention}

PCI is the mainstay of treatment for ACS. Although women referred for this procedure have a lower prevalence of prior AMI and left-ventricular dysfunction than men, they have more heart failure that presumably relates to diastolic dysfunction. Of interest, despite the greater burden of comorbid disease, advanced age and severe angina, the extent of angiographic epicardial disease appears to be less than in men. ${ }^{397}$

In the early days of PCI, registry data demonstrated higher procedural risk and decreased efficacy in women. More recent results from the 1997-98 National Heart, Lung, and Blood Institute Registry suggest that sex differences in outcomes have decreased, and the proportion of women undergoing this procedure has increased to $35 \%$. Despite increased age and more comorbid conditions, including diabetes, hypertension and heart failure, rates of procedural success (95.0\% v. $94.2 \%)$, in-hospital death (2.2\% v. I. $3 \%)$, AMI $(2.3 \%$ v. $3.0 \%)$ and emergency CABG (I.3\% V. I. $4 \%$ ) were not different between women and men, respectively. At I year, mortality was significantly higher in women than men $(6.5 \%$ v. $4.3 \%$ ), as was the combined end point of death-MI-CABG (I8.3\% v. I4.4\%). However, after controlling for baseline differences, sex was not a significant predictor of death, but remained independently associated with the combined end point. This result was driven by the need for subsequent revascularization and may reflect the lower use of stents in women. ${ }^{398}$

No sex-specific results have been published from the numerous trials comparing bare metal stents with balloon angioplasty. A recent report evaluating in-hospital mortality and target vessel revascularization in patients undergoing elective PCI using 3.0-4.0-mm stents showed no sex differences. ${ }^{399} \mathrm{In}$ trials of drug-eluting stents (DESs), both the SIRIUS and TAXUS IV trials demonstrated similar reductions in restenosis, target vessel revascularization and major adverse cardiac events at I year in women and men. ${ }^{400,401}$ Evidence for longterm outcomes with DESs are lacking, but early data suggest that DESs result in favourable outcomes in small vessels in both women and men. ${ }^{402}$

In a CCORT evaluation of outcomes after PCI in Canada between 1992/93 and 2000/or, female sex emerged as an independent predictor of in-hospital mortality (OR I.28; 95\% CI I.I5-I.42). ${ }^{403}$ This result is difficult to interpret as the timeframe of this evaluation covers the balloon angioplasty era for which outcomes in women are known to be poor, as well as the stent era and the start of the DES era, where results have been shown to be better.

Despite evidence of improved outcomes in the contemporary PCI era, vascular complications remain more prevalent among women. Although the development of less aggressive anticoagulation regimens, increased use of weight-adjusted heparin dosing and the use of smaller sheath sizes have reduced vascular complications over time, women still have a 2 -fold higher risk of access-site hematomas, bleeding complications requiring transfusion and retroperitoneal bleeds. ${ }^{400}$

\section{Primary $\mathrm{PCl}$ and thrombolysis in ST elevation myocardial infarction}

Prompt coronary reperfusion, by PCI or thrombolysis, is the standard of care in ST elevation MI. Clinical trials examining the efficacy of thrombolysis have shown similar benefits in women and men after adjustment for baseline differences, but a greater risk of bleeding in women. ${ }^{385,389-391,393}$ Hochman and colleagues ${ }^{385}$ examined outcomes in GUSTO IIb patients by type of coronary syndrome and determined that women with ST elevation had a nonsignificant trend toward greater risk of death or recurrent MI (OR I.27; 95\% CI 0.98-I.63) compared with men, while there was no difference in the non-ST elevation group (OR 0.93; 95\% CI 0.72-I.2) and a protective effect in those with unstable angina (OR o.65; 95\% CI $0.49^{-0.87}$ ). A recent meta-analysis of primary PCI v. thrombolysis in patients with ST elevation MI found that primary PCI was significantly better at reducing overall shortterm death, non-fatal reinfarction, stroke and the combined end point of death-non-fatal MI-stroke. ${ }^{404}$ However, sexspecific outcomes were not reported.

\section{Early revascularization in non-ST elevation myocardial infarction}

A meta-analysis of early invasive strategy (PCI or CABG) v. conservative treatment in non-ST elevation MI established that primary PCI reduced reinfarction, severe angina and readmission to hospital over a mean follow-up period of I7 months, but with an early mortality hazard that only became a mortality benefit over the long term. ${ }^{405}$ Again, this meta-analysis did not report sex-specific outcomes; however, 2 of the trials included in the analysis did investigate sexspecific outcomes. The Fragmin and Fast Revascularization during Instability in Coronary artery disease (FRISC II) trial, which enrolled 749 women (30.5\%), reported a significant 
interaction between sex and early invasive strategy; men, but not women, experienced a reduction in death and recurrent AMI. ${ }^{406}$ In a subsequent analysis of the data from this trial, it was noted that the sex difference in outcome was only in the CABG group (RR 3.74; 95\% CI I.89-7.40), not the PCI group (RR I.03; 95\% CI 0.60-I.80). ${ }^{406}$

RITA 3, a British Heart Foundation randomized trial of early invasive strategy v. conservative management, ${ }^{407}$ found a significant interaction between sex and intervention strategy ( $p=0.007)$, with men benefiting from an early invasive approach (OR $0.63 ; 95 \%$ CI $0.4 \mathrm{I}-0.98$ ), but not women (OR I.79; 95\% CI 0.95-3.35). ${ }^{408}$ In contrast, the TACTICS-TIMI I8 study did not find that women were less likely than men to benefit from an early invasive strategy. ${ }^{409}$ A cohort study of early revascularization (50\% PCI) in 1450 patients with nonST elevation MI demonstrated that women had comparable short-term outcomes (HR 0.8I; 95\% CI 0.44-I.48) and better long-term outcomes (HR o.65; 95\% CI 0.42-0.99) compared with men. ${ }^{410}$ Comparisons of in-hospital and late mortality rates between women and men after primary PCI for AMI are presented in Fig. Io. ${ }^{400}$

\section{Summary}

- After elective PCI, short-term mortality, target vessel revascularization and restenosis rates are similar in women and men.

- Thrombolysis is equally effective in women and men.

- Women have a 2-fold higher risk of bleeding complications than men.

\section{Knowledge gap}

- What is the biologic and pathophysiologic basis for lessextensive angiographic disease in women?

- Do women with non-ST elevation MI benefit from an early invasive strategy?

- Is primary PCI superior to thrombolysis in women with ST elevation MI?

\section{Coronary artery bypass graft surgery}

The Society of Thoracic Surgeons (STS) database in the United States shows an increase in the proportion of females undergoing CABG from $25.7 \%$ in 1990 to $28.7 \%$ in I999. ${ }^{411}$ In Canada, women constitute $22.3 \%$ of CABG patients, and this remained stable between $1992 / 93$ and $2000 /$ OI. $^{412}$

\section{0-day mortality}

Sex differences in operative mortality following CABG remain controversial. The issue is difficult to resolve given the lack of women in the few randomized trials that have evaluated the efficacy of CABG compared with medical therapy or PCI. ${ }^{413-415}$ Observational studies comparing short-term mortality (inhospital or 30-day) between men and women provide conflicting evidence, with several studies reporting increased mortality in women, ${ }^{379,388,412,416-418}$ but some demonstrating equivalent outcomes after adjustment for baseline differences. ${ }^{419-423}$ However, the weight of evidence indicates that

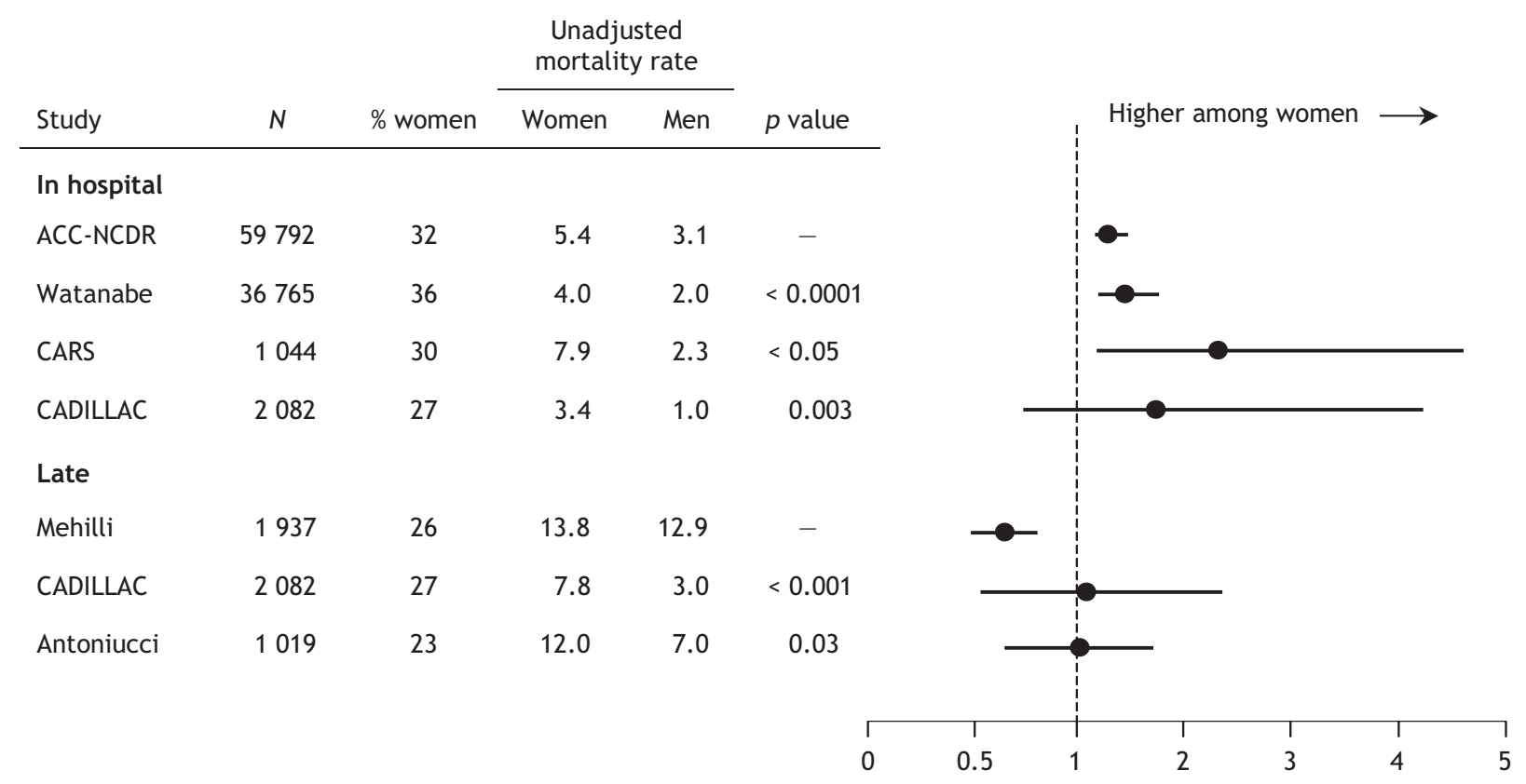

Adjusted OR $(95 \% \mathrm{Cl})$

Fig. 10: In-hospital and late mortality rates among women versus men after primary percutaneous coronary intervention for acute myocardial infarction. Note: ACC-NCDR = American College of Cardiology National Cardiovascular Data Registry; CARS = Coumadin Aspirin Reinfarction Study; CADILLAC = Controlled Abciximab and Device Investigation to Lower Late Angioplasty Complications; OR = odds ratio; $\mathrm{Cl}=$ confidence interval. Reproduced with permission from the American Heart Association (Circulation 2005;111:940-53). ${ }^{400}$ 
short-term mortality is higher in women. The most recent data from the STS National Cardiac Surgery Database for 2002 indicate an operative mortality of $3.54 \%$ in women compared with $2.15 \%$ in men. ${ }^{424}$ It is important to note that mortality rates have fallen significantly over time, with a greater decrease in women than men. ${ }^{425}$

Several theories have been advanced to explain the higher mortality in women, including older age, greater burden of comorbid disease and more urgent revascularization. However, women had better preserved left-ventricular function and less extensive coronary disease. ${ }^{384,388}$ Smaller coronary arteries in women have also been proposed as a possible explanation for the higher mortality rate, ${ }^{426}$ but more recent research indicates that the proportion of women with small coronary arteries $(<\mathrm{I} .5 \mathrm{~mm})$ is no different than the proportion of men, $57 \%$ and $59 \%$ respectively. ${ }^{427}$

\section{Long-term mortality}

In contrast, female sex does not appear to confer increased risk of long-term mortality. ${ }^{379,422,428-431}$ In some studies, women had even better long-term survival than men after adjusting for risk factors. ${ }^{379,420}$ The reasons for improved longterm, but not short-term, survival are speculative. Survival bias may be a factor or the improved long-term survival may be a reflection of longer life expectancy in women.

Another indication for CABG is to obtain symptom relief and long-term improvement in function and quality of life. Although studies in these areas have not been consistent, the evidence suggests that after CABG women have worse symptom status, poorer physical function, more depression and lower quality of life compared with men..$^{432,433}$ Depression at the time of CABG has been shown to influence functional outcomes negatively, and this effect is stronger in women than in men. ${ }^{434}$

\section{Off-pump outcomes}

Women may have better outcomes with off-pump surgery. ${ }^{435-438}$ In women-only cohorts, those undergoing offpump surgery had better outcomes than women undergoing conventional CABG. ${ }^{436,437}$ Studies that compared women and men undergoing off-pump surgery demonstrated that female sex was not associated with worse outcomes. ${ }^{435,438}$ The results of the latter studies should be interpreted with caution as they were retrospective and the sample sizes were small. However, larger, all-female studies are also not definitive, as patient selection cannot be ruled out. Specifically, there is evidence that internal mammary arteries are more commonly used in offpump patients compared with conventional CABG. Thus, the improved outcomes may be associated with increased use of these arteries. ${ }^{424}$

\section{Summary}

- Although mortality rates after CABG surgery have fallen significantly over time, short-term mortality remains higher among women than among men.

- Women appear to have better long-term survival after CABG surgery.

- Women may have better outcomes with off-pump surgery.

\section{Knowledge gap}

- Further assessment of the potential role of vessel size in short-term outcomes is warranted.

- Further evaluation of the benefits of off-pump surgery in women is warranted.

\section{Heart failure}

Information on sex differences in heart failure outcomes is limited and not consistent. Among epidemiologic studies, women appear to have better survival rates than men. ${ }^{49,440}$ In the Framingham study, the I-year mortality rate was $36 \%$ in women compared with $43 \%$ in men (HR $0.64 ; 95 \% \mathrm{CI}$ $0.54-0.77) .{ }^{439}$ In NHANES-I, the I-year mortality rate was $23.8 \%$ and $54.4 \%$ in women and men, respectively. ${ }^{440}$ Similarly, in 2 retrospective cohort studies of elderly Medicare patients, women had better survival than men. ${ }^{441,442}$ Vaccarino and colleagues ${ }^{442}$ reported lower age-adjusted 6-month mortality in women compared with men (RR o.8I; 95\% CI o.68-0.95), which persisted at I year, whereas 30-day mortality did not differ. However, after adjustment for baseline differences, the 6-month mortality risk for women was comparable with that of men (RR 0.90; 95\% CI -0.75-I.08). In contrast, women in the Studies of Left Ventricular Dysfunction (SOLVD) registry had a higher I-year mortality rate $(22 \%)$ than men $(17 \%) .{ }^{442}$

\section{Atrial fibrillation}

Evidence from the Framingham study suggests that there is no sex difference in mortality rate in patients with atrial fibrillation (OR I.2; 95\% CI 0.98-I.49). ${ }^{32}$ Analysis of data from the Canadian Registry of Atrial Fibrillation (CARAF), which enrolled patients at the time of their first ECG-documented episode of atrial fibrillation, found that women were, on average, 5 years older than men and more likely to be symptomatic. ${ }^{36}$ During annual follow-up visits, women were also significantly more likely to report episodes of paroxysmal atrial fibrillation, but progression to permanent atrial fibrillation did not vary by sex. 


\title{
Outcomes of CVD in women and men - post-admission drug therapy
}

\author{
Karin H. Humphries, William Amin Ghali, Jafna Cox, Veena Guru and Colleen Norris
}

There is mounting evidence to suggest that women and men respond differently to drug therapy. This sex-based difference may affect the outcomes of patients with CVD.

\section{Search strategy}

Manuscripts were identified by searching MEDLINE between I982 and June 2005, using the keywords "gender," "sex," "women," "female," "acute myocardial infarction," "congestive heart failure," "atrial fibrillation" AND "ACE inhibitors," "aspirin," "GPIIb/IIIa inhibitors," "beta-blockers," "statins," "digoxin," "spironolactone," "warfarin" and "rate and rhythm control therapy." The reference lists from relevant articles were also searched to identify additional studies. Wherever possible, randomized clinical trials, systematic reviews and meta-analyses were identified.

\section{Acute myocardial infarction}

Practice guidelines based on evidence from randomized clinical trials support the use of ACE inhibitors, ASA, betablockers and statins in patients with AMI without contraindications. ${ }^{443-445}$

\section{ACE inhibitors}

A systematic overview of Ioo ooo patients, randomly assigned to short-term treatment with ACE inhibitors following AMI, failed to demonstrate a statistically significant reduction in risk for women. This may be a reflection of the small number of women enrolled in these trials (22\%-27\%), rather than lack of effect of ACE inhibition in women. ${ }^{446}$ In contrast, a meta-analysis of long-term ACE inhibition demonstrated comparable outcomes in men and women with significant reductions in the composite end point (death-heart failure-MI) in men (OR 0.7I; $95 \% \mathrm{CI}$ $0.65-0.77)$ and women (OR $0.79 ; 95 \%$ CI $0.67-0.93$ ) $\left(p_{\text {interaction }}=0.34\right) \cdot{ }^{447}$

\section{ASA}

The Antiplatelet Trialists' Collaboration reviewed I45 trials of ASA use and found that among high-risk patients, women and men benefited equally from the use of ASA in terms of reduction in vascular events. ${ }^{448}$ ASA use prevented vascular events in 37 out of roo men, compared with 33 of roo women. Sex-specific outcomes were not presented in the most recent update from the Antiplatelet Trialists' Collaboration, which reviewed 287 studies of antiplatelet therapy involving 135000 patients. ${ }^{449}$ In contrast, ASA use for primary prevention has not been shown to be of benefit in women. In the large Women's Health Study, ASA had a nonsignificant effect on AMI (RR I.02; 95\% CI 0.84-I.25; $p=0.83$ ) and death from cardiovascular causes (RR 0.95; $95 \%$ CI
$0.74-\mathrm{I} .22 ; p=0.68)$, but there was weak evidence that ASA reduced the risk of stroke ( $\mathrm{RR} 0.83 ; 95 \%$ CI $0.69-0.99$; $p=0.04) .{ }^{450}$ In a recent sex-specific meta-analysis of ASA for the primary prevention of cardiovascular events, ASA was shown to reduce the risk of ischemic stroke in women (OR 0.76 ; 95\% CI 0.63-0.93), but not in men (OR I.00; 95\% CI $0.72-$ I.4I) ${ }^{451}$ Consistent with the Women's Health Study, ASA use in women was not associated with a decreased risk of MI (OR I.oI; 95\% CI 0.84-I.2I) in contrast with men (OR o.68; 95\% CI 0.54-0.86). ${ }^{451}$

\section{Platelet glycoprotein IIb/IIla inhibitors}

These agents have been shown to reduce cardiac complications in patients undergoing PCI by blocking the glycoprotein $\mathrm{IIb} / \mathrm{III}$ a receptor, which is the final common pathway leading to platelet aggregation. The literature reports that women have increased platelet function compared with men and, thus, might be expected to benefit more than men from glycoprotein IIb/IIIa inhibition. ${ }^{452}$ A pooled analysis of 3 large PCI trials - Evaluation of $7 \mathrm{E}_{3}$ for the Prevention of Ischemic Complications (EPIC), Evaluation in Percutaneous Transluminal Coronary Angioplasty to Improve Long-Term Outcome with Abciximab GP IIb/IIIa blockade (EPILOG) and Evaluation of Platelet IIb/IIIa Inhibitor for Stent (EPISTENT) demonstrated no gender difference in the benefit derived from glycoprotein IIb/IIIa use. Men had a $4 \mathrm{I} \%$ reduction in the composite end point of death-MI-revascularization $(p<0.00 \mathrm{I})$ whereas women had a $38 \%$ reduction $(p=0.0 \mathrm{I}){ }^{453}$

Three recent meta-analyses of platelet glycoprotein IIb/IIIa inhibitors were identified. ${ }^{454-456}$ One comparing glycoprotein IIb/IIIa inhibitors with placebo or standard therapy in 3266 patients treated with primary PCI for AMI demonstrated a significant reduction in the 30 -day composite end point death-reinfarction-ischemic or urgent target-vessel revascularization (OR 0.54; 95\% CI 0.40-0.72). A sex-specific analysis of outcomes was not provided, even though the study population included $26.1 \%$ women $(n=852) .{ }^{454}$ Similarly, a meta-analysis of glycoprotein IIb/IIIa inhibitors use in 27 II5 patients with ST elevation MI did not provide sex-specific outcomes, nor did it indicate how many women were included in the evaluation. ${ }^{455}$ The third analysis by Boersma and colleagues ${ }^{456}$ evaluated the efficacy of glycoprotein IIb/IIIa inhibitors in patients with ACS who were not routinely scheduled to undergo early revascularization. In this population of 3I 402 patients (35\% female), glycoprotein IIb/IIIa inhibitors were shown to be efficacious with a $9 \%$ 30-day reduction in death or MI (OR 0.9I; 95\% CI 0.85-0.98). A highly significant sex-treatment interaction was noted ( $\left.p_{\text {interaction }}<0.00 \mathrm{I}\right)$, with men experiencing benefit (OR 0.8I; 95\% CI 0.75-0.89), while women were at increased risk of death or MI (OR I.I5; 95\% CI I.OI-I.30). The sex difference remained, even after adjusting for baseline differences. However, when patients were strati- 
fied by baseline troponin levels, the risk estimates suggested that, in the troponin-positive group, both sexes benefited from treatment, whereas, in the troponin-negative group, neither benefited. The results of this stratified analysis should be interpreted with caution, as $65 \%$ of patients were excluded due to missing troponin values.

\section{Beta-blockers}

Information on sex differences in outcomes following treatment with beta-blockers is lacking. A meta-analysis of betablocker use after AMI by Freemantle and colleagues ${ }^{457}$ did not provide any sex-specific outcomes; however, 2 observational studies, the Worcester Heart Attack Study ${ }^{458}$ and the National Cooperative Cardiovascular Project, ${ }^{459}$ did report sex-specific outcomes. In a community-wide study of ro 374 patients admitted to hospital with confirmed AMI between 1975 and I999, Silvet and colleagues ${ }^{458}$ reported beneficial effects of beta-blocker use in both men (OR 0.22; 95\% CI 0.I8-0.27) and women (OR $0.32 ; 95 \%$ CI $0.26-0.39$ ) in terms of inhospital mortality. Krumholz and colleagues ${ }^{459}$ evaluated outcomes in II5 015 patients 65 years and older who survived hospital admission with a confirmed AMI between 1994 and I995 and reported comparable I-year mortality in men (RR $0.83 ; 95 \%$ CI $0.76-0.9 \mathrm{I}$ ) and women (RR $0.89 ; 95 \% \mathrm{CI}$ $0.8 \mathrm{I}-0.97)$.

\section{Statins}

The first major randomized controlled trial of statins in patients with AMI was the Scandinavian Simvastatin Survival Study (4S). ${ }^{460,461}$ Women constituted only $19 \%$ of the 4444 patients in the trial. The primary end point, mortality, was significantly reduced in men (RR o.66; 95\% CI 0.53-0.80), but not in women (RR I.I2; 95\% CI 0.65-I.93). The secondary end point, CHD death-MI-resuscitated cardiac arrest, was significantly reduced in both men (RR $0.66 ; 95 \% \mathrm{CI}$ $0.58-0.76$ ) and women (RR 0.65; 95\% CI 0.47-0.9I). Another major trial in patients with AMI, but average cholesterol levels, was the Cholesterol and Recurrent Events (CARE) trial. Again, women made up only $14 \%$ of the 4159 participants, who were randomly chosen to receive pravastatin or placebo. ${ }^{462}$ In a separate evaluation of outcomes in women, treatment with pravastatin resulted in a $43 \%(95 \% \mathrm{CI} 4-66)$ reduction in the primary end point, CAD death and MI, and a $46 \%$ (95\% CI 22-62) reduction in the combined end point, which also included CABG or PCI. ${ }^{463}$ In men, the risk reduction for the combined end point was only $20 \%$. A test for interaction between sex and therapy was significant $(p=0.048)$ suggesting that women had better outcomes than men, but this result should be interpreted with caution, as this was not an a priori hypothesis. The more recent Medical Research Council/British Heart Foundation Heart Protection Study of simvastatin demonstrated comparable efficacy in men and women, who were at high risk of death from CAD. ${ }^{464}$ In a subgroup analysis by sex, the relative risk reduction in women was $18.9 \%$ compared with $21.7 \%$ in men, a difference that was not significant $\left(p_{\text {interaction }}=0.76\right)$.
In a recent meta-analysis of Io randomized controlled trials of statins for primary and secondary prevention, women made up I8.9\% of the total sample $(n=23447) .{ }^{465}$ The summary relative risk ratios (RRR) were not significantly different for women (RRR $0.77 ; 95 \% \mathrm{CI} 0.64-0.94$ ) and men (RRR $0.74 ; 95 \%$ CI $\left.0.69-0.79 ; p_{\text {interaction }}=0.37\right)$. Although the dichotomy of primary and secondary prevention may be somewhat artificial, most of the evidence for the efficacy of statins comes from secondary prevention trials. A systematic review of 6 primary prevention trials concluded that lipid lowering did not reduce total mortality (RR $0.95 ; 95 \% \mathrm{CI} 0.62-\mathrm{I} .46$ ) or CHD events RR 0.87; 95\% CI o.69-I.09) in women. ${ }^{466}$

\section{Summary}

- Evidence of the benefit of short-term treatment with ACE inhibitors in women is lacking; however, long-term treatment reduces the risk of recurrent events.

- ASA use after AMI is equally efficacious in women and men, but ASA use for primary prevention is not of benefit in women.

- There is evidence that primary prevention with ASA may reduce the risk of stroke in women.

- Although clinical trial evidence for use of beta-blockers after AMI in women is lacking, observational trials have demonstrated short- and long-term effectiveness.

- Statin therapy is equally effective in women and men.

\section{Knowledge gap}

- The benefits of ASA use in women appear to be limited to secondary prevention. The lack of effectiveness in primary prevention requires further exploration.

\section{Heart failure}

Current clinical guidelines recommend therapy with multiple drugs, including ACE inhibitors and beta-blockers to reduce morbidity and mortality, digoxin to reduce readmission to hospital, and the addition of spironolactone in patients with more severe symptoms. ${ }^{467,468}$

\section{ACE inhibitors}

As in other areas of cardiovascular research, women have been underrepresented in heart failure trials. In an overview of 30 randomized trials of ACE inhibitors, neither the reduction in mortality nor the combined end point of mortality and heart failure hospitalizations was significant in women. ${ }^{469}$ This finding is difficult to interpret, as it may be a reflection of the underenrolment of women in the earlier trials, rather than evidence of less benefit of ACE inhibitors in women with decreased left-ventricular ejection fraction.

The Heart Outcomes Prevention Evaluation (HOPE) trial undertook a preplanned analysis of the effect of ramipril in high-risk women without heart failure and with preserved left-ventricular function. Women constituted $21 \%$ of the study cohort, and $37.5 \%$ had a prior AMI. Women experi- 
enced similar benefits to men. Specifically, women treated with ramipril had significant reductions in the primary end point of MI, stroke or cardiovascular death (RR $0.77 ; 95 \% \mathrm{CI}$ $0.62-0.96$ ), as well as fewer strokes (RR $0.64 ; 95 \% \mathrm{CI} 0.43-$ 0.96 ) and fewer cardiovascular deaths (RR 0.62; $95 \% \mathrm{CI}$ $0.44-0.88) .{ }^{470}$

\section{Beta-blockers}

In a post-hoc analysis of the $898(23 \%)$ women enrolled in the Metoprolol CR/XL Randomised Intervention Trial in Congestive Heart Failure (MERIT-HF) trial of extended-release metoprolol added to optimal therapy with a diuretic and an ACE inhibitor, women on metoprolol experienced a significant $(21 \%)$ reduction in the primary combined end point of all-cause mortality-all-cause hospitalization. ${ }^{471}$ Similarly, in a post hoc analysis of Cardiac Insufficiency Bisoprolol Study (CIBIS) II, a study of bisoprolol added to a diuretic and ACE inhibitors, women not only benefited from beta-blockade, but mortality was significantly lower in women compared with men (HR 0.64; 95\% CI 0.47-0.86). ${ }^{472}$ A pooled analysis of 3 trials of beta-blockade - MERIT-HF, CIBIS II, Carvedilol Prospective Randomized Cumulative Survival (COPERNICUS) - revealed a significant female survival advantage (RR $0.69 ; 95 \%$ CI 0.5I-0.93). ${ }^{471}$

\section{Digoxin}

In a post hoc analysis of the Digitalis Investigation Group trial of digoxin in patients with heart failure and depressed ventricular systolic function, women had increased risk of allcause mortality (HR I.23; 95\% CI I.02-I.47), which was not seen in men assigned to digoxin (HR $0.93 ; 95 \%$ CI $\left.0.85^{-1.02)}\right)^{473}$ A recent retrospective analysis of this study determined that excess mortality is seen only when serum concentrations of digoxin exceed I.2 ng/mL (HR I.33; 95\% CI I.00-I.76); at concentrations of $0.5^{-0.9} \mathrm{ng} / \mathrm{mL}$, there was no excess mortality in women (HR 0.8; 95\% CI 0.62-I.I3). ${ }^{474} \mathrm{~A}$ test for interaction between sex, digoxin concentration and mortality was not significant, but this result should be interpreted with caution, as the sample size in this subgroup analysis was small ( $n=89$ women).

\section{Spironolactone}

In the Randomized Aldactone Evaluation Study (RALES), a retrospective analysis by sex revealed that the reduction in risk of death among patients on spironolactone (0.70; $95 \% \mathrm{CI}$ $0.60-0.82$ ) was similar for men and women. ${ }^{475}$ Sex-specific relative risks were not provided.

\section{Summary}

- The efficacy of ACE inhibitors is uncertain given the small number of women in trials of these drugs and the lack of direct comparisons with men.

- Post hoc analyses suggest that beta-blockers and spironolactone are equally efficacious in women and men.

\section{Knowledge gap}

- Most clinical trials have focused on patients with decreased left-ventricular ejection fraction, whereas women are more likely to have preserved ventricular systolic function. Further research is required to evaluate the effectiveness of therapies in this patient group, which comprises predominantly elderly women.

\section{Atrial fibrillation}

\section{Warfarin}

Undoubtedly the most important advance in atrial fibrillation therapy has been the decreased risk of stroke in patients treated with warfarin. Some evidence suggests that elderly women are less likely to receive warfarin than their male counterparts. According to CARAF, women 75 years of age and older were $54 \%$ less likely to receive warfarin, compared with men in this age group. ${ }^{36}$ This is consistent with results from a British community survey of warfarin use in patients with atrial fibrillation, where the lowest warfarin use was among elderly women. ${ }^{476}$

In an analysis of pooled data from the 5 major antithrombotic trials, women comprised $26 \%$ of the study cohort. ${ }^{477} \mathrm{Fe}-$ male participation ranged from no women in the Stroke Prevention in Nonrheumatic Atrial Fibrillation (SPINAF) trial to $47 \%$ women in the Atrial Fibrillation, Aspirin, and Anticoagulation (AFASAK) trial. ${ }^{478,479}$ In women, warfarin treatment reduced the risk of stroke by $84 \%$ ( $95 \% \mathrm{CI} 55-95$ ), compared with $60 \%$ (95\% CI 35-76) in men. Although ASA resulted in a significant decreased risk of stroke in men (44\%), in women the $23 \%$ reduction did not achieve statistical significance.

In CARAF, women on warfarin therapy, predominantly those less than 75 years of age, were 3.35 times more likely than men on warfarin to experience a major bleed. ${ }^{36}$ Although increased female risk of bleeds has also been described in people undergoing thrombolytic therapy for AMI and oral anticoagulation after hospital admission for deep vein thrombosis, ${ }^{385}$ increased risk of bleeds was not reported in any of the trials of warfarin use in atrial fibrillation patients. This may reflect the difference in the intensity of anticoagulation monitoring in clinical trials compared with "real world" experience.

\section{Rate and rhythm control therapy}

There were no sex differences in response to treatment in the Atrial Fibrillation Follow-up Investigation of Rhythm Management (AFFIRM) study, which investigated the efficacy of 2 treatment strategies - rate control v. rhythm control - in high-risk atrial fibrillation patients. Both men (adjusted HR I.20) and women (adjusted HR I.30) had a nonsignificant increased risk of death in the rhythm control arm compared with the rate control arm. ${ }^{480}$

\section{Critical analysis of studies}

Wherever possible, we have evaluated randomized controlled 
trial evidence or meta-analyses based on randomized controlled trials. In some instances, trial evidence was lacking and prospective cohort studies were reviewed. Universally, women were underrepresented in clinical trials and consequently in the meta-analyses, thus limiting the power to detect differences if they do exist. Indeed, the risk of a type-II error is quite large and must be considered when evaluating trials and analyses where no differences were noted.

Where sex differences were noted, these may be due to inadequate adjustment for baseline differences in age and comorbidities, as women enrolled in clinical trials are on average older than men and present with a greater burden of comorbid disease. The most important limitation was the overall lack of sex-specific information in published studies. Although most studies now enrol women, few provide sexspecific outcomes or test for interactions to determine whether sex differences do exist.

\section{Summary}

- Warfarin use in women with atrial fibrillation is efficacious for the prevention of stroke, but warfarin is underused in elderly women.

- There is some evidence that women with atrial fibrillation may not benefit from ASA use.

- There appear to be no sex differences in response to rate and rhythm control therapy.

\section{Knowledge gap}

- The apparent increased risk of bleeding in women treated with anticoagulants merits further investigation.

\section{Conclusions}

CVD affects both women and men, but it is the leading cause of mortality in women. Although many aspects of the disease are similar in women and men, there is a growing body of evidence to support sex and gender dimorphisms in the prevalence, presenting symptoms, management and outcomes of CVD. However, because data are retrieved from retrospective, observational and cross-sectional cohort studies, definitive conclusions about why there are sex differences cannot be drawn. It is imperative that welldesigned studies be conducted in which women are adequately represented. These studies must be sufficiently powered to allow statistical inferences and identification of sex-specific outcomes. Understanding how sex and gender differences translate into CVD will help improve the health of women and men.

\section{This article has been peer reviewed.}

From the Divisions of Internal Medicine (Pilote, Dasgupta) and Clinical Epidemiology (Pilote, Dasgupta, Libersan), The McGill University Health Centre Research Institute, McGill University, Montréal, Que.; Division of Cardiovascular Surgery, Sunnybrook and Women's College Health Sciences Centre, Insititute for Clinical Evaluative Sciences (Guru), University of Toronto, Toronto, Ont.; Centre for Health Evaluation and Outcome Sciences, St. Paul's
Hospital (Humphries), University of British Columbia, Vancouver, BC; Department of Psychology (McGrath), Concordia University, Montréal, Que.; University of Alberta (Norris), Edmonton, Alta.; Faculty of Medicine, Department of Community Health Sciences (Rabi), Calgary, Alta.; Centre hospitalier de l'Université de Montréal Research Centre, Hôtel-Dieu (Tremblay, Hamet, Petrovich) and Groupe de recherche interdisciplinaire en santé, Département de médecine sociale et préventive (Barnett, O'Loughlin), University of Montreal, Montréal, Que.; Institut national de santé publique du Québec (Alamian, Paradis), Québec, Que.; New Halifax Infirmary Site, QEII Health Sciences Center (Cox), Dalhousie University, Halifax, NS; Department of Medicine and Community Health Sciences (Ghali), University of Calgary, Calgary, Alta.; York University (Grace), University Health Network, Toronto, Ont.; Department of Epidemiology and Biostatistics (Ho), McGill University, Montréal, Que.; Department of Community Health and Epidemiology (Kirkland), Dalhousie University, Halifax, NS; Département de pédiatrie (Lambert), Hôpital Ste-Justine and University of Montreal, Montréal, Que.; Centre for Clinical Epidemiology \& Community Studies (Tagalakis), Jewish General Hospital-Sir Mortimer B. Davis, McGill University, Montréal, Que.

Competing interests: Dr. Pilote received financial assistance from Merck Frosst to travel to the Canadian Cardiovascular Society in Ottawa in 2006. None declared by the other authors.

Each author has contributed substantially to conception and design, or acquisition of data, or analysis and interpretation of data; drafted the article or revised it critically for important intellectual content and gave final approval of the version to be published.

This project is part of GENESIS Interdisciplinary Capacity Enhancement Team, an interdisciplinary enhancement study of the gender and sex determinants of cardiovascular disease funded by the Canadian Institutes of Health Research and the Heart and Stroke Foundation of Canada, grant no. 72565.

\section{REFERENCES}

I. The changing face of heart disease and stroke in Canada 20oo. Ottawa: Heart and Stroke Foundation; I999. Available: www.phac-aspc.gc.ca/ccdpc-cpcmc/cvd -mcv/publications/pdf/card2ke.pdf (accessed 2000 Dec. I9).

2. Thom T, Haase N, Rosamond W, et al. Heart disease and stroke statistics - 2006 update: a report from the American Heart Association Statistics Committee and Stroke Statistics Subcommittee. Circulation 2005;II3:e85-I5I.

3. Marrugat J, Elosua R, Aldasoro E, et al.; IBERICA Investigators. Regional variability in population acute myocardial infarction cumulative incidence and mortality rates in Spain 1997 and 1998. Eur J Epidemiol 2004;19:831-9.

4. Tunstall-Pedoe H, Kuulasmaa K, Mahonen M, et al. Contribution of trends in survival and coronary-event rates to changes in coronary heart disease mortality: Ioyear results from 37 MONICA Project populations. Lancet I999;353:1547-57. Available: www.heartstats.org/temp/TABsp2.2spwebo4.xls (accessed 2006 Nov 24).

5. Arciero TJ, Jacobsen SJ, Reeder GS, et al. Temporal trends in the incidence of coronary disease. Am JMed 2004;117:228-33

6. World health statistics 2006. Geneva: World Health Organization; 2006. Available: www.who.int/whosis/whostat2006.pdf (accessed 2006 Dec I9).

7. World Health Organization. Changes in death rates from CHD, men and women aged 35-74, between 1990 and 2000, selected countries. [Web site of the British Heart Foundation], 2006. Available: www.heartstats.org/temp/Figspi .5 bspwebo6.xls (accessed 2006 Dec 5 ).

8. Levi F, Lucchini F, Negri E, et al. Trends in mortality from cardiovascular and cerebrovascular diseases in Europe and other areas of the world. Heart 2002;88:119-24.

9. Manuel DG, Leung M, Nguyen K, et al. Burden of cardiovascular disease in Canada. Can J Cardiol 2003;19:997-1004

Io. Vaccarino V, Krumholz HM, Yarzebski J, et al. Sex differences in 2-year mortality after hospital discharge for myocardial infarction. Ann Intern Med 200I; I34: I73-8I.

II. Vaccarino V, Parsons L, Every NR, et al. Sex-based differences in early mortality after myocardial infarction. National Registry of Myocardial Infarction 2 Participants. NEngl J Med I999;34I:217-25.

I2. Vaccarino V, Horwitz RI, Meehan TP, et al. Sex differences in mortality after myocardial infarction: evidence for a sex-age interaction. Arch Intern Med 1998;158: 2054-62.

I3. Lloyd-Jones DM. The risk of congestive heart failure: sobering lessons from the Framingham Heart Study. Curr Cardiol Rep 2001;3:184-90.

I4. Davies M, Hobbs F, Davis R, et al. Prevalence of left-ventricular systolic dysfunction and heart failure in the Echocardiographic Heart of England Screening study: a population based study. Lancet 200I;358:439-44.

I5. Mosterd A, Hoes AW, de Bruyne MC, et al. Prevalence of heart failure and left ventricular dysfunction in the general population: the Rotterdam study. Eur Heart I999;20:447-55 
I6. Abhayaratna WP, Smith WT, Becker NG, et al. Prevalence of heart failure and systolic ventricular dysfunction in older Australians: the Canberra Heart Study. Med J Aust 2006;184:I5I-4

17. Redfield MM, Jacobsen SJ, Burnett JC Jr, et al. Burden of systolic and diastolic ventricular dysfunction in the community: appreciating the scope of the heart failure epidemic. JAMA 2003;289:194-202.

I8. Jong P, Vowinckel E, Liu PP, et al. Prognosis and determinants of survival in patients newly hospitalized for heart failure: a population-based study. Arch Intern Med 2002;162:I689-94.

19. Lee DS, Johansen H, Gong Y, et al. Regional outcomes of heart failure in Canada. Can J Cardiol 2004;20:599-607.

20. Wenger NK. Women, heart failure, and heart failure therapies. Circulation 2002; I05:1526-8

2I. Lee WY, Capra AM, Jensvold NG, et al. for the Epidemiology, Practice, Outcomes, and Cost of Heart Failure (EPOCH) study. Gender and risk of adverse outcomes in heart failure. Am J Cardiol 2004;94:1147-52.

22. Roger VL, Weston SA, Redfield MM, et al. Trends in heart failure incidence and survival in a community-based population. JAMA 2004;292:344-50.

23. Koelling TM, Chen RS, Lubwama RN, et al. The expanding national burden of heart failure in the United States: the influence of heart failure in women. $A m$

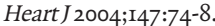

24. Philbin EF, DiSalvo TG. Influence of race and gender on care process, resource use, and hospital-based outcomes in congestive heart failure. Am J Cardiol 1998; 82:76-8I.

25. Ryder KM, Benjamin EJ. Epidemiology and significance of atrial fibrillation. Am $J$ Cardiol I999;84(9A):I3IR-8R.

26. Feinberg WM, Blackshear JL, Laupacis A, et al. Prevalence, age distribution, and gender of patients with atrial fibrillation. Analysis and implications. Arch Intern Med I995; I55:469-73.

27. Kannel WB, Wolf PA, Benjamin EJ, et al. Prevalence, incidence, prognosis, and predisposing conditions to atrial fibrillation: population-based estimates. Am Cardiol $1998 ; 82(8 \mathrm{~A}): 2 \mathrm{~N}-9 \mathrm{~N}$

28. Benjamin EJ, Levy D, Vaziri SM, et al. Independent risk factors for atrial fibrillation in a population-based cohort. The Framingham Heart Study. JAMA I994;27I 840-4.

29. Friberg J, Scharling H, Gadsboll N, et al. Sex-specific increase in the prevalence of atrial fibrillation (the Copenhagen City Heart Study). Am J Cardiol 2003;92 I4I9-23.

30. Wolf PA, Benjamin EJ, Belanger AJ, et al. Secular trends in the prevalence of atrial fibrillation: the Framingham study. Am Heart J I996;131:790-5.

3I. Wolf PA, Mitchell JB, Baker CS, et al. Impact of atrial fibrillation on mortality, stroke, and medical costs. Arch Intern Med I998;158:229-34

32. Benjamin EJ, Wolf PA, D'Agostino RB, et al. Impact of atrial fibrillation on the risk of death: the Framingham Heart Study. Circulation I998;98:946-52.

33. Khairallah F, Ezzedine R, Ganz LI, et al. Epidemiology and determinants of outcome of admissions for atrial fibrillation in the United States from I996 to $200 \mathrm{I}$ Am J Cardiol 2004;94:500-4

34. Stewart S, MacIntyre K, MacLeod MM, et al. Trends in hospital activity, morbidity and case fatality related to atrial fibrillation in Scotland, I986-1996. Eur Heart 200I;22:693-70I.

35. Wattigney WA, Mensah GA, Croft JB. Increased atrial fibrillation mortality: United States, I980-1998. Am J Epidemiol 2002;155:819-26.

36. Humphries $\mathrm{KH}$, Jackevicius C, Gong Y, et al. Population rates of hospitalization for atrial fibrillation/flutter in Canada. Can J Cardiol 2004;20:869-76.

37. Norris CM, Ghali WA, Galbraith PD, et al. Women with coronary artery disease report worse health-related quality of life outcomes compared to men. Health Qual Life Outcomes 2004;2:2I.

38. Berenson GS, Srinivasan SR, Bao W, et al. Association between multiple cardiovascular risk factors and atherosclerosis in children and young adults. The Bogalusa Heart Study. N Engl J Med I998;338:1650-6.

39. Mahoney LT, Burns TL, Stanford W, et al. Coronary risk factors measured in childhood and young adult life are associated with coronary artery calcification in young adults: the Muscatine study. J Am Coll Cardiol 1996;27:277-84

40. Chen E, Matthews KA, Boyce WT. Socioeconomic differences in children's health: how and why do these relationships change with age? Psychol Bull 2002;128: 295-329.

4I. Janz KF, Dawson JD, Mahoney LT. Tracking physical fitness and physical activity from childhood to adolescence: the Muscatine Study. Med Sci Sports Exerc 2000; 32:1250-7.

42. Bao W, Threefoot SA, Srinivasan SR, et al. Essential hypertension predicted by tracking of elevated blood pressure from childhood to adulthood: the Bogalus Heart Study. Am J Hypertens 1995;8:657-65.

43. Guo SS, Huang C, Maynard LM, et al. Body mass index during childhood, adolescence, and young adulthood in relation to adult overweight and adiposity: the Fels Longitudinal Study. Int J Obes Relat Metab Disord 2000;24:1628-35.

44. Nicklas TA, von Duvillard SP, Berenson GS. Tracking of serum lipids and lipoproteins from childhood to dyslipidemia in adults: the Bogalusa Heart Study. Int Sports Med 2002;23(suppl I):S39-43

45. Ogden CL, Flegal KM, Carroll MD, et al. Prevalence and trends in overweight among US children and adolescents, I999-2000. JAMA 2002;288:1728-32.

46. Shields M. Measured obesity: overweight Canadian children and adolescents. Ottawa: Statistics Canada; 2005. Available: www.statcan.ca/english/research/82 620-MIE/200500I/pdf/cobesity.pdf (accessed 2006 Dec 3).

47. Willms JD, Tremblay MS, Katzmarzyk PT. Geographic and demographic variation in the prevalence of overweight Canadian children. Obes Res 2003;1I:668-73.
48. Cole TJ, Bellizzi MC, Flegal KM, et al. Establishing a standard definition for child overweight and obesity worldwide: International survey. BMJ 2000;320:1240-3

49. Tremblay MS, Willms JD. Secular trends in the body mass index of Canadian children. $C M A J$ 2000;163:1429-33.

50. Freedman DS, Khan LK, Dietz WH, et al. Relationship of childhood obesity to coronary heart disease risk factors in adulthood: the Bogalusa Heart Study. Pediatrics 2001;108:712-8.

51. Kelder SH, Osganian SK, Feldman HA, et al. Tracking of physical and physiological risk variables among ethnic subgroups from third to eighth grade: the Child and Adolescent Trial for Cardiovascular Health cohort study. Prev Med 2002;34: 324-33.

52. Paradis G, Lambert M, O'Loughlin J, et al. Blood pressure and adiposity in children and adolescents. Circulation 2004;110:1832-8.

53. Freedman DS, Dietz WH, Srinivasan SR, et al. The relation of overweight to cardiovascular risk factors among children and adolescents: the Bogalusa Heart Study. Pediatrics 1999;103:1175-82

54. Stan S, Levy E, Delvin EE, et al. Distribution of LDL particle size in a population based sample of children and adolescents and relationship with other cardiovascular risk factors. Clin Chem 2005;5I:II92-200.

55. Paradis G, Lambert M, O'Loughlin J, et al. The Quebec Child and Adolescen Health and Social Survey: design and methods of a cardiovascular risk factor survey for youth. Can J Cardiol 2003;19:523-3I.

56. de Ferranti SD, Gauvreau K, Ludwig DS, et al. Prevalence of the metabolic syn drome in American adolescents. Findings from the Third National Health and Nutrition Examination Survey. Circulation 2004;110:2494-7.

57. Ford ES, Mokdad AH, Ajani UA. Trends in risk factors for cardiovascular disease among children and adolescents in the United States. Pediatrics 2004;II4:I534-44.

58. Genovesi S, Giussani M, Pieruzzi F, et al. Results of blood pressure screening in population of school-aged children in the province of Milan: role of overweight. J Hypertens 2005;23:493-7.

59. Lauer RM, Clarke WR. Childhood risk factors for high adult blood pressure: the Muscatine Study. Pediatrics I989;84:633-4I.

6o. Paradis G, Lambert M, O'Loughlin J, et al. Facteurs de risque de maladies cardiovasculaires. In: Enquête sociale et de santé auprès des enfants et adolescents québécois 1999. Québec: Institut de la statistique du Québec; 2002. p. 345-70.

6I. National High Blood Pressure Education Program Working Group on Hypertension Control in Children and Adolescents. Update on the 1987 task force report on high blood pressure in children and adolescents. Pediatrics 1996 ;98:649-58.

62. Dasgupta K, O'Loughlin J, Chen S, et al. Emergence of sex differences in prevalence of high systolic blood pressure. Analysis of a longitudinal adolescent cohort. Circulation 2006;II4:2663-70.

63. Muntner P, He J, Cutler JA, et al. Trends in blood pressure among children and adolescents. JAMA 2004;29I:2107-I3.

64. Rosner B, Prineas R, Daniels SR, et al. Blood pressure differences between blacks and whites in relation to body size among US children and adolescents. Am J Epidemiol 2000;I5I:I007-I9

65. Morrison JA, Sprecher DL, Barton BA, et al. Overweight, fat patterning, and cardiovascular disease risk factors in black and white girls: the National Heart, Lung, and Blood Institute Growth and Health Study. J Pediatr I999;135:458-64.

66. Vlajinac H, Miljus D, Adanja B, et al. Blood pressure levels in 7 to I4-year-old Belgrade children. JHum Hypertens 2003;17:76I-5.

67. Global youth tobacco survey (GYTS). [Web site of the Centers for Disease Control and Prevention], 2006. Available: www.cdc.gov/tobacco/global/gyts/GYTS_factsheets.htm (accessed 2006 Nov 24).

68. National Tobacco Information Online System: country data. [Web site of the Centers for Disease Control and Prevention], 2003. Available: apps.nccd.cdc.gov/nations/nations/Country_Specific_indicators.asp (accessed 2006 Nov 24).

69. Global Youth Tobacco Survey Collaborating Group. Differences in worldwide tobacco use by gender: findings from the Global Youth Tobacco Survey. J Sch Health 2003;73:207-I5

70. 2002 youth smoking survey - technical report. Ottawa: Health Canada, Minister of Supply and Services Canada; 2005. Available: www.hc-sc.gc.ca/hl-vs/pubs/tobac-tabac/yss-etj-2002/index_e.html (accessed 2006 Nov 24).

7I. Canadian Community Health Survey profiles. [Web site of Statistics Canada], 2003. Available: www. statcan.ca/bsolc/english/bsolc? catno $=82-576$ -X\&CHROPG=I (accessed 2006 Dec 3).

72. Gilmore J. Report on smoking in Canada, 1985 to 200I. Ottawa: Minister of Industry, Statistics Canada; 2002. Available: www.statcan.ca/english/research 182Fo077XIE/82F0077XIE200I00I.pdf (accessed 2006 Nov 29). Cat. no. 82 Foo 77 XIE-OI.

73. Canadian tobacco use monitoring survey (CTUMS), February-June 2004. [Web site of Health Canada.] Available: www.hc-sc.gc.ca/hl-vs/tobac-tabac/researchrecherche/stat/ctums-esutc/fs-if/2000/2000youth_e.html (accessed 2006 Dec Iو).

74. Karp I, O'Loughlin J, Paradis G, et al. Smoking trajectories of adolescent novice smokers in a longitudinal study of tobacco use. Ann Epidemiol 2005;15:445-52.

75. Turner L, Mermelstein R, Flay B. Individual and contextual influences on adolescent smoking. Ann N Y Acad Sci 2004;102I:I75-97.

76. Demory-Luce D, Morales M, Nicklas T, et al. Changes in food group consumption patterns from childhood to young adulthood: the Bogalusa Heart Study. J Am Die Assoc 2004;I04:I684-9I.

77. Troiano RP, Briefel RR, Carroll MD, et al. Energy and fat intakes of children and adolescents in the United States: data from the National Health and Nutrition Examination Surveys. Am J Clin Nutr 2000;72(Suppl):1343S-53S.

78. Nicklas TA, Elkasabany A, Srinivasan SR, et al. Trends in nutrient intake of Ioyear-old children over two decades (1973-I994): the Bogalusa Heart Study. Am 
Epidemiol 200I;153:969-77.

79. Sturm R. Childhood obesity - what we can learn from existing data on societa trends, part 2. Prev Chronic Dis 2005;2(2):A20. Available: www.cdc.gov/pcd /issues/2005/apr/04_0039.htm (accessed 2006 Nov 29).

8o. Nielsen SJ, Siega-Riz AM, Popkin BM. Trends in food locations and sources among adolescents and young adults. Prev Med 2002;35:107-I3.

8I. Jahns L, Siega-Riz AM, Popkin BM. The increasing prevalence of snacking among US children from 1977 to 1996 . J Pediatr 2001;138:493-8

82. Veugelers PJ, Fitzgerald AL, Johnston E. Dietary intake and risk factors for poor diet quality among children in Nova Scotia. Can J Public Health 2005;96:212-6.

83. Phillips S, Jacobs Starkey LJ, Gray-Donald K. Food habits of Canadians: food sources of nutrients for the adolescent sample. Can J Diet Pract Res 2004;65:8I-4.

84. Cavadini C, Siega-Riz AM, Popkin BM. US adolescent food intake trends from I965 to 1996. Arch Dis Child 2000;83:18-24.

85. Janssen I, Katzmarzyk P, Boyce WF, et al. Overweight and obesity in Canadian adolescents and their associations with dietary habits and physical activity patterns. JAdolesc Health 2004;35:360-7.

86. French SA, Lin B-H, Guthrie JF. National trends in soft drink consumption among children and adolescents age 6 to I7 years: prevalence, amounts, and sources, I977/I978 to I994/1998. J Am Diet Assoc 2003; I03:I326-3I.

87. Leisure-time physical activity, by age group and sex, household population aged I and over, Canada, 2003. Ottawa: Statistics Canada; 2003. Catalogue no. 82-22I, Vol. 2004, No. I.

88. US Department of Health and Human Services. Physical activity and health: a report of the Surgeon General. Atlanta: US Department of Health and Human Services, Centers for Disease Control and Prevention, National Center for Chronic Disease Prevention and Health Promotion; 1996. Available: www.cdc.gov /nccdphp/sgr/pdf/sgrfull.pdf (accessed 2006 Nov 9).

89. Higgins JW, Gaul C, Gibbons S, et al. Factors influencing physical activity levels among Canadian youth. Can J Public Health 2003;94:45-5I.

9o. Eisenmann JC, Bartee RT, Wang MQ. Physical activity, TV viewing, and weight in U.S. youth: 1999 Youth Risk Behavior Survey. Obes Res 2002;10:379-85.

9I. Andersen RE, Crespo CJ, Bartlett SJ, et al. Relationship of physical activity and television watching with body weight and level of fatness among children: results from the Third National Health and Nutrition Examination Survey. JAMA I998;279:938-42.

92. Simons-Morton BG, McKenzie TJ, Stone E, et al. Physical activity in a multiethnic population of third graders in four states. Am J Public Health $1997 ; 87: 45-50$.

93. Young people in Canada: their health and well-being. Health Behaviour of SchoolAged Children (HBSC) Study. Ottawa: Health Canada; 2004. Available: www.phacaspc.gc.ca/dca-dea/publications/hbsc-2004/pdf/hbsc_summary_2004_e.pdf (accessed 2006 Dec 3)

94. Centers for Disease Control and Prevention. Participation in high school physical education - United States, I99I-2003. MMWR Morb Mortal Wkly Rep 2004;53: $844-7$

95. Nader PR. National Institute of Child Health and Human Development Study of Early Child Care and Youth Development Network. Frequency and intensity of activity of third-grade children in physical education. Arch Pediatr Adolesc Med 2003; I57:185-90.

96. Health Canada. Exercise and leisure activities. In: Trends in the health of Canadian youth. Ottawa: Health Canada; I999. Available: www.phac-aspc.gc.ca/dca-dea /publications/pdf/hbsc_08ch8_e.pdf (accessed 2006 Nov 9).

97. Wilson DK, Williams J, Evans A, et al. Brief report: a qualitative study of gender preferences and motivational factors for physical activity in underserved adolescents. J Pediatr Psychol 2005;30:293-7.

98. Aaron DJ, Storti KL, Robertson RJ, et al. Longitudinal study of the number and choice of leisure time physical activities from mid to late adolescence: implications for school curricula and community recreation programs. Arch Pediatr Adolesc Med 2002;156:1075-80.

99. Jago R, Anderson CB, Baranowski T, et al. Adolescent patterns of physical activity differences by gender, day, and time of day. Am J Prev Med 2005;28:447-52.

roo. Nelson MC, Gordon-Larsen P, Adair LS, et al. Adolescent physical activity and sedentary behavior: patterning and long-term maintenance. Am J Prev Med 2005 28:259-66.

IoI. Vilhjalmsson R, Kristjansdottir G. Gender differences in physical activity in older children and adolescents: the central role of organized sport. Soc Sci Med 2003;56 363-74.

102. Garcia AW, Broda MA, Frenn M, et al. Gender and developmental differences in exercise beliefs among youth and prediction of their exercise behavior. $J$ Sch Health $1995 ; 65: 213-9$.

I03. Wang CK, Chatzisarantis NL, Spray CM, et al. Achievement goal profiles in schoo physical education: differences in self-determination, sport ability beliefs, and physical activity. BrJEduc Psychol 2002;72:433-45.

I04. Biddle SJ, Gorely T, Stensel DJ. Health-enhancing physical activity and sedentary behaviour in children and adolescents. J Sports Sci 2004;22:679-70I.

I05. Tergerson JL, King KA. Do perceived cues, benefits, and barriers to physical activity differ between male and female adolescents? J Sch Health 2002;72:374-80.

Io6. Brodersen NH, Steptoe A, Williamson S, et al. Sociodemographic, developmental environmental, and psychological correlates of physical activity and sedentary behavior at age II to I2. Ann Behav Med 2005;29:2-II.

I07. Sallis JF, Zakarian JM, Hovell MF, et al. Ethnic, socioeconomic, and sex differences in physical activity among adolescents. J Clin Epidemiol 1996;49:125-34.

Io8. Maia JA, Thomis M, Beunen G. Genetic factors in physical activity levels: a twin study. Am J Prev Med 2002;23(2 Suppl):87-9I.

Io9. Anderssen N, Wold B. Parental and peer influences on leisure-time physical activ- ity in young adolescents. Res Q Exerc Sport 1992;63:34I-8.

IIo. Duncan SC, Duncan TE, Strycker LA. Sources and types of social support in youth physical activity. Health Psychol 2005;24:3-10.

III. Hume C, Salmon J, Ball K. Children's perceptions of their home and neighborhood environments, and their association with objectively measured physical activity: a qualitative and quantitative study. Health Educ Res 2005;20:I-I3.

II2. Sallis JF, Conway TL, Prochaska JJ, et al. The association of school environments with youth physical activity. Am J Public Health 2001;91:618-20.

II3. McKenzie TL, Marshall SJ, Sallis JF, et al. Leisure-time physical activity in school environments: an observational study using SOPLAY. Prev Med 2000;30:70-7.

II4. Stone EJ, McKenzie TL, Welk GJ, et al. Effects of physical activity interventions in youth: review and synthesis. Am J Prev Med I998;15:298-315

II5. Marshall SJ, Gorely T, Biddle SJ. A descriptive epidemiology of screen-based media use in youth: a review and critique. J Adolesc 2006;29:333-49.

II6. Statistics Canada. Children's participation in sedentary activities, in hours per week, by age group and sex, household population aged I2 to I7, Canadian Community Health Survey cycle 2.2, Canada and provinces. Ottawa: Statistics Canada; 2004

II7. Canadian Cardiovascular Society 1998 Consensus Conference on the Prevention of Cardiovascular Diseases: the role of the cardiovascular specialist. Can J Cardio I999;I5(Suppl G):IG-II9G.

II8. Raitakari OT, Porkka KV, Rasanen L, et al. Relations of life-style with lipids, blood pressure and insulin in adolescents and young adults. The Cardiovascular Risk in Young Finns Study. Atherosclerosis I994;III:237-46.

II9. Bergstrom E, Hernell O, Persson LA. Cardiovascular risk indicators cluster in girls from families of low socio-economic status. Acta Paediatr 1996;85:1083-90.

120. Pate RR, Heath GW, Dowda M, et al. Associations between physical activity and other health behaviors in a representative sample of US adolescents. Am J Public Health $1996 ; 86: 1577-81$.

I2I. Pronk NP, Anderson LH, Crain AL, et al. Meeting recommendations for multiple healthy lifestyle factors. Prevalence, clustering, and predictors among adolescent, adult, and senior health plan members. Am J Prev Med 2004;27:25-33.

I22. McKenna M, Taylor W, Marks J, et al. Current issues and challenges in chronic disease control. In: Brownson R, Remington P, Davis J, editors. Chronic disease epidemiology and control. Washington: American Public Health Association; I998. p.I-26.

I23. Grundy S, Pasternak R, Greenand P, et al. Assessment of cardiovascular risk by use of multiple-risk-factor assessment equations. A statement for healthcare professionals from the American Heart Association and the American College of Cardiology. J Am Coll Cardiol I999;34:I348-59.

I24. Genest J, Frohlich J, Fodor G, et al.; Working Group on Hypercholesterolemia and Other Dyslipidemias. Recommendations for the management of dyslipidemia and the prevention of cardiovascular disease: summary of the 2003 update. CMA 2003;I69:92I-4.

I25. National Cholesterol Education Program (NCEP) Expert Panel on Detection; Evaluation and Treatment of High Blood Cholesterol in Adults. (Adult Treatment Pane III). Executive summary of the third report of the national cholesterol education program (NCEP) expert panel on detection, evaluation, and treatment of high blood cholesterol in adults (Adult Treatment Panel III). JAMA 200I;285:2486-97.

I26. A national dialogue on healthy body weights, December 7-9, 200I, Toronto: summary of proceedings. Ottawa: Obesity Canada and the Canadian Institutes of Health Research Institute of Nutrition, Metabolism, and Diabetes; 200I. Available: www.cihr-irsc.gc.ca/e/pdf_240Io.htm (accessed 2006 Dec 3).

127. Vidal J. Updated review on the benefits of weight loss. Int J Obes Relat Metab Disord 2002;26(Suppl 4):S25-8.

I28. Boule N, Haddad E, Kenny G, et al. Effects of exercise on glycemic control and body mass in type 2 diabetes mellitus: a meta-analysis of controlled clinical trials. JAMA 200I;286:1218-27.

I29. Fagard R. Physical activity in the prevention and treatment of hypertension in the obese. Med Sci Sports Exerc I999;3I(Suppl II):S624-30.

I30. American Diabetes Association. Diabetes mellitus and exercise. Diabetes Care 2002;25(Suppl I):S64-8. Available: care.diabetesjournals.org/cgi/content/full/25 /suppl_I/s64 (accessed 2006 Dec 3).

I3I. American Diabetes Association. Management of dyslipidemia in adults with diabetes. Diabetes Care 2002;25(Suppl I):S74-7. Available: care.diabetesjournals.org /cgi/content/full/25/suppl_I/s74 (accessed 2006 Dec 3).

I32. American Diabetes Association. Treatment of hypertension in adults with diabetes Diabetes Care 2002;25(Suppl I):S7I-3. Available: care.diabetesjournals.org/cg /content/full/25/suppl_I/s7I (accessed 2006 Dec 3 ).

I33. Wallace J. Exercise in hypertension. A clinical review. Sports Med 2003:33:585-98.

I34. Ekelund L, Haskell W, Johnson J, et al. Physical fitness as predictor of cardiovascular mortality in asymptomatic North American men. The Lipid Research Clinics Mortality Follow-up Study. N Engl J Med I988;319:1379-84

I35. Mora S, Redberg R, Cui Y, et al. Ability of exercise testing to predict cardiovascular and all-cause death in asymptomatic women: a 20-year follow-up of the Lipid Research Clinics Prevalence Study. JAMA 2003;290:1600-7.

I36. Williamson D, Madans J, Pamuk E, et al. A prospective study of childbearing and Io-year weight gain in US white women 25 to 45 years of age. Int J Obes Relat Metab Disord 1994;18:56r-9.

I37. Flegal KM, Carroll MD, Ogden CL, et al. Prevalence and trends in obesity among US adults, I999-2000. JAMA 2002;288:1723-7.

138. Canadian community health survey: a first look. The Daily May 2002. [Web site of Statistics Canada], 2002. Available: www.statcan.ca/Daily/English/020508 do20508a.htm (accessed 2006 Dec 3).

I39. National Health and Nutrition Examination Survey: Healthy weight, overweight, 
and obesity among U.S. adults. [Web site of the Centers for Disease Control and Prevention]. Available: www.cdc.gov/nchs/data/nhanes/databriefs/adultweight.pdf (accessed 2006 Dec. I9)

I40. Tremblay MS, Pérez CE, Ardern CI, et al. Obesity, overweight and ethnicity. Health Rep 2005;16:23-34.

I4I. Visscher TL, Seidell JC. Time trends (I993-I997) and seasonal variation in body mass index and waist circumference in the Netherlands. Int J Obes Relat Metab Disord 2004;28:1309-I6.

142. Milewicz A, Jedrzejuk D, Lwow F, et al. Prevalence of obesity in Poland. Obes Rev 2005;6:II3-4

I43. Kaluski DN, Berry EM. Prevalence of obesity in Israel. Obes Rev 2005;6:115-6.

I44. Kim DM, Ahn CW, Nam SY. Prevalence of obesity in Korea. Obes Rev 2005;6: II7-2I.

I45. Nishida C, Mucavele P. Monitoring the rapidly emerging public health problem of overweight and obesity: the WHO Global Database on Body Mass Index. SCN News 2005;(29):5-I2.

I46. Serdula MK, Ivery D, Coates RJ, et al. Do obese children become obese adults? A review of the literature. Prev Med 1993;22:167-77.

I47. Wing R, Matthews K, Kuller L, et al. Weight gain at the time of menopause. Arch Intern Med I99I;I51:97-102.

I48. Bidlingmeyer I, Burnier M, Bidlingmeyer $M$, et al. Isolated office hypertension: a prehypertensive state? J Hypertens 1996;14:327-32.

I49. Sobal J, Rauschenbach BS, Frongillo EA Jr. Marital status, fatness and obesity. Soc Sci Med 1992;35:915-23.

I50. Pitsavos C, Panagiotakos D, Lentzas Y, et al. Epidemiology of leisure-time physical activity in socio-demographic, lifestyle and psychological characteristics of men and women in Greece: the ATTICA Study. BMC Public Health 2005;5:37.

I5I. Gal DL, Santos AC, Barros H. Leisure-time versus full-day energy expenditure: cross-sectional study of sedentarism in a Portuguese urban population. $B M C P u b$ lic Health 2005;5:16.

I52. Barengo NC, Nissinen A, Tuomilehto J, et al. Twenty-five-year trends in physical activity of 30- to 59-year-old populations in eastern Finland. Med Sci Sports Exerc 2002;34:1302-7.

153. Iwai N, Yoshiike N, Saitoh S, et al. Leisure-time physical activity and related lifestyle characteristics among middle-aged Japanese. Japan Lifestyle Monitoring Study Group. J Epidemiol 2000;10:226-33.

I54. Matthews CE, Freedson PS, Hebert JR, et al. Seasonal variation in household, occupational, and leisure time physical activity: longitudinal analyses from the seasona variation of blood cholesterol study. Am J Epidemiol 200I;I53:172-83

155. Blair SN, Kohl HW III, Paffenbarger RS Jr, et al. Physical fitness and all-cause mortality. A prospective study of healthy men and women. JAMA I989;262:2395-40I.

156. Chen J, Millar WJ. Starting and sustaining physical activity. Health Rep 2001;12: 33-43.

I57. Brownson RC, Baker EA, Housemann RA, et al. Environmental and policy determinants of physical activity in the United States. Am J Public Health 200I;9I 1995-2003.

158. King AC, Castro C, Wilcox S, et al. Personal and environmental factors associated with physical inactivity among different racial-ethnic groups of U.S. middle-aged and older-aged women. Health Psychol 2000;19:354-64

I59. Lee C. Factors related to the adoption of exercise among older women. J Behav Med I993;16:323-34.

I6o. Martins D, Nelson K, Pan D, et al. The effect of gender on age-related blood pressure changes and the prevalence of isolated systolic hypertension among older adults: data from NHANES III. J Gend Specif Med 200I;4:10-3, 20.

I6I. Burt VL, Whelton P, Roccella EJ, et al. Prevalence of hypertension in the US adult population. Results from the Third National Health and Nutrition Examination Survey, I988-1991. Hypertension 1995;25:305-I3

I62. Wiinberg N, Hoegholm A, Christensen HR, et al. 24-h ambulatory blood pressure in 352 normal Danish subjects, related to age and gender. Am J Hypertens 1995;8: 978-86.

I63. The SURF report 2: surveillance of chronic disease risk factors. Country-level data and comparable estimates. Geneva: World Health Organization; 2005. Available: www.who.int/ncd_surveillance/infobase/web/surf2/start.html (accessed 2006 Dec 3).

I64. Wolf-Maier K, Cooper RS, Banegas JR, et al. Hypertension prevalence and blood pressure levels in 6 European countries, Canada, and the United States. JAMA 2003;289:2363-9.

165. Reckelhoff JF. Gender differences in the regulation of blood pressure. Hypertension 2001;37:1199-208.

I66. Ellis JA, Wong ZY, Stebbing M, et al. Sex, genes and blood pressure. Clin Exp Pharmacol Physiol 2001;28:1053-5

I67. Haffner S, Lehto S, Ronnemaa T, et al. Mortality from coronary heart disease in subjects with type 2 diabetes and in nondiabetic subjects with and without prio myocardial infarction. N Engl J Med I998 339:229-34.

I68. Haffner SM. Epidemiology of insulin resistance and its relation to coronary arter disease. Am J Cardiol 1999;84:IIJ-4J.

I69. Estimated prevalence of diabetes and numbers of people with diabetes, 2003 and 2025, selected countries, the world. Brussels: International Diabetes Federation; 2003. [Web site of the British Heart Foundation]. Available: www.heartstats.org /temp/TABspi2.8spwebo6.xls (accessed 2006 Dec. I)

170. Hu FB, Stampfer MJ, Solomon CG, et al. The impact of diabetes mellitus on mor tality from all causes and coronary heart disease in women: 20 years of follow-up. Arch Intern Med 200I;161:1717-23.

I7I. Ghali WA, Quan H, Norris CM, et al. Prognostic significance of diabetes as a predictor of survival after cardiac catheterization. Am J Med 2000;109:543-8.
172. Graham MM, Ghali WA, Faris PD, et al.; APPROACH Investigators. Sex differences in the prognostic importance of diabetes in patients with ischemic heart disease undergoing coronary angiography. Diabetes Care 2003;26:3142-7.

173. Lee WL, Cheung AM, Cape D, et al. Impact of diabetes on coronary artery disease in women and men: a meta-analysis of prospective studies. Diabetes Care 2000 ; 23(7):962-8.

174. Kanaya AM, Grady D, Barrett-Connor E. Explaining the sex difference in coronary heart disease mortality among patients with type 2 diabetes mellitus. A meta-analysis. Arch Intern Med 2002;162:1737-45

I75. Huxley R, Barzi F, Woodward M. Excess risk of fatal coronary heart disease associated with diabetes in men and women: meta-analysis of 37 prospective cohort studies. BMJ 2006 332:73-8.

176. Hu G, Jousilahti P, Qiao Q, et al. The gender-specific impact of diabetes and myocardial infarction at baseline and during follow-up on mortality from all causes and coronary heart disease. J Am Coll Cardiol 2005;45:I4I3-8.

I77. Steinberg HO, Paradisi G, Cronin J, et al. Type II diabetes abrogates sex differences in endothelial function in premenopausal women. Circulation 2000;101:2040-6.

178. Sowers JR. Insulin and insulin-like growth factors in normal and pathologic cardiovascular physiology. Hypertension I997;29:69I-9.

I79. Wexler D, Grant RW, Meigs JB, et al. Sex disparities in the treatment of cardiac risk factors in patients with type 2 diabetes. Diabetes Care 2005;28:514-20.

I8o. National Cholesterol Education Program: ATP III guidelines at-a-glance quick desk reference. Bethesda, MD: National Institutes of Health; 200I. Available: www.nhlbi.nih.gov/guidelines/cholesterol/atglance.pdf (accessed 2006 Dec I9).

I8I. Centers for Disease Control and Prevention. Trends in cholesterol screening and awareness of high blood cholesterol - United States, I99I-2003. MMWR Morb Mortal Wkly Rep 2005;54:865-70.

I82. Langille DB, Joffres MR, MacPherson KM, et al. Prevalence of risk factors for cardiovascular disease in Canadians 55 to 74 years of age: results from the Canadian Heart Health Surveys, I986-I992. CMAJ I999; 161 (8 Suppl):S3-9.

I83. Bass KM, Newschaffer CJ, Klag MJ, et al. Plasma lipoprotein levels as predictors of cardiovascular death in women. Arch Intern Med I993;153:2209-I6.

I84. Johnson CL, Rifkind BM, Sempros CT, et al. Declining serum total cholesterol levels among US adults: the National Health and Nutrition Examination Surveys. IAMA I993;269:3002-8.

I85. Castelli WP, Anderson K, Willson PW, et al. Lipids and risk of coronary heart disease: the Framingham Study. Ann Epidemiol I $992 ; 2: 23-8$.

I86. Sharrett AR, Ballantyne CM, Coady SA, et al. Coronary heart disease prediction from lipoprotein cholesterol levels, triglycerides, lipoprotein(a), apolipoproteins A-I and B, and HDL density subfractions: the Atherosclerosis Risk in Communities (ARIC) Study. Circulation 200I;I04:II08-13.

187. Castelli WP. Epidemiology of triglycerides: a view from Framingham. Am J Cardio I992;70:3 H-9H.

I88. Gordon DJ, Probstfield JL, Garrison RJ, et al. High-density lipoprotein cholestero and cardiovascular disease: four prospective American studies. Circulation I989; 79:8-I5

I89. Knopp RH, Zhu X, Bonet B. Effects of estrogens on lipoprotein metabolism and cardiovascular disease in women. Atherosclerosis I994;IIo:S83-9I.

Igo. Krauss RM. Dense low density lipoproteins and coronary artery disease. Am J Car diol $1995 ; 75: 53 \mathrm{~B}-7 \mathrm{~B}$.

IgI. Hokanson JE, Austin MA. Plasma triglyceride level is a risk factor for cardiovascular disease independent of high-density lipoprotein cholesterol level: a meta-analysis of population-based prospective studies. J Cardiovasc Risk 1996;3:213-9.

I92. Tkac I, Kimball BP, Lewis G, et al. The severity of coronary atherosclerosis in type 2 diabetes mellitus is related to the number of circulating triglyceride-rich lipoprotein particles. Arterioscler Thromb Vasc Biol I997;17:3633-8

I93. Makomaski Illing EM, Kaiserman MJ. Mortality attributable to tobacco use in Canada and its regions, 1998. Can J Public Health 2004;95:38-44.

194. Kirkland S, Greaves L, Devichand P. Gender differences in smoking and self reported indicators of health. BMC Womens Health 2004;4(Suppl I):S7.

I95. Canadian Tobacco Use Monitoring Survey (CTUMS), 2003, wave I. Summary of results. [Web site of Health Canada], 2005. Available: www.hc-sc.gc.ca/hl-vs/tobac -tabac/research-recherche/stat/ctums-esutc/2003/index_e.html (accessed 2006 Dec I).

I96. Canadian Tobacco Use Monitoring Survey (CTUMS), 2004, wave I. Summary of results. [Web site of Health Canada], 2005. Available: www.hc-sc.gc.ca/hl-vs/tobac -tabac/research-recherche/stat/ctums-esutc/2004/index_e.html (accessed 2006 Dec I).

197. Health and social support, I985. General Social Survey, Cycle I. Ottawa: Statistics Canada; I988. Cat. no. II-612E, no.r.

I98. Canadian Tobacco Use Monitoring Survey (CTUMS), 2002, wave I. Summary of results. [Web site of Health Canada], 2005. Available: www.hc-sc.gc.ca/hl-vs/tobac -tabac/research-recherche/stat/ctums-esutc/2002/index_e.html (accessed 2006 Dec I).

199. The national strategy: moving forward - the 2005 progress report on tobacco control: smoking prevalence in Canada. [Web site of Health Canada], 2005. Available: www.hc-sc.gc.ca/hl-vs/pubs/tobac-tabac/foward-avant/part3_e.html (accessed 2006 Dec I).

20o. Mackay J, Eriksen M. The tobacco atlas. Geneva: World Health Organization; 2002. Available: www.who.int/tobacco/statistics/tobacco_atlas/en/ (accessed 2006 Dec I).

20I. Watson JM, Scarinci IC, Klesges RC, et al. Relationships among smoking status, ethnicity, socioeconomic indicators, and lifestyle variables in a biracial sample of women. Prev Med 2003;37:138-47.

202. Cavelaars AE, Kunst AE, Geurts JJ, et al. Educational differences in smoking: Inter- 
national comparison. BMJ 2000;320:1102-7.

203. Stewart MJ, Brosky G, Gillis A, et al. Disadvantaged women and smoking. Can J Public Health i $996 ; 87: 257-60$.

204. Richey Sharrett A, Coady SA, Folsom AR, et al. Smoking and diabetes differ in their associations with subclinical atherosclerosis and coronary heart disease - the ARIC Study. Atherosclerosis 2004;172:143-9.

205. Bolego C, Poli A, Paoletti R. Smoking and gender. Cardiovasc Res 2002;53:568-76.

206. Newby DE, Wright RA, Labinjoh C, et al. Endothelial dysfunction, impaired endogenous fibrinolysis, and cigarette smoking: a mechanism for arterial thrombosis and myocardial infarction. Circulation I999;99:14II-5.

207. Ridker PM, Hennekens $\mathrm{CH}$, Buring JE, et al. C-reactive protein and other markers of inflammation in the prediction of cardiovascular disease in women. $\mathrm{N} \mathrm{Engl} \mathrm{J}$ Med 2000;342:836-43

208. Danesh J, Wheeler JG, Hirschfield GM, et al. C-reactive protein and other circulating markers of inflammation in the prediction of coronary heart disease. $\mathrm{N} \mathrm{Engl}$ Med 2004;350:1387-97.

209. Khor LL, Muhlestein JB, Carlquist JF, et al. Sex- and age-related differences in the prognostic value of $\mathrm{C}$-reactive protein in patients with angiographic coronary artery disease. Am J Med 2004; II7:657-64

2Io. Muhlestein JB, Horne BD, Carlquist JF, et al. Cytomegalovirus seropositivity and Creactive protein have independent and combined predictive value for mortality in patients with angiographically demonstrated coronary artery disease. Circulation 2000;102:1917-23

2II. Bertran N, Camps J, Fernandez-Ballart J, et al. Diet and lifestyle are associated with serum C-reactive protein concentrations in a population-based study. J Lab Clin Med 2005;I45:4I-6.

2I2. Panagiotakos DB, Pitsavos C, Zeimbekis A, et al. The association between lifestylerelated factors and plasma homocysteine levels in healthy individuals from the "ATTICA" Study. Int J Cardiol 2005;98:47I-7.

2I3. Dalery K, Lussier-Cacan S, Selhub J, et al. Homocysteine and coronary artery disease in French Canadian subjects: relation with vitamins BI2, B6, pyridoxal phosphate, and folate. Am J Cardiol I995;75:1107-II.

2I4. Eikelboom JW, Lonn E, Genest J Jr, et al. Homocyst(e)ine and cardiovascular disease: a critical review of the epidemiologic evidence. Ann Intern Med I999;I3I: $363-75$.

215. Homocysteine Studies Collaboration. Homocysteine and risk of ischemic heart disease and stroke: a meta-analysis. JAMA 2002;288:2015-22.

2I6. Srinivasan SR, Ehnholm C, Elkasabany A, et al. Influence of apolipoprotein E polymorphism on serum lipids and lipoprotein changes from childhood to adulthood the Bogalusa Heart Study. Atherosclerosis I999; I43:435-43.

217. Ballantyne CM, Herd JA, Stein EA, et al. Apolipoprotein E genotypes and response of plasma lipids and progression-regression of coronary atherosclerosis to lipidlowering drug therapy. JAm Coll Cardiol 2000;36:1572-8.

218. Schaefer EJ, Lamon-Fava S, Johnson S, et al. Effects of gender and menopausal status on the association of apolipoprotein E phenotype with plasma lipoprotein levels. Results from the Framingham Offspring Study. Arterioscler Thromb 1994;I4 IIO5-I3.

2I9. Lahoz C, Schaefer EJ, Cupples LA, et al. Apolipoprotein E genotype and cardiovascular disease in the Framingham Heart Study. Atherosclerosis 200I; $154: 529-37$.

220. Moore JH, Reilly SL, Ferrell RE, et al. The role of the apolipoprotein E polymor phism in the prediction of coronary artery disease age of onset. Clin Genet I997; 5I:22-5.

22I. Danesh J, Collins R, Appleby P, et al. Association of fibrinogen, C-reactive protein, albumin, or leukocyte count with coronary heart disease: meta-analysis of prospective studies. JAMA I998;279:1477-82.

222. Maresca G, Di Blasio A, Marchioli R, et al. Measuring plasma fibrinogen to predict stroke and myocardial infarction. An update. Arterioscler Thromb Vasc Biol 1999 I9:1368-77.

223. Rajecki M, Pajunen P, Jousilahti P, et al. Hemostatic factors as predictors of stroke and cardiovascular diseases: the FINRISK '92 Hemostasis Study. Blood Coagul Fibrinolysis 2005; I6:119-24.

224. Voetsch B, Loscalzo J. Genetics of thombophilia: impact on atherogenesis. Curr Opin Lipidol 2004;15:129-43.

225. Danesh J, Lewington S, Thompson SG, et al.; Fibrinogen Studies Collaboration. Plasma fibrinogen level and the risk of major cardiovascular diseases and nonvascular mortality: an individual participant meta-analysis. JAMA 2005;294:1799-809.

226. Vorster HH. Fibrinogen and women's health. Thromb Res 1999;95:137-54.

227. Ossei-Gerning N, Wilson IJ, Grant PJ. Sex differences in coagulation and fibrinolysis in subjects with coronary artery disease. Thromb Haemost I998;79:736-40.

228. Vorster HH, Jerling JC, Steyn K, et al. Plasma fibrinogen of black South Africans: the BRISK study. Public Health Nutr 1998;1:169-76.

229. Krobot K, Hense HW, Cremer P, et al. Determinants of plasma fibrinogen: relation to body weight, waist-to-hip ratio, smoking, alcohol, age, and sex. Results from the second MONICA Augsburg Survey, I989-I990. Arterioscler Thromb I992;I2: $780-8$.

230. Thompson SG, Kienast J, Pyke SD, et al. Hemostatic factors and the risk of myocardial infarction or sudden death in patients with angina pectoris. $N \mathrm{Engl} J \mathrm{Med}$ I995;332:635-4I.

231. Hamsten A, de Faire U, Walldius G, et al. Plasminogen activator inhibitor in plasma: risk factor for recurrent myocardial infarction. Lancet $1987 ; 2: 3-9$

232. Scarabin PY, Aillaud MF, Amouyel P, et al. Associations of fibrinogen, factor VII and PAI-I with baseline findings among I0,500 male participants in a prospective study of myocardial infarction: the PRIME Study. Thromb Haemost I998;80: 749-56.

233. Nordenhem A, Leander K, Hallqvist J, et al. The complex between tPA and PAI-I: risk factor for myocardial infarction as studied in the SHEEP project. Thromb Res 2005;II6:223-32.

234. Kohler HP, Grant PJ. Plasminogen-activator inhibitor type I and coronary artery disease. NEngl J Med 2000;342:1792-80I.

235. Kroon UB, Silfverstolpe G, Tengborn L. The effects of transdermal estradiol and oral conjugated estrogens on haemostasis variables. Thromb Haemost 1994;71: 420-3.

236. Gebara OC, Mittleman MA, Sutherland P, et al. Association between increased estrogen status and increased fibrinolytic potential in the Framingham Offspring Study. Circulation 1995;91:1952-8.

237. Yamada $Y$, Izawa H, Ichihara S, et al. Prediction of the risk of myocardial infarction from polymorphisms in candidate genes. N Engl J Med 2002;347:I916-23.

238. Grancha S, Estellés A, Tormo G, et al. Plasminogen activator inhibitor-I (PAI-I) promoter $4 \mathrm{G} / 5 \mathrm{G}$ genotype and increased PAI-I circulating levels in post menopausal women with coronary artery disease. Thromb Haemost 1999;8I: 5I6-2I.

239. Danesh J, Collins R, Peto R. Lipoprotein(a) and coronary heart disease. Metaanalysis of prospective studies. Circulation 2000;102:1082-5.

240. Cantin B, Despres JP, Lamarche B, et al. Association of fibrinogen and lipoprotein(a) as a coronary heart disease risk factor in men (the Quebec Cardiovascular Study). Am J Cardiol 2002;89:662-6.

24I. Solfrizzi V, Panza F, Colacicco AM, et al. Relation of lipoprotein(a) as coronary risk factor to type 2 diabetes mellitus and low-desity lipoprotein cholesterol in patients $>$ or $=65$ years of age (the Italian Longitudinal Study on Aging). Am J Cardio 2002;89:825-9.

242. Shai I, Rimm EB, Hankinson SE, et al. Lipoprotein(a) and coronary heart disease among women: beyond a cholesterol carrier? Eur Heart J 2005;26:1633-9.

243. LaRosa JC. Lipids and cardiovascular disease: do the findings and therapy apply equally to men and women? Womens Health Issues I992;2:102-II.

244. Hattersley L. Trends in life expectancy by social class: an update. Health Stat $Q$ I999;2:16-24.

245. Winkleby MA, Cubbin C. Influence of individual and neighbourhood socioeconomic status on mortality among black, Mexican-American and white women and men in the United States. J Epidemiol Community Health 2003;57:444-52.

246. Marmot MG, Smith GD, Stansfeld S, et al. Health inequalities among British civil servants: the Whitehall II study. Lancet I991;337:1387-93.

247. Gerward S, Tyden P, Hansen O, et al. Survival rate 28 days after hospital admission with first myocardial infarction. Inverse relationship with socio-economic circumstances. JIntern Med 2006;259:164-72.

248. Baigi A, Holmen A, Hogstedt B, et al. Birthplace and social characteristics as risk factors for acute myocardial infarction in Halland, Sweden. Public Health 2002; II6:279-84.

249. Thurston RC, Kubzansky LD, Kawachi I, et al. Is the association between socioeconomic position and coronary heart disease stronger in women than in men? Am J Epidemiol 2005; 62 2:57-65.

250. Dunlop S, Coyte PC, McIsaac W. Socio-economic status and the utilisation of physicians' services: results from the Canadian National Population Health Survey. Soc Sci Med 2000;51:123-33.

25I. Alter DA, Naylor CD, Austin P, et al. Effects of socioeconomic status on access to invasive cardiac procedures and on mortality after acute myocardial infarction. $N$ Engl J Med I999;34I:1359-67.

252. Heisler M, Langa KM, Eby EL, et al. The health effects of restricting prescription medication use because of cost. Med Care 2004;42:626-34.

253. Colhoun HM, Hemingway H, Poulter NR. Socio-economic status and blood pressure: an overview analysis. J Hum Hypertens I998;12:9I-110.

254. Brunner EJ, Marmot MG, White IR, et al. Gender and employment grade differences in blood cholesterol, apolipoproteins and haemostatic factors in the Whitehall II study. Atherosclerosis 1993;102:195-207.

255. Robbins J, Vaccarino V, Zhang H, et al. Socioeconomic status and type 2 diabetes in African American and non-Hispanic white women and men: evidence from the Third National Health and Nutrition Examination Survey. Am J Public Health 200I; 9I:76-84.

256. Kelly C, Booth GL. Diabetes in Canadian women. BMC Womens Health 2004; 4(Suppl I):Si6.

257. Yusuf S, Hawken S, Ounpuu S, et al. Effect of potentially modifiable risk factors associated with myocardial infarction in 52 countries (the INTERHEART study): case-control study. Lancet 2004;364:937-52.

258. Inaba A, Thoits PA, Ueno K, et al. Depression in the United States and Japan: gender, marital status, and SES patterns. Soc Sci Med 2005;61:2280-92.

259. Hopson SD, Marshall-Williams S. The relationship between employment status and women's physical and psychological health. Second International Conference on Women, Heart Disease, and Stroke, 2005 Feb I6-ig; Orlando. Abstract P49.

26o. Van Lenthe FJ, Gevers E, Joung IM, et al. Material and behavioral factors in the explanation of educational differences in incidence of acute myocardial infarction: the GLOBE study. Ann Epidemiol 2002;12:535-42.

26r. Wang N, Iwasaki M, Otani T, et al. Perceived health as related to income, socioeconomic status, lifestyle, and social support factors in a middle-aged Japanese. JEpidemiol 2005;15:155-62.

262. McSweeney JC. Women's narratives: evolving symptoms of myocardial infarction. $J$ Women Aging 1998; 10:67-83.

263. McSweeney JC, Cody M, Crane PB. Do you know them when you see them? Women's prodromal and acute symptoms of myocardial infarction. J Cardiovasc Nurs 2001;15:26-38.

264. DeVon HA, Zerwic JJ. Symptoms of acute coronary syndromes: are there gender differences? A review of the literature. Heart Lung 2002;31:235-45. 
265. Boccardi L, Verde M. Gender differences in the clinical presentation to the emergency department for chest pain. Ital Heart J 2003;4:37I-3

266. DeVon HA, Zerwic JJ. The symptoms of unstable angina: do women and men differ? Nurs Res 2003;52:108-18.

267. Glassman AH, O'Connor CM, Califf RM, et al. Sertraline treatment of major depression in patients with acute MI or unstable angina. JAMA 2002;288:70I-9.

268. Goldberg RJ, O'Donnell C, Yarzebski J, et al. Sex differences in symptom presentation associated with acute myocardial infarction: a population-based perspective. Am Heart Ji998;136:189-95.

269. Maynard C, Litwin PE, Martin JS, et al. Gender differences in the treatment and outcome of acute myocardial infarction. Results from the Myocardial Infarction Triage and Intervention Registry. Arch Intern Med I992;I52:972-6.

270. Meischke H, Larsen MP, Eisenberg MS. Gender differences in reported symptoms for acute myocardial infarction: impact on prehospital delay time interval. Am Emerg Med I998;16:363-6.

27I. Lerner DJ, Kannel WB. Patterns of coronary heart disease morbidity and mortality in the sexes: a 26-year follow-up of the Framingham population. Am Heart I986;III:383-90.

272. Bahr R, Christenson R, Farin $\mathrm{H}$, et al. Prodromal symptoms of acute myocardial infarction: overview of evidence. Md Med 200I;(Suppl):49-59.

273. McSweeney JC, Cody M, O'Sullivan P, et al. Women's early warning symptoms of acute myocardial infarction. Circulation 2003;108:2619-23.

274. Biagini E, Elhendy A, Bax JJ, et al. Seven-year follow-up after dobutamine stress echocardiography: impact of gender on prognosis. J Am Coll Cardiol 2005;45 93-7.

275. Al-Khalili F, Wamala SP, Orth-Gomer K, et al. Prognostic value of exercise testing in women after acute coronary syndromes (the Stockholm Female Coronary Risk Study). Am J Cardiol 2000;86:2II-3.

276. Gulati M, Pratap P, Kansal P, et al. Gender differences in the value of ST-segment depression during adenosine stress testing. Am J Cardiol 2004;94:997-1002.

277. Imran MB, Palinkas A, Pasanisi EM, et al. Optimal reading criteria in stress echocardiography. Am J Cardiol 2002;90:444-5.

278. Mehta RH, Eagle KA. Missed diagnosis of acute coronary syndromes in the emergency room - Continuing challenges. N Engl J Med 2000;342:1207-IO.

279. Al-Khalili F, Svane B, Wamala SP, et al. Clinical importance of risk factors and exercise testing for prediction of significant coronary artery stenosis in women recovering from unstable coronary artery disease: the Stockholm Female Coronary Risk Study. Am Heart J 2000;139:97I-8.

28o. Balk EM, Ioannidis JP, Salem D, et al. Accuracy of biomarkers to diagnose acute cardiac ischemia in the emergency department: a meta-analysis. Ann Emerg Med 200I;37:478-94.

28I. Lee TH, Goldman L. Evaluation of the patient with acute chest pain. $N$ Engl J Med 2000;342:1187-95

282. Williams RI, Fraser AG, West RR. Gender differences in management after acute myocardial infarction: not 'sexism' but a reflection of age at presentation. J Public Health (Oxf) 2004;26:259-63

283. Bowker TJ, Turner RM, Wood DA, et al. A national Survey of Acute Myocardial Infarction and Ischaemia (SAMII) in the U.K.: characteristics, management and inhospital outcome in women compared to men in patients under 70 years. Eur Heart J 2000;2I:I458-63

284. Marrugat J, Garcia M, Elosua R, et al. Short-term ( 28 days) prognosis between genders according to the type of coronary event ( $Q$-wave versus non-Q-wave acute myocardial infarction versus unstable angina pectoris). Am J Cardiol 2004;94:II6I-5.

285. Taneva E, Bogdanova V, Shtereva N. Acute coronary syndrome, comorbidity, an mortality in geriatric patients. Ann NY Acad Sci 2004;I0I9:I06-IO.

286. Christenson RH, Leino EV, Giugliano RP, et al. Usefulness of prodromal unstable angina pectoris in predicting better survival and smaller infarct size in acute myocardial infarction (the InTIME-II Prodromal Symptom Substudy). Am J Cardio 2003;92:598-600.

287. Bahr RD, Leino EV, Christenson RH. Prodromal unstable angina in acute myocardial infarction patients: prognostic value of short- and long-term outcome and predictor of infarct size. Am Heart J 2000; I40:126-33.

288. Chen L-C, Chen Y-W, Lin S-J, et al. Clinical and angiographic determinants of adverse cardiac events in patients with stent restenosis. Catheter Cardiovasc Interv 2002;55:33I-7.

289. Schwertz DW, Penckofer S. Sex differences and the effects of sex hormones on hemostasis and vascular reactivity. Heart Lung 200I;30:40I-26.

29o. Beckman JA, Ganz J, Creager MA, et al. Relationship of clinical presentation and calcification of culprit coronary artery stenoses. Arterioscler Thromb Vasc Biol 200I;21:I6I8-22.

29I. Redberg RF, Cannon RO III, Bairey Merz N, et al. Women's ischemic syndrome evaluation: current status and future research directions: report of the National Heart, Lung and Blood Institute Workshop: October 2-4, 2002: Section 2: stable ischemia: pathophysiology and gender differences. Circulation 2004;109:e47-9.

292. Pedersen SS, Middel B. Increased vital exhaustion among type-D patients with ischemic heart disease. J Psychosom Res 200I;51:443-9.

293. Méthot J, Hamelin BA, Bogaty P, et al. Does hormonal status influence the clinica presentation of acute coronary syndromes in women? J Womens Health (Larchmt) 2004;13:695-702.

294. McSweeney JC, Crane PB. An act of courage: women's decision-making processes regarding outpatient cardiac rehabilitation attendance. Rehabil Nurs 2001;26: I32-40.

295. Kimble LP, McGuire DB, Dunbar SB, et al. Gender differences in pain characteristics of chronic stable angina and perceived physical limitation in patients with coronary artery disease. Pain 2003;I0I:45-53
296. Ryan CJ, DeVon HA, Zerwic JJ. Typical and atypical symptoms: diagnosing acute coronary syndromes accurately. Am J Nurs 2005;105:34-6.

297. Pope JH, Aufderheide TP, Ruthazer R, et al. Missed diagnoses of acute cardiac ischemia in the emergency department. NEngl J Med 2000;342:1163-70.

298. Ely D, Caplea A, Dunphy G, et al. Spontaneously hypertensive rat Y chromosome increases indexes of sympathetic nervous system activity. Hypertension 1997;29:613-8.

299. Dumas P, Kren V, Krenova D, et al. Identification and chromosomal localization of ecogenetic components of electrolyte excretion. J Hypertens 2002;20:209-17.

30o. Uehara Y, Shin WS, Watanabe T, et al. A hypertensive father, but not hypertensive mother, determines blood pressure in normotensive male offspring through body mass index. J Hum Hypertens I998;12:44I-5.

30I. Ellis JA, Stebbing M, Harrap SB. Association of the human Y chromosome with high blood pressure in the general population. Hypertension 2000;36:73I-3.

302. Charchar FJ, Tomaszewski M, Padmanabhan S, et al. The Y chromosome effect on blood pressure in two European populations. Hypertension 2002;39:353-6.

303. Charchar FJ, Tomaszewski M, Lacka B, et al. Association of the human Y chromosome with cholesterol levels in the general population. Arterioscler Thromb Vasc Biol 2004;24:308-I2.

304. Shoji M, Tsutaya S, Shimada J, et al. Lack of association between Y chromosome Alu insertion polymorphism and hypertension. Hypertens Res 2002;25:I-3.

305. Garcia EC, Gonzalez P, Castro MG, et al. Association between genetic variation in the $\mathrm{Y}$ chromosome and hypertension in myocardial infarction patients. Am J Med Genet A 2003;122:234-7

306. Ely D, Turner M, Milsted A. Review of the Y chromosome and hypertension. Braz Med Biol Res 2000;33:679-9I.

307. McBride MW, Carswell HV, Graham D, et al. Genetic and gender determinants of cerebrovascular disease. Semin Nephrol 2002;22:127-34.

308. Monastyrskaia EA, Murashev AN, Khokhlova ON, et al. [Genetic aspects of arteria hypertension: the role of Y chromosome and mitochondrial DNA]. Ross Fiziol Zh Im IM Sechenova 2000;86:67I-80. [In Russian.]

309. Hilbert P, Lindpaintner K, Beckmann JS, et al. Chromosomal mapping of two genetic loci associated with blood-pressure regulation in hereditary hypertensive rats. Nature I99I;353:52I-9

3Io. Herrera VL, Traverse S, Lopez LV, et al. X-linked locus associated with hypertensive renal disease susceptibility in Dahl rats. J Hypertens 2003;21:67-7I.

3II. Yagil C, Sapojnikov M, Kreutz R, et al. Role of chromosome X in the Sabra rat model of salt-sensitive hypertension. Hypertension 1999;33:26I-5.

312. Martin MM, Elton TS. The sequence and genomic organization of the human type 2 angiotensin receptor. Biochem Biophys Res Commun I995;209:554-62.

313. Lichiardopol C, Mota M. Cardiovascular risk factors in Turner syndrome. Rom Intern Med 2004;42:371-9.

314. Landin-Wilhelmsen K, Bryman I, Wilhelmsen L. Cardiac malformations and hypertension, but not metabolic risk factors, are common in Turner syndrome. J Clin Endocrinol Metab 200r:86:4166-70.

315. Sinagra G, Di Lenarda A, Brodsky GL, et al. New insights into the molecular basis of familial dilated cardiomyopathy. Ital Heart J 200I;2:280-6.

3I6. Schmieder RE, Erdmann J, Delles C, et al. Effect of the angiotensin II type 2-receptor gene $(+\mathrm{I} 675 \mathrm{G} / \mathrm{A})$ on left ventricular structure in humans. J Am Coll Cardio 200I;37:175-82

317. Jin JJ, Nakura J, Wu Z, et al. Association of angiotensin II type 2 receptor gene variant with hypertension. Hypertens Res 2003;26:547-52

318. Bernstein KE. Two ACEs and a heart. Nature 2002;417:799-802.

3I9. Danilczyk U, Eriksson U, Crackower MA, et al. A story of two ACEs. J Mol Med 2003;8r:227-34.

320. Oudit GY, Crackower MA, Backx PH, et al. The role of ACE2 in cardiovascular physiology. Trends Cardiovasc Med 2003;13:93-IoI.

32I. Benjafield AV, Wang WY, Morris BJ. No association of angiotensin-converting enzyme 2 gene (ACE2) polymorphisms with essential hypertension. Am J Hypertens 2004; $17: 624-8$

322. Labuda M, Uwabo J, Sun Y, et al. Polymorphism in ACE2 gene is associated with hypertension and hypertension-related phenotypes in French-Canadians. [Abstract]. Can J Cardiol 2004;20(Suppl D):48D.

323. Ueno T, Tremblay J, Kunes J, et al. Rat model of familial combined hyperlipidemia as a result of comparative mapping. Physiol Genomics 2004;17:38-47.

324. Ueno T, Tremblay J, Kunes J, et al. Gender-specific genetic determinants of blood pressure and organ weight: pharmacogenetic approach. Physiol Res 2003;52: 689-700.

325. Moreno C, Dumas P, Kaldunski ML, et al. Genomic map of cardiovascular phenotypes of hypertension in female Dahl S rats. Physiol Genomics 2003;15:243-57.

326. Hamet P, Merlo E, Seda O, et al. Quantitative founder-effect analysis of French Canadian families identifies specific loci contributing to metabolic phenotypes of hypertension. Am J Hum Genet 2005;76:815-32.

327. Weiss LA, Pan L, Abney M, et al. The sex-specific genetic architecture of quantitative traits in humans. Nat Genet 2006;38:218-22.

328. Schwartz F, Duka A, Sun F, et al. Mitochondrial genome mutations in hypertensive individuals. Am J Hypertens 2004;17:629-35.

329. Watson B Jr, Khan MA, Desmond RA, et al. Mitochondrial DNA mutations in black Americans with hypertension-associated end-stage renal disease. Am J Kidney Dis 200I; 38:529-36.

330. Fukuda M, Nakano S, Imaizumi N, et al. Mitochondrial DNA mutations are associated with both decreased insulin secretion and advanced microvascular complications in Japanese diabetic subjects. J Diabetes Complications 1999;13:277-83

331. Heston TF, Lewis LM. Gender bias in the evaluation and management of acute nontraumatic chest pain. The St.Louis Emergency Physicians' Association Research Group. Fam Pract Res J1992;12:383-9. 
332. Dellborg M, Swedberg K. Acute myocardial infarction: difference in the treatment between men and women. Qual Assur Health Care I993;5:26I-5.

333. Bakler T, Baburin A, Teesalu R, et al. Comparison of management and 30-day mortality of acute myocardial infarction in men versus women in Estonia. Acta Cardiol 2004;59:275-8I.

334. Zubaid M, Rashed WA, Thalib L, et al. Differences in thrombolytic treatment and in-hospital mortality between women and men after acute myocardial infarction. Jpn Heart J 200I; 42:669-76.

335. Jackevicius CA, Alter D, Cox J, et al. Acute treatment of myocardial infarction in Canada 1999-2002. Can J Cardiol 2005;21:145-52.

336. Austin PC, Tu JV, Daly PA, et al. The use of quantile regression in health care research: a case study examining gender differences in the timeliness of thrombolytic therapy. Stat Med 2005;24:79I-8I6.

337. Feliciano J, Fiarresga AJ, Timoteo AT, et al. Differences in outcome in primary angioplasty in women. Rev Port Cardiol 2005;24:I93-20I

338. Kaplan KL, Fitzpatrick P, Cox C, et al. Use of thrombolytic therapy for acute myocardial infarction: effects of gender and age on treatment rates. J Thromb Throm bolysis 2002;13:2I-6.

339. Heer T, Schiele R, Schneider S, et al. Gender differences in acute myocardial in farction in the era of reperfusion (the MITRA registry). Am J Cardiol 2002;89: 5 II -7 .

340. Theres H, Maier B, Matteucci Gothe R, et al. Influence of gender on treatment and short-term mortality of patients with acute myocardial infarction in Berlin. $Z$ Kardiol 2004;93:954-63.

34I. de Gevigney G, Mosnier S, Ecochard R, et al. Are women with acute myocardial infarction managed as well as men? Does it have consequences on in-hospital mortality? Analysis of an unselected cohort of $80 \mathrm{I}$ women and 1,718 men. Acta Cardio 200I;56:169-79.

342. Martinez-Selles M, Lopez-Palop R, Perez-David E, et al. Influence of age on gender differences in the management of acute inferior or posterior myocardial infarction. Chest 2005;128:792-7.

343. Carrabba N, Santoro GM, Balzi D, et al. In-hospital management and outcome in women with acute myocardial infarction (data from the AMI-Florence Registry). Am J Cardiol 2004;94:1118-23.

344. Hanratty B, Lawlor DA, Robinson MB, et al. Sex differences in risk factors, treatment and mortality after acute myocardial infarction: an observational study. J Epidemiol Community Health 2000;54:912-6.

345. Vacek JL, Handlin LR, Rosamond TL, et al. Gender-related differences in reperfusion treatment allocation and outcome for acute myocardial infarction. Am J Car diol I995; 6:226-9.

346. Wolinsky FD, Wyrwich KW, Gurney JG. Gender differences in the sequelae of hospitalization for acute myocardial infarction among older adults. J Am Geriatr Soc I999;47:15I-8.

347. Wyatt PA, Ratner PA. Evaluating treatment-seeking for acute myocardial infarction in women. Can J Cardiovasc Nurs 2004; I4:39-45.

348. Goff DC Jr, Feldman HA, McGovern PG, et al. Prehospital delay in patients hospitalized with heart attack symptoms in the United States: the REACT trial. Rapid Early Action for Coronary Treatment (REACT) Study Group. Am Heart J I999;138: I046-57.

349. Lefler LL, Bondy KN. Women's delay in seeking treatment with myocardial infarction: a meta-synthesis. J Cardiovasc Nurs 2004;19:25I-68.

350. Moser DK, McKinley S, Dracup K, et al. Gender differences in reasons patients delay in seeking treatment for acute myocardial infarction symptoms. Patient Educ Couns 2005;56:45-54.

35I. Goldberg R, Goff D, Cooper L, et al. Age and sex differences in presentation of symptoms among patients with acute coronary disease: the REACT trial. Coron Artery Dis 2000;II:399-407.

352. Kannel WB, Abbott RD. Incidence and prognosis of unrecognized myocardial infarction. An update on the Framingham study. N Engl J Med I984;3II:II44-7.

353. Pilote L, Beck CA, Karp I, et al. Secondary prevention after acute myocardial infarction in four Canadian provinces, I997-2000. Can J Cardiol 2004;20:6I-7.

354. Harrold LR, Lessard D, Yarzebski J, et al. Age and sex differences in the treatmen of patients with initial acute myocardial infarction: a community-wide perspective. Cardiology 2003;99:39-46.

355. Bongard V, Grenier O, Ferrieres J, et al. Drug prescriptions and referral to cardiac rehabilitation after acute coronary events: comparison between men and women in the French PREVENIR Survey. Int J Cardiol 2004;93:217-23.

356. Ben-Ami T, Gilutz H, Porath A, et al. No gender difference in the clinical management and outcome of unstable angina. Isr Med Assoc J 2005;7:228-32.

357. Nilsson P, Brandstrom $\mathrm{H}$, Lingfors $\mathrm{H}$, et al. Gender differences in secondary prevention of coronary heart disease: reasons to worry or not? Scand J Prim Health Care 2003;21:37-42.

358. Norrman S, Stegmayr B, Eriksson M, et al. Depressive mood after a cardiac event: gender inequality and participation in rehabilitation programme. Eur J Cardiovasc Nurs 2004;3:295-302.

359. Stewart DE, Abbey SE, Shnek ZM, et al. Gender differences in health information needs and decisional preferences in patients recovering from an acute ischemic coronary event. Psychosom Med 2004;66:42-8.

360. Lavie CJ, Milani RV. Benefits of cardiac rehabilitation and exercise training in elderly women. Am J Cardiol 1997;79:664-6.

36r. Weitzman S, Cooper L, Chambless L, et al. Gender, racial, and geographic differences in the performance of cardiac diagnostic and therapeutic procedures for hospitalized acute myocardial infarction in four states. Am J Cardiol 1997;79:722-6.

362. Garg PP, Landrum MB, Normand SL, et al. Understanding individual and small area variation in the underuse of coronary angiography following acute myocardial infarction. Med Care 2002;40:614-26.

363. Wong Y, Rodwell A, Dawkins S, et al. Sex differences in investigation results and treatment in subjects referred for investigation of chest pain. Heart 200I;85: I49-52.

364. Rathore SS, Wang Y, Radford MJ, et al. Sex differences in cardiac catheterization after acute myocardial infarction: the role of procedure appropriateness. Ann Intern Med 2002;137:487-93.

365. Chiriboga DE, Yarzebski J, Goldberg RJ, et al. A community-wide perspective of gender differences and temporal trends in the use of diagnostic and revascularization procedures for acute myocardial infarction. Am J Cardiol 1993;71:268-73.

366. Gan SC, Beaver SK, Houck PM, et al. Treatment of acute myocardial infarction and 30-day mortality among women and men. N Engl J Med 2000;343:8-I5.

367. Harrold LR, Esteban J, Lessard D, et al. Narrowing gender differences in procedure use for acute myocardial infarction: insights from the Worcester Heart Attack Study. J Gen Intern Med 2003;18:423-31.

368. Krumholz HM, Douglas PS, Lauer MS, et al. Selection of patients for coronary angiography and coronary revascularization early after myocardial infarction: is there evidence for a gender bias? Ann Intern Med ig92;II6:785-90.

369. Roeters van Lennep JE, Zwinderman AH, Roeters van Lennep HW, et al. Gender differences in diagnosis and treatment of coronary artery disease from I98I to I997. No evidence for the Yentl syndrome. Eur Heart J 2000;2I:9II-8.

370. Miller TD, Roger VL, Hodge DO, et al. Gender differences and temporal trends in clinical characteristics, stress test results and use of invasive procedures in patients undergoing evaluation for coronary artery disease. J Am Coll Cardiol 200I;38: 690-7.

37I. Mark DB, Shaw LK, DeLong ER, et al. Absence of sex bias in the referral of patients for cardiac catheterization. N Engl J Med I994;330:IIoI-6.

372. Lauer MS, Pashkow FJ, Snader CE, et al. Gender and referral for coronary angiography after treadmill thallium testing. Am J Cardiol 1996;78:278-83.

373. Travin MI, Johnson LL. Assessment of coronary artery disease in women. Curr Opin Cardiol 1997;12:587-94.

374. Alter DA, Naylor CD, Austin PC, et al. Biology or bias: practice patterns and longterm outcomes for men and women with acute myocardial infarction. J Am Coll Cardiol 2002;39:1909-I6.

375. Pilote L, Merrett P, Karp I, et al. Cardiac procedures after an acute myocardial infarction across nine Canadian provinces. Can J Cardiol 2004;20:49I-500.

376. King KM, Ghali WA, Faris PD, et al. Sex differences in outcomes after cardiac catheterization: effect modification by treatment strategy and time. JAMA 2004; 29I:I220-5.

377. Ulrich MR, Brock DM, Ziskind AA. Analysis of trends in coronary artery bypass grafting and percutaneous coronary intervention rates in Washington state from I987 to 200I. Am J Cardiol 2003;92:836-9.

378. Petticrew $M$, McKee $M$, Jones J. Coronary artery surgery: are women discriminated against? BMJ I993;306:1164-6.

379. Guru V, Fremes SE, Tu JV. Time-related mortality for women after coronary artery bypass graft surgery: a population-based study. J Thorac Cardiovasc Surg 2004; I27:1158-65.

380. Malenka DJ, Wennberg DE, Quinton HA, et al. Gender-related changes in the practice and outcomes of percutaneous coronary interventions in Northern New England from I994 to 1999. J Am Coll Cardiol 2002;40:2092-IOI.

38I. Davis KB, Chaitman B, Ryan T, et al. Comparison of I5-year survival for men and women after initial medical or surgical treatment for coronary artery disease: a CASS registry study. Coronary Artery Surgery Study. J Am Coll Cardiol 1995;25: I000-9.

382. Ghali WA, Faris PD, Galbraith PD, et al. Sex differences in access to coronary revascularization after cardiac catheterization: importance of detailed clinical data. Ann Intern Med 2002; I36:723-32.

383. Bell MR, Berger PB, Holmes DR Jr, et al. Referral for coronary artery revascularization procedures after diagnostic coronary angiography: evidence for gender bias? J Am Coll Cardiol I995;25:1650-5.

384. Wenger NK. Coronary heart disease: the female heart is vulnerable. Prog Cardiovasc Dis 2003;46:199-229.

385. Hochman JS, Tamis JE, Thompson TD, et al. Sex, clinical presentation, and outcome in patients with acute coronary syndromes. Global Use of Strategies to Open Occluded Coronary Arteries in Acute Coronary Syndromes IIb Investigators. N Engl J Med I999;341:226-32.

386. Rosengren A, Wallentin L. K Gitt A, Behar S, Battler A, Hasdai D. Sex, age, and clinical presentation of acute coronary syndromes. Eur Heart J 2004;25:663-70.

387. Greenland P, Reicher-Reiss H, Goldbourt U, et al. In-hospital and I-year mortality in I, 524 women after myocardial infarction. Comparison with 4,315 men. Circulation I991;83:484-91

388. Vaccarino V, Abramson JL, Veledar E, et al. Sex differences in hospital mortality after coronary artery bypass surgery: evidence for a higher mortality in younger women. Circulation 2002;105:1176-8I.

389. White HD, Barbash GI, Modan M, et al. After correcting for worse baseline characteristics, women treated with thrombolytic therapy for acute myocardial infarction have the same mortality and morbidity as men except for a higher incidence of hemorrhagic stroke. The Investigators of the International Tissue Plasminogen Activator/Streptokinase Mortality Study. Circulation I993;88:2097-103.

390. Stone GW, Grines CL, Browne KF, et al. Comparison of in-hospital outcome in men versus women treated by either thrombolytic therapy or primary coronary angioplasty for acute myocardial infarction. Am J Cardiol 1995;75:987-92.

391. Weaver WD, White HD, Wilcox RG, et al. Comparisons of characteristics and outcomes among women and men with acute myocardial infarction treated with thrombolytic therapy. GUSTO-I investigators. JAMA 1996;275:777-82. 
392. Kober L, Torp-Pedersen C, Ottesen M, et al. Influence of gender on short- and long-term mortality after acute myocardial infarction. TRACE study group. Am J Cardiol I996;77:1052-6.

393. Malacrida R, Genoni M, Maggioni AP, et al. A comparison of the early outcome of acute myocardial infarction in women and men. The Third International Study of Infarct Survival Collaborative Group. N Engl J Med I998;338:8-I4.

394. Gottlieb S, Harpaz D, Shotan A, et al. Sex differences in management and outcome after acute myocardial infarction in the I9gos: a prospective observational community-based study. Israeli Thrombolytic Survey Group. Circulation 2000;102 2484-90.

395. Vaccarino V, Krumholz HM, Berkman LF, et al. Sex differences in mortality after myocardial infarction. Is there evidence for an increased risk for women? Circulation I995;9I:I86I-7I.

396. Tu JV, Austin PC, Filate WA, et al. Outcomes of acute myocardial infarction in Canada. Can J Cardiol 2003;19:893-901.

397. Jacobs AK. Coronary revascularization in women in 2003: sex revisited. Circulation 2003;107:375-7.

398. Jacobs AK, Johnston JM, Haviland A, et al. Improved outcomes for women undergoing contemporary percutaneous coronary intervention: a report from the $\mathrm{Na}$ tional Heart, Lung, and Blood Institute Dynamic Registry. J Am Coll Cardiol 2002; 39:I608-I4

399. Chauhan MS, Ho KK, Baim DS, et al. Effect of gender on in-hospital and one-year outcomes after contemporary coronary artery stenting. Am J Cardiol 2005;95 IOI-4.

400. Lansky AJ, Hochman JS, Ward PA, et al. Percutaneous coronary intervention and adjunctive pharmacotherapy in women: a statement for healthcare professionals from the American Heart Association. Circulation 2005;III:940-53.

40I. Holmes DR Jr, Leon MB, Moses JW, et al. Analysis of I-year clinical outcomes in the SIRIUS trial: a randomized trial of a sirolimus-eluting stent versus a standard stent in patients at high risk for coronary restenosis. Circulation 2004;109:634-40.

402. Ardissino D, Cavallini C, Bramucci E, et al. Sirolimus-eluting v, uncoated stents for prevention of restenosis in small coronary arteries: a randomized trial. JAMA 2004 292:2727-34

403. Jamal SM, Shrive FM, Ghali WA, et al. In-hospital outcomes after percutaneous coronary intervention in Canada: 1992/93 to 2000/or. Can J Cardiol 2003;19:782-9.

404. Keeley EC, Boura JA, Grines CL. Primary angioplasty versus intravenous thrombolytic therapy for acute myocardial infarction: a quantitative review of 23 randomised trials. Lancet 2003;361:13-20.

405. Mehta SR, Cannon CP, Fox KA, et al. Routine vs selective invasive strategies in patients with acute coronary syndromes: a collaborative meta-analysis of randomized trials. JAMA 2005;293:2908-I7.

406. Lagerqvist B, Safstrom K, Stahle E, et al. Is early invasive treatment of unstable coronary artery disease equally effective for both women and men? FRISC II Study Group Investigators. J Am Coll Cardiol 200I;38:4I-8.

407. Fox KA, Poole-Wilson PA, Henderson RA, et al. Interventional versus conservative treatment for patients with unstable angina or non-ST-elevation myocardial infarction: the British Heart Foundation RITA 3 randomised trial. Randomized Intervention Trial of unstable Angina. Lancet 2002;360:743-5I.

408. Clayton TC, Pocock SJ, Henderson RA, et al. Do men benefit more than women from an interventional strategy in patients with unstable angina or non-ST-elevation myocardial infarction? The impact of gender in the RITA 3 trial. Eur Heart 2004;25:I64I-50.

409. Cannon CP, Weintraub WS, Demopoulos LA, et al. Comparison of early invasive and conservative strategies in patients with unstable coronary syndromes treated with the glycoprotein IIb/IIIa inhibitor tirofiban. N Engl J Med 200I;344:I879-87.

4Io. Mueller C, Neumann FJ, Roskamm H, et al. Women do have an improved longterm outcome after non-ST-elevation acute coronary syndromes treated very early and predominantly with percutaneous coronary intervention: a prospective study in I,450 consecutive patients. J Am Coll Cardiol 2002;40:245-50.

4II. Ferguson TB Jr, Hammill BG, Peterson ED, et al. A decade of change-risk profiles and outcomes for isolated coronary artery bypass grafting procedures, I990-I999: a report from the STS National Database Committee and the Duke Clinical Research Institute. Society of Thoracic Surgeons. [discussion 489-9o]. Ann Thorac Surg 2002;73:480-9.

4I2. Ghali WA, Quan H, Shrive FM, et al. Outcomes after coronary artery bypass graft surgery in Canada: 1992/93 to 2000/or. Can J Cardiol 2003;19:774-8I.

4I3. Yusuf S, Zucker D, Peduzzi P, et al. Effect of coronary artery bypass graft surgery on survival: overview of Io-year results from randomised trials by the Coronary Artery Bypass Graft Surgery Trialists Collaboration. Lancet I994;344:563-70.

4I4. Solomon AJ, Gersh BJ. Management of chronic stable angina: medical therapy, percutaneous transluminal coronary angioplasty, and coronary artery bypass graft surgery. Lessons from the randomized trials. Ann Intern Med I998;128:216-23.

4I5. Varnauskas E. Twelve-year follow-up of survival in the randomized European Coronary Surgery Study. N Engl J Med I988;319:332-7.

4I6. Fisher LD, Kennedy JW, Davis KB, et al. Association of sex, physical size, and operative mortality after coronary artery bypass in the Coronary Artery Surgery Study (CASS). J Thorac Cardiovasc Surg I982;84:334-4I.

4I7. Edwards FH, Carey JS, Grover FL, et al. Impact of gender on coronary bypass operative mortality. Ann Thorac Surg 1998;66:125-31.

4I8. Aldea GS, Gaudiani JM, Shapira OM, et al. Effect of gender on postoperative outcomes and hospital stays after coronary artery bypass grafting. Ann Thorac Surg 1999;67:1097-103.

4I9. Koch CG, Khandwala F, Nussmeier N, et al. Gender and outcomes after coronary artery bypass grafting: a propensity-matched comparison. J Thorac Cardiovas Surg 2003;126:2032-43
420. Abramov D, Tamariz MG, Sever JY, et al. The influence of gender on the outcome of coronary artery bypass surgery. [discussion 806]. Ann Thorac Surg 2000;70:800-5.

42I. Carey JS, Cukingnan RA, Singer LK. Health status after myocardial revascularization: inferior results in women. Ann Thorac Surg I995;59:II 2-7.

422. Hammar N, Sandberg E, Larsen FF, et al. Comparison of early and late mortality in men and women after isolated coronary artery bypass graft surgery in Stockholm, Sweden, I980 to I989. J Am Coll Cardiol I997;29:659-64.

423. Woods SE, Noble G, Smith JM, et al. The influence of gender in patients undergoing coronary artery bypass graft surgery: an eight-year prospective hospitalized cohort study. J Am Coll Surg 2003;196:428-34.

424. Edwards FH, Ferraris VA, Shahian DM, et al. Gender-specific practice guidelines for coronary artery bypass surgery: perioperative management. Ann Thorac Surg 2005;79:2189-94.

425. O'Rourke DJ, Malenka DJ, Olmstead EM, et al. Improved in-hospital mortality in women undergoing coronary artery bypass grafting. Northern New England Cardiovascular Disease Study Group. Ann Thorac Surg 2001;71:507-II.

426. Christakis GT, Weisel RD, Buth KJ, et al. Is body size the cause for poor outcomes of coronary artery bypass operations in women? [discussion I356-8]. J Thorac Cardiovasc Surg 1995; I10:1344-56.

427. Mickleborough LL, Carson S, Ivanov J. Gender differences in quality of distal vessels: effect on results of coronary artery bypass grafting. J Thorac Cardiovasc Surg 2003;126:950-8.

428. Jacobs AK, Kelsey SF, Brooks MM, et al. Better outcome for women compared with men undergoing coronary revascularization: a report from the Bypass Angioplasty Revascularization Investigation (BARI). Circulation 1998;98:1279-85.

429. Brandrup-Wognsen G, Berggren H, Hartford M, et al. Female sex is associated with increased mortality and morbidity early, but not late, after coronary artery bypass grafting. Eur Heart Ji996;17:1426-31.

430. Risum O, Abdelnoor M, Nitter-Hauge S, et al. Coronary artery bypass surgery in women and in men; early and long-term results. A study of the Norwegian population adjusted by age and sex. Eur J Cardiothorac Surg 1997;11:539-46.

431. Herlitz J, Brandrup-Wognsen G, Karlson BW, et al. Mortality, risk indicators of death, mode of death and symptoms of angina pectoris during 5 years after coronary artery bypass grafting in men and women. J Intern Med 2000;247:500-6.

432. Vaccarino V, Lin ZQ, Kasl SV, et al. Gender differences in recovery after coronary artery bypass surgery. J Am Coll Cardiol 2003;4I:307-I4.

433. Herlitz J, Wiklund I, Sjoland H, et al. Relief of symptoms and improvement of health-related quality of life five years after coronary artery bypass graft in women and men. Clin Cardiol 2001;24:385-92.

434. Mallik S, Krumholz HM, Lin ZQ, et al. Patients with depressive symptoms have lower health status benefits after coronary artery bypass surgery. Circulation 2005 III:27I-7.

435. Athanasiou T, Al-Ruzzeh S, Del Stanbridge $\mathrm{R}$, et al. Is the female gender an independent predictor of adverse outcome after off-pump coronary artery bypass grafting? Ann Thorac Surg 2003;75:1153-60.

436. Mack MJ, Brown P, Houser F, et al. On-pump versus off-pump coronary artery bypass surgery in a matched sample of women: a comparison of outcomes. Circulation 2004; IIO:III-6.

437. Brown PP, Mack MJ, Simon AW, et al. Outcomes experience with off-pump coronary artery bypass surgery in women. [discussion 2120]. Ann Thorac Surg 2002; 74:2113-9.

438. Capdeville M, Chamogeogarkis T, Lee JH. Effect of gender on outcomes of beating heart operations. Ann Thorac Surg 2001;72:Sio22-5.

439. Ho KK, Anderson KM, Kannel WB, et al. Survival after the onset of congestive heart failure in Framingham Heart Study subjects. Circulation I993;88:107-I5.

440. Schocken DD, Arrieta MI, Leaverton PE, et al. Prevalence and mortality rate of congestive heart failure in the United States. J Am Coll Cardiol I992;20:30I-6.

44I. Rathore SS, Foody JM, Wang Y, et al. Sex, quality of care, and outcomes of elderly patients hospitalized with heart failure: findings from the National Heart Failure Project. Am Heart J 2005;I49:I2I-8.

442. Vaccarino V, Chen YT, Wang Y, et al. Sex differences in the clinical care and outcomes of congestive heart failure in the elderly. Am Heart JI999;138:835-42.

443. Antman EM, Anbe DT, Armstrong PW, et al. ACC/AHA guidelines for the management of patients with ST-elevation myocardial infarction-executive summary. A report of the American College of Cardiology/American Heart Association Task Force on Practice Guidelines (Writing Committee to Revise the I999 Guidelines for the Management of Patients with Acute Myocardial Infarction). J Am Coll Cardio 2004;44:67I-7I9.

444. Fallen EL, Cairns J, Dafoe W, et al. Management of the postmyocardial infarction patient: a consensus report-revision of I99I CCS guidelines. Can J Cardio I995; II:477-86.

445. Ryan TJ, Antman EM, Brooks NH, et al. 1999 update: ACC/AHA guidelines for the management of patients with acute myocardial infarction. A report of the American College of Cardiology/American Heart Association Task Force on Practice Guidelines (Committee on Management of Acute Myocardial Infarction). J Am Coll Cardiol i999;34:890-9II.

446. ACE Inhibitor Myocardial Infarction Collaborative Group. Indications for ACE inhibitors in the early treatment of acute myocardial infarction: systematic overview of individual data from 100 ooo patients in randomized trials. Circulation 1998;97: 2202-I2.

447. Flather MD, Yusuf S, Kober L, et al. Long-term ACE-inhibitor therapy in patients with heart failure or left-ventricular dysfunction: a systematic overview of data from individual patients. ACE-Inhibitor Myocardial Infarction Collaborative Group. Lancet 2000;355:1575-81. 
448. Collaborative overview of randomised trials of antiplatelet therapy-I: Prevention of death, myocardial infarction, and stroke by prolonged antiplatelet therapy in various categories of patients. Antiplatelet Trialists' Collaboration. BMJ I994;308. 8I-Io6.

449. Collaborative meta-analysis of randomised trials of antiplatelet therapy for prevention of death, myocardial infarction, and stroke in high risk patients. BMJ 2002; 324:7I-86

450. Ridker PM, Cook NR, Lee IM, et al. A randomized trial of low-dose aspirin in the primary prevention of cardiovascular disease in women. N Engl J Med 2005;352 I293-304.

45I. Berger JS, Roncaglioni MC, Avanzini F, et al. Aspirin for the primary prevention of cardiovascular events in women and men: a sex-specific meta-analysis of randomized controlled trials. JAMA 2006;295:306-I3.

452. Faraday N, Goldschmidt-Clermont PJ, Bray P. Gender differences in platelet GP IIb/IIIa activation. Thromb Haemost I997;77:748-54.

453. Cho L, Topol EJ, Balog C, et al. Clinical benefit of glycoprotein IIb/IIIa blockade with abciximab is independent of gender. Pooled analysis from EPIC, EPILOG and EPISTENT trials. J Am Coll Cardiol 2000;36:38I-6.

454. Kandzari DE, Hasselblad V, Tcheng JE, et al. Improved clinical outcomes with abciximab therapy in acute myocardial infarction: a systematic overview of randomized clinical trials. Am Heart J 2004; I47:457-62.

455. De Luca G, Suryapranata H, Stone GW, et al. Abciximab as adjunctive therapy to reperfusion in acute ST-segment elevation myocardial infarction: a meta-analysis of randomized trials. JAMA 2005;293:1759-65.

456. Boersma E, Harrington RA, Moliterno DJ, et al. Platelet glycoprotein IIb/IIIa inhibitors in acute coronary syndromes: a meta-analysis of all major randomised clinical trials. Lancet 2002;359:189-98.

457. Freemantle N, Cleland J, Young P, et al. beta Blockade after myocardial infarction systematic review and meta regression analysis. BMJ 1999;318:1730-7.

458. Silvet H, Spencer F, Yarzebski J, et al. Communitywide trends in the use and outcomes associated with beta-blockers in patients with acute myocardial infarction the Worcester Heart Attack Study. Arch Intern Med 2003;163:2175-83.

459. Krumholz HM, Radford MJ, Wang Y, et al. National use and effectiveness of \{beta\}-blockers for the treatment of elderly patients after acute myocardial infarction: National Cooperative Cardiovascular Project. JAMA I998;280:623-9.

46o. Randomised trial of cholesterol lowering in 4444 patients with coronary heart disease: the Scandinavian Simvastatin Survival Study (4S). Lancet I994;344:I383-9.

46I. Miettinen TA, Pyorala K, Olsson AG, et al. Cholesterol-lowering therapy in women and elderly patients with myocardial infarction or angina pectoris: findings from the Scandinavian Simvastatin Survival Study (4S). Circulation I997;96:42II-8.

462. Sacks FM, Pfeffer MA, Moye LA, et al. The effect of pravastatin on coronary events after myocardial infarction in patients with average cholesterol levels. Cholesterol and Recurrent Events Trial Investigators. N Engl J Med 1996;335:I00I-9.

463. Lewis SI, Sacks FM, Mitchell IS, et al. Effect of pravastatin on cardiovascular events in women after myocardial infarction: the cholesterol and recurrent events (CARE) trial. J Am Coll Cardio 1998;32:140-6.

464. MRC/BHF Heart Protection Study of cholesterol lowering with simvastatin in 20,536 high-risk individuals: a randomised placebo-controlled trial. Lancet 2002; 360:7-22.

465. Cheung BM, Lauder IJ, Lau CP, et al. Meta-analysis of large randomized controlled trials to evaluate the impact of statins on cardiovascular outcomes. Br J Clin Pharmacol 2004;57:640-51.
466. Walsh JM, Pignone M. Drug treatment of hyperlipidemia in women. JAMA 2004; 291:2243-52.

467. Hunt S, Abraham WT, Chin MH, et al. ACC/AHA 2005 guideline update for the diagnosis and management of chronic heart failure in the adult - summary article: a report of the American College of Cardiology/American Heart Association Task Force on Practice Guidelines (Writing Committee to Update the 200I Guidelines for the evaluation and Management of Heart Failure). J Am Coll Cardiol 2005;46: III6-43.

468. Liu P, Arnold JM, Belenkie I, et al. The 2002/3 Canadian Cardiovascular Society consensus guideline update for the diagnosis and management of heart failure. Can J Cardiol 2003;19:347-56.

469. Garg R, Yusuf S. Overview of randomized trials of angiotensin-converting enzyme inhibitors on mortality and morbidity in patients with heart failure. Collaborative Group on ACE Inhibitor Trials. JAMA I995;273:1450-6.

470. Lonn E, Roccaforte R, Yi Q, et al. Effect of long-term therapy with ramipril in highrisk women. J Am Coll Cardiol 2002;40:693-702.

47I. Ghali JK, Pina IL, Gottlieb SS, et al.; MERIT-HF Study Group. Metoprolol CR/XL in female patients with heart failure: analysis of the experience in Metoprolol Extended-Release Randomized Intervention Trial in Heart Failure (MERIT-HF). Circulation 2002;105:1585-91.

472. Simon T, Mary-Krause M, Funck-Brentano C, et al. Sex differences in the prognosis of congestive heart failure: results from the Cardiac Insufficiency Bisoprolol Study (CIBS II). Circulation 200I;I03:375-80.

473. Rathore SS, Wang Y, Krumholz HM. Sex-based differences in the effect of digoxin for the treatment of heart failure. N Engl J Med 2002;347:I403-II.

474. Adams KF Jr, Patterson JH, Gattis WA, et al. Relationship of serum digoxin concentration to mortality and morbidity in women in the Digitalis Investigation Group Trial: a retrospective analysis. J Am Coll Cardiol 2005;46:497-504.

475. Pitt B, Zannad F, Remme WJ, et al. The effect of spironolactone on morbidity and mortality in patients with severe heart failure. Randomized Aldactone Evaluation Study Investigators. N Engl J Med I999;341:709-I7.

476. Sudlow M, Thomson R, Thwaites B, et al. Prevalence of atrial fibrillation and eligibility for anticoagulants in the community. Lancet 1998;352:1167-71.

477. Risk factors for stroke and efficacy of antithrombotic therapy in atrial fibrillation. Analysis of pooled data from five randomized controlled trials. Arch Intern Med I994; I54:I449-57.

478. Petersen P, Boysen G, Godtfredsen J, et al. Placebo-controlled, randomised trial of warfarin and aspirin for prevention of thromboembolic complications in chronic atrial fibrillation. The Copenhagen AFASAK study. Lancet I989;1:175-9.

479. Stroke Prevention in Atrial Fibrillation Study. Final results. Circulation I991;84: 527-39.

480. Curtis AB, Gersh BJ, Corley SD, et al. Clinical factors that influence response to treatment strategies in atrial fibrillation: the Atrial Fibrillation Follow-up Investigation of Rhythm Management (AFFIRM) study. Am Heart J 2005;I49:645-9.

Correspondence to: Dr. Louise Pilote, The McGill University Health Centre Research Institute, Divisions of Internal Medicine and Clinical Epidemiology, 687 av. Des Pins Ouest, $A 4.23$, Montréal QC H3A IAI; fax 514 934-8293; louise.pilote@mcgill.ca 